Mara Westling Allodi and Tamara Zappaterra (Eds.)

Users' Needs Report on Play for Children with Disabilities

Parents' and children's views 

Mara Westling Allodi and Tamara Zappaterra (Eds.)

\section{Users' Needs Report \\ on Play for Children \\ with Disabilities}

Parents' and children's views 
ISBN 978-3-11-053745-1

e-ISBN 978-3-11-053748-2

\section{(cc) BY-NC-ND}

This work is licensed under the Creative Commons Attribution-NonCommercial-NoDerivs 3.0 License. For details go to http://creativecommons.org/licenses/by-nc-nd/3.0/.

(c) 2019 Mara Westling Allodi and Tamara Zappaterra

Published by De Gruyter Poland Ltd, Warsaw/Berlin

Part of Walter de Gruyter GmbH, Berlin/Boston

The book is published with open access at www.degruyter.com.

\section{Library of Congress Cataloging-in-Publication Data}

A CIP catalog record for this book has been applied for at the Library of Congress.

www.degruyter.com

Cover illustration: Axel Westling, 5 year, Sweden 


\section{Contents}

Mara Westling Allodi and Tamara Zappaterra

Introduction -1

\section{Section 1. Surveys to Associations and Parents on Play of Children with Disabilities}

Pedro Encarnação and Maria Saridaki

1

1.1 The importance of play for the sake of play -7

1.2 Barriers to play for children with disabilities $-\mathbf{8}$

1.3 Case study methodology: an opportunity for disability studies $\mathbf{9}$

References -13

\section{Pedro Encarnação}

2 Methodology: the survey aimed at assessing the children with disabilities play needs from the perspective of parents and children -15

$2.1 \quad$ Surveys development and data collection procedures -15

2.1.1 Questionnaire for parents' associations — 16

2.1.2 Questionnaire for parents of children with disabilities $-\mathbf{1 7}$

2.1.3 Data collection -18

References -20

Appendix -21

Mara Westling Allodi, Maria Gladh, Eira Suhonen, Marjatta Takala, and Tamara Zappaterra

3 Perceptions of Members in Parents' Associations for Children with

Disabilities of their Children's Opportunities to Play — 29

3.1 Parents' Associations survey 29

3.1.1 Participating Countries — 29

3.1.2 Types of impairment/disability represented and ages - $\mathbf{3 0}$

3.1.3 Parents' Association members — 32

3.1.4 Opportunities to play according to the needs - 32

3.1.5 Parents' happiness/satisfaction with their children's play - 32

3.1.6 The importance of play "for play's sake" for children with disabilities - $\mathbf{3 6}$

3.1.7 Needs of the children in order to play (more, better)? - 38

3.1.8 Play environments and play partners - $\mathbf{4 0}$

3.1.9 Changes in the play of children with disabilities - 41 
Mara Westling Allodi, Tamara Zappaterra, Marjatta Takala, Elina Viljamaa, Eira Suhonen and Alisa Alijoki

4 Parents of a child with disabilities and their views about their child's play -42

4.1 Participating Countries -42

4.2 Family relationships -43

4.3 Characteristics of the children -43

4.3.1 Age of the children -43

4.3.2 Gender distribution -43

4.3.3 Type of impairment/disability -44

4.4 Parents' words about play -44

4.5 Places and companions for play -49

4.6 The child's needs about play according to the parents -54

4.7 Children's experiences of play -63

Mara Westling Allodi, Tamara Zappaterra and Donatella Fantozzi

5 Comments on the results of the Associations' and Parents' Surveys -70 References -75

\section{Section 2. Case Studies Based on Literature Reviews from three Countries}

Egle Celiesiene and Marjatta Takala

6 Introduction to the Section -80

6.1 Topics of relevance and novelty $-\mathbf{8 0}$

$6.2 \quad$ Methodology -82

6.3 Short project description $-\mathbf{8 2}$

References -83

Eira Suhonen, Marjatta Takala, Alisa Alijoki, and Elina Viljamaa

7 Children with and without disabilities in Finnish early childhood education -84

7.1 Public health care services for children with disabilities - 84

7.1.1 Child and family policy in Finland -84

7.1.2 Child welfare clinic -84

7.2 Early childhood education services $-\mathbf{8 5}$

7.2.1 Daycare and preschool education services $-\mathbf{8 6}$

7.2.2 Some statistics -86

7.3 Early childhood special education $-\mathbf{8 7}$ 
7.3.1 Inclusive education $-\mathbf{8 7}$

7.3.2 Some examples of assessments and interventions programs $-\mathbf{8 8}$

7.3.2.1 Intervention program focusing all children $\mathbf{-} \mathbf{8 8}$

7.3.2.2 Intervention programs focusing children with special needs $\mathbf{8 9}$

7.4 Some examples of assessment and intervention programs - $\mathbf{8 9}$

7.5 Summary of the nine play studies in Finland $-\mathbf{9 0}$

7.5.1 Background of the studies -90

7.5.2 Users' needs -90

7.5.3 Barriers to play -91

7.5.4 What facilitators help children to play? - 91

7.5.5 Concluding remarks $\mathbf{9 2}$

7.6 Discussion -92

References -92

Egle Celiešiene, Giedrė Kvieskienė and Angelė Kaušylienė

8 Play for children with disabilities: the users' needs in the Lithuanian context -95

$8.1 \quad$ Introduction -95

8.2 Outline of Lithuanian social security and education of children with SEN -96

8.3 Case study: good practice models and improvements in Lithuania $\mathbf{9 7}$

8.4 Socialization and daily activities of children with disabilities and SEN 98

8.5 Conclusions $-\mathbf{1 0 1}$

References -102

Mara Westling Allodi, Johanna Lundqvist, Elisabet Lundström, Lise Roll-Pettersson, Jenny Rosendahl, Eva Siljehag and Rano Zakirova Engstrand

9 Play for children with disabilities: the users' needs in the Swedish context -104

9.1 Background -104

9.2 Aims and method -104

9.3 Description of the Swedish policy and context 105

9.4 Mapping of the users' needs $-\mathbf{1 0 8}$

9.4.1 The studies included $\mathbf{1 0 8}$

9.4.2 Users' needs $\mathbf{1 0 9}$

9.4.3 Barriers - 110

9.4.4 Facilitators - 111

9.4.5 Recommendations - 112

9.5 Discussion - 113

References - 114 
Cecilia Sik-Lanyi and Veronika Szucs

10 Play for children with disabilities: some reflections on the results on the users' needs and on the role of technologies - 117

10.1 Short summary of the Section n. $2-\mathbf{1 1 7}$

10.2 New technologies - 117

10.3 Developing games based on users' needs - 119

10.3.1 Colour Deficient (colour blind) persons — 120

$10.4 \quad$ Conclusion $-\mathbf{1 2 2}$

References -122

Contributors -124 


\section{Mara Westling Allodi and Tamara Zappaterra Introduction}

This book is the result of a specific part of the European research project "LUDI. Play for Children with Disabilities” (http://ludi-network.eu), a COST funded Action (www. cost.eu/TD1309, 2014-2018) that collected a multidisciplinary international network of professionals, researchers and practitioners, devoted to the study and enhancement of play for children with disabilities.

The Action is aimed at the creation of a general awareness on the quality of life of children with disabilities, starting from a crucial aspect, i.e. play activities, and initiating a process of cultural and social change that will break down the barriers that hinder the full exercise of their right to play and will pave the way to the realization of a true social inclusion. ${ }^{1}$

Participants to the research project were organized into 4 Working Groups, as will be explained in more detail in the section on theoretical framework of the Action. The book collects the results of the Working Group 4, Methods, tools and frameworks for the development of the child with disabilities play, which has the final goal to provide guidelines for the play of children with disabilities.

The research field and the Working Group 4 aims are to collect and develop previous studies on play for children with disabilities in order to produce an overview on this theme, to develop intervention models and training and policies addresses. The book represents the first outcome of this line of research: a Users'Needs Report on children with disabilities play. Who are the users? They are representatives of family associations, families of children with disabilities, and children themselves, but also practitioners and researchers of different field, such as healthcare, education, industry, technological, policy makers.

The book is divided into two Sections that are the result of two different research phases and covers different but complementary aspects of the research line of Working Group 4. The aim of the report is to investigate the users' needs on the matter of play for children with different disabilities and in various contexts. The users' needs were collected by means of surveys addressed to disability associations and to parents of children with disabilities (Section 1) and by means of case studies at a country level, based on reviews of research and reports from three national contexts (Section 2).

The report is compiled by members of the LUDI Working Group 4. The members of the LUDI Core Group and Management Committee contributed to the development of the questionnaires, under the supervision of Serenella Besio, Chair of the Action. Pedro Encarnação and Mara Westling Allodi supported the management and Tamara

1 www.cost.eu/TD1309; www.ludi-network.eu. 
Prevendar coordinated the data collection. ${ }^{2}$ Several colleagues from the other countries represented by LUDI participated to the mapping of users' needs in the case studies.

In Section 1 the users are representatives of associations for disabilities, parents of children with disabilities and, to a lesser extent, the children themselves. Through an empirical research conducted by two semi-structured questionnaires we investigated the needs of children with disabilities in the play. The two questionnaires were developed by members of the LUDI network in January-February 2016 and distributed to 31 LUDI national coordinators. The structure and issues of the questionnaires are similar, but the version for the parents contained more open questions. The identification of questions to ask the representatives and parents has been driven by the knowledge that the Action LUDI aims at reaching a large and triple impact:

1. scientific, on the recognition of the right to play for children with disabilities, and on the adoption of measures to allow the exercise of this right;

2. societal, by training parents and professionals to become proficient at interacting with children with disabilities in order to give them the chance to learn and grow through play;

3. technological, by planning and designing technology products and tools for play as well as by expanding the number of people able to use them and also improving their competence.

The coordinators translated the questionnaires into 23 languages. The questionnaires were distributed to at least 3 associations and 3 parents in the respective countries. The coordinators translated back the collected answers into English and reported them into a web-survey tool. The survey was performed from April to June 2016. 75 answers were collected from associations in 24 countries and 129 from parents in 26 countries. The answers were analyzed with content and thematic analysis.

Hearing the direct voice of users as players - in our case the perception of parents and children themselves - is a line of action planned by LUDI. It is a methodology of research already accredited in different fields, i.e. it is a research methodology widely used in the construction of models of quality systems and in the quality review processes.

In order to develop suitable and relevant policies, practices and professional training on the topic of play for children with disabilities, it is vital to sensibly take into account the users' needs in their daily lives, and in particular, in this case, the needs of children with disabilities, their parents and families. The views of persons that are target for products, educational and social services are essential in order to develop facilities and products that truly and responsively match their needs. Listening to people's needs and eliciting their evaluations make it possible for them

2 Respectively from: Italy, Portugal, Sweden and Croatia. 
to participate in and influence the future development of products and practices. In doing so, it is recommended for the developers also to consider a whole range of experiences, and from a variety of contexts, in which there might be different policies, attitudes, resources and barriers, which may affect accordingly the users' experiences and needs. Based on this rationale, the task at hand was to investigate the available knowledge and to collect empirical accounts on the topic of users' needs for children with disabilities.

In section 2 the users' needs have been investigated indirectly and with reference to specific national contexts as "case studies" in three European countries, Lithuania, Finland and Sweden. To ensure a common structure to the study, the reviews at country level were based on a shared protocol. Previous literature searches in scientific research databases revealed that very limited research was available, if any, on the topic of parents' and children's views on play, and even less on users' needs on play for children with disabilities. The reviews at a country level were consequently chosen with the aim of collecting empirical evidence that might be available in the local context, as grey literature, research, official reports and evaluations that were not reported in scientific articles.

Shortly, as we shall detail at the end of the report, the results shows that:

- Children with disabilities needs to play and to have all the positive experiences that children experience when they play in various environments and with peers, friends, relatives.

- Play is a vital and fundamental need that is not always fulfilled for children with disabilities.

- There is needs for adaptations in toys and environments.

- Children with disabilities and their parents should be involved in planning so that they can influence policies and practices.

- Training for teachers and other professionals should be improved so that they can be more sensitive and skilled in supporting play in inclusive settings.

- Policies and indicators should be developed and implemented in field of play and disability and evaluations carried out. 

Section 1. Surveys to Associations and Parents on Play of Children with Disabilities 


\section{Pedro Encarnação and Maria Saridaki 1 "LUDI. Play for children with disabilities"}

The aim of "LUDI - Play for Children with Disabilities" was to create a novel and autonomous field of research and intervention on play for children with disabilities. The Action integrates the joint efforts of more than 100 researchers, practitioners, and users, from 32 European countries and many different backgrounds (computer science, education, engineering, medicine, occupational therapy, physical therapy, psychology, sociology, speech and language pathology, among others). As set in its Memorandum of Understanding (COST, 2013:3), «the network has three main objectives:

- collecting and systematizing all existing competence and skills: educational researches, clinical initiatives, know-how of resources centers and users' associations;

- developing new knowledge related to settings, tools and methodologies associated with the play of children with disabilities;

- disseminating the best practices emerging from the joint effort of researchers, practitioners and users».

To accomplish these goals, the Action was organized into four Working Groups (WGs): Working Group 1 - Children's play in relation to the types of disabilities

Working Group 2 - Tools and technologies for the play of children with disabilities

Working Group 3 - Contexts for play of children with disabilities

Working Group 4 - Methods, tools and frameworks for the development of the child with disabilities' play.

In the first two years of the Action, Working Group 1 worked towards defining the framework for LUDI. A definition and a classification of play were adopted, after a thorough review of the many available in the literature. Following a biopsychosocial model of disability, as advocated in the World Health Organization ICF - International Classification of Functioning, Disability and Health (World Health Organization, 2001), a working definition of disability and a categorization of childhood disabilities were formulated. Finally, Working Group 1 addressed the characteristics of play in children with different disabilities. All the above was published in the book Play Development in Children with Disabilities (Besio, Bulgarelli, \& Stancheva-Popkostadinova, 2017).

Meanwhile, Working Group 2 created a database of play systems with records describing the play experience of children with disabilities using toys, assistive technology, or within environments specially designed for play. These examples are meant to inspire users and practitioners, and foster cooperation and discussion between all stakeholders. Since one of the WG2 objectives is to critically review guidelines for the design and assessment of assistive technology and environments to support play for children with disabilities, the database also collects the methods 
used in each play experience to assess accessibility, usability, and effectiveness of the assistive technology or environment. This database is publicly available at http://ludi. utad.pt/.

It was the goal of WG3, during the first part of the Action, to examine the environmental barriers to play and recreation for children and young persons with disabilities. This was done through a narrative review of existing research and knowledge on play for children with disabilities within four key physical contexts: the home, educational settings, the built environment and the natural environment. Conclusions of this analysis were published in the book Environmental barriers to play and recreation for children and young persons with disabilities (Barron, et al., 2017).

Faithful to the motto Nothing About Us Without Us, the Action LUDI strives to hear the voices of children with disabilities and their representatives, and involve them in all the work conducted within the network. One of the steps in that direction is the assessment of the children with disabilities play needs from their perspective. This was the first goal of WG4 and the result of that work is now published in this book.

\subsection{The importance of play for the sake of play}

According to Garvey (1990:4) «Play is a range of voluntary, intrinsically motivated activities normally associated with recreational pleasure and enjoyment». Several characterizations of play have been proposed. In the LUDI Action, play is classified along two dimensions: cognitive and social (Table 1).

Table 1.1. LUDI Classification of the types of play (Bulgarelli \& Bianquin, 2017)

\begin{tabular}{ll}
\hline Dimension & Type of play \\
\hline Cognitive & Practice \\
& Symbolic \\
& Constructive \\
& Play with rules (including videogames) \\
\hline Social & Solitary \\
& Parallel \\
& Associative \\
& Cooperative
\end{tabular}

Practice play, typical in the first two years of life, includes simple body actions or experimentation of body, and visual and tactile experimentation of objects. Symbolic play involves giving new significations to objects, persons, actions or events. This type of play typically emerges in the end of the second year of life. Constructive play consists of building or assembling something. It also appears by the age of two. Play with rules encompasses all those play activities which have rules that are accepted and followed by the players. It usually emerges at the age of three. In solitary play children 
play alone and independently, even if in presence of other persons. Parallel play occurs when more than one children independently engage in the same play activity, without interacting with each other. When children are together, each engaged in his/ her own play activity, but sharing, taking turns, or any other form of consideration of the other's play activity, there's associative play. In cooperative play children play together with a common goal or purpose. More details on these definitions can be found in (Besio, Bulgarelli, \& Stancheva-Popkostadinova, 2017).

Play is the most prevalent activity in childhood. While playing children develop motor, language, and social skills (Besio, Bulgarelli, \& Stancheva-Popkostadinova, 2017) and the references therein). Realizing children's predisposition to play and the benefits of play activities, several disciplines have devised play-like activities with secondary goals. For example, educators may set up play activities to teach math concepts (many of those activities are easily found these days searching the Internet for "play" and "math"). Or occupational therapists may use play activities to develop a particular functional skill (see for example (Couch, Deitz, \& Kanny, 1998). However, arguably these play-like activities miss some of the characteristics of play. For example, often these activities are chosen and led by an adult, and not by the child; or they are motivated by the product and not by the process. Accordingly, the activity has a goal different from just playing.

Although the importance of play-like activities should not be underestimated, the LUDI Action focuses on play for the sake of play activities. These are activities whose purpose and objective are the play itself. Benefits of these activities are seen as a side effect of them, and activities are not set to pursue any particular benefit. The apparently incoherent rationale is that play activities will have the greatest outcomes if they have no defined outcomes.

\subsection{Barriers to play for children with disabilities}

According to the ICF (World Health Organization, 2002), disability is an umbrella term for impairments, activity limitations and participation restrictions, including environmental factors that interact with all these components. Children with disabilities may thus have their quality of play compromised as a consequence of a limitation in a body structure or function that prevents engaging in an activity or in a life situation. For an analysis of the factors related to the individual and play, please refer to (Besio, 2008).

From the environment perspective, play by children with disabilities may also be impacted by attitudes of others, lack of supporting technology or environments, or the prevailing policies. In Barron, et al. (2017) examples of these environmental barriers were identified in the literature. For example, 'risk-aversion' attitudes towards children may prevent them from playing, with the argument that children should never be put at risk, thus neglecting the benefits of play over potential risks. There is 
a lack of information concerning assistive technology to support play. Some countries lack clear policies and legislation in relation to accessible and usable spaces for play (either built or natural environments).

It is well documented in the literature that play deprivation has several detrimental consequences, including anxiety, frustration, passivity (Missiuna \& Pollock, 1991), decreased sense of self-efficacy, self-confidence, satisfaction and wellbeing (Blanche, 2008), and ultimately learned helplessness (Butler, 1986). All these impact the child's future functioning in educational, community and work contexts (Missiuna \& Pollock, 1991).

\subsection{Case study methodology: an opportunity for disability studies}

A case study is a research approach that is used to produce an in-depth, multi-faceted understanding of a phenomenon, which can be an event, group, or social process, in its real-life context. It is an established research design that is used extensively in a wide variety of disciplines, principally in the social sciences (Crowe et al, 2011). Before discussing further the importance of this methodology in disability studies we should highlight some of its different definitions and clarify its overall importance.

Case study methodology, «is both the process of learning about the case and the product of our learning» (Stake, 1995:237) allowing researchers to focus on searching, seeking, and inquiring in order to provide the necessary insight for a deeper understanding of the phenomenon, its origins, development, and recent form.

As a research methodology, a case study can be defined in a variety of ways, the central principle being the need to explore an event or phenomenon in depth and in its natural context. Some of its definitions are rather broad:

«A case study is here defined as an in-depth, multi-faceted investigation using qualitative research methods, of a single social phenomenon. The study is conducted in great detail and often relies on the use of several data sources» (Feagin, Orum \& Sjoberg, 1991:2).

Other definitions are much more narrow and specific:

«A case study is an empirical inquiry that, investigates a contemporary phenomenon within its real-life context, especially when the boundaries between phenomenon and context are not clearly evident» (Yin, 1994:13).

Case study provides an important methodological option that forms a nice complement to the range of methods available to social scientists for research into society and its components. Obtaining and presenting a holistic depiction of the phenomenon, is a characteristic of the case study method (Suryani, 2008). A case study emphasizes the whole rather than its atomized components.

Case studies permit identification and description of phenomena. Labeling phenomena is the first step to cataloging them, discovering and recording their characteristics. Researchers using the case study method can develop more 
comprehensive analytical depictions of the phenomenon, how it works, and the interrelationships between its components. These depictions can be useful in conveying an abstract understanding of the phenomenon. Case studies enable the development of "grounded theory" (Glaser \& Strauss, 1967). Case studies can also provide answers to the "why" question and explain the reasons people take certain actions, at least as perceived by them. The researcher's analysis may suggest whether the reasons offered seem accurate. Findings from a detailed case study research enable the researcher to test existing theories and their validity.

This holistic approach is able to highlight the actual societal issues. According to Tsiolis «the main concern of every researcher is to develop methods that are suitable to illuminate the actual problems of people» (Tsiolis, 2004) and case study methodology seems to be a suitable method towards this goal.

Richness of data is another vital characteristic of this methodology. Detailed data about the phenomenon enables the development of in-depth understanding, allowing the reader to obtain a strong sense of the phenomenon, and derive his or her own conclusion about it (Mazumdar \& Geis, 2001).

The case study method provides several benefits that quantitative and experimental approaches do not, though depending on the research question, those methods provide some other benefits that case study does not (Mazumdar \& Geis, 2001). Several criticisms have raised questions about the use and popularity of case study as a research method. A frequent criticism of case study research is that it is not possible to draw a generalisation from the analysis of a single case (Ianni, 2003).

However the answer is again in the purpose of the researcher and the type of research he/she decides to carry out (Ianni, 2003). "Case study research is not sampling research. We do not study a case primarily to understand other cases. [...] The real business of case study is particularization, not generalization» (Stake, 1995:8).

Regarding that criticism, Cohen and Manion explain that case studies involve the «observation of the characteristics of an individual unit - a child, a clique, a class, a school or a community» (1994:124). Therefore, after such observations and investigation of the subject, case studies aim to establish generalisations that can be applied to a wider audience.

«The purpose of such observation is to probe deeply and to analyse intensively the multifarious phenomena that constitute the life cycle of the unit with a view to establishing generalizations about the wider population to which that unit belongs» (Cohen \& Manion, 1994:106).

Geis (1991:217) has claimed that «case study material will rarely be published today by any of the leading journals» which might be a reason for its decline in popularity. However since generalization seems to be the main problematic of using case studies as a methodology, it has to be reminded that in a case study we are in the field of 'naturalistic enquiry', whose "meaning in use now, in educational research 
and evaluation, emphasizes the idiosyncrasy and intentionality of human action, the importance of biography, history and particular circumstance» (Davis, 1994:21).

Especially regarding disability studies, case study methodology can offer great potential in raising the voice of the person with disabilities, especially if is focuses on special in-depth understanding. Apprehending and depicting the complexity of the phenomenon is a main feature of the case study method that fits with the demanding nature of disability studies.

According to Yin (2003) there are some limitations of a case study approach. First, people may think that case study researchers do not follow systematic procedures and may have biased views that probably influence the findings and the conclusions. However, according to Suryani, similarly to all other researchers, case study researchers should «stay in a neutral position in reporting the facts or at least triangulating the data to ensure that the claims are supported» (2008:121).

As a qualitative research approach, a disability study case might be an individual or a group/collective; it might also be simple or complex. Some examples of individual cases might be a child, an adult, a student, with one or multiple disabilities, a person's experience or phase in life, a teacher, parent or caretaker. On the other hand, a collective or complex case might be in the form of home environment, educational or working environment, neighbourhood, or region (Suryani, 2008; Myriad Consultants, 2005; New Zealand Ministry of Health, 2000).

According to Mazumdar \& Geis, in disability studies, statistical reports can reduce emotions to «dry and dreary numerical formulations that fail to convey the most significant elements of the world of persons with disabilities and provide little advanced understanding of that world» (2001:256). For persons with disabilities, being the subject of impersonal study rather than of sincere attempts at empathetic understanding, can at times be exasperating, a demonstration of distancing by others that hides many ethical implications for the study subjects. From observation to analysis, case study methodology offers a particularly valuable tool for conveying beliefs and feelings in a clear manner, allowing the person with disabilities or hers/his caretakers to present their situation, experience and needs (Mazumdar \& Geis, 2001).

Case studies can give a better sense of the effects of disability. In their encounters and dealings with the natural, human-made, and social world, persons with particular disabilities have specific experiences. Describing these in detail and providing a rich understanding is important for researchers who desire to obtain a more complete sense of the experience of a variety of disabilities.

Oliver and Hasler (1987) provide examples of different effects of various disabilities and how the services offered by the Spinal Injuries Association assisted these persons with disabilities. They also describe how professionals charged with assisting persons with disabilities exercise their power and how sharing of power with persons with disabilities would conceptualize solutions differently needs (Mazumdar \& Geis, 2001). 
A case study enables the researcher to offer to the reader an in-depth sense of the context, social and physical, of the life of a person with a particular disability or multiple disabilities. Two persons with the same apparent disability may experience different contextual situations (Imrie, 1996:147) depending on societal, psychological or environmental reasons. For example, Matthews (1983) describes her situation and that of some others who had different experiences. She describes how the institution, including doctors and staff, were unwilling to make adjustments and failed to understand how persons with disabilities felt.

Case studies have been also used in the educational experience of students with disabilities, allowing an in-depth view and analysis of their everyday struggles, strengths and needs. Especially regarding the introduction of educational and technological innovations in special or inclusive education settings there have been many researches that were based on the case study methodology (Bates et al, 2015; Brown et al, 2011).

Finally, and perhaps most importantly, case studies afford the depiction of the emotions of persons with disabilities. In a case study a researcher can express the feelings associated with being disabled and their feelings towards current policies and social situations (Mazumdar \& Geis, 2001). In data collection stage, the researchers in a qualitative case study tend to spend more time on research locations, have personal interest and contact with the case or participants, as well as make reflection and certain meanings about the natural phenomenon (Suryani, 2008).

Like most other methods, case study method has strengths, weaknesses, and potentials. However, case study approach provides important qualitative insights into the experiences of an individual or a group of persons with disabilities. Case studies, when done properly, can produce lasting and crucially important contributions. Disability studies can gain from case studies in the manner that fields of education, anthropology, sociology, medicine, information systems, and many other realms of intellectual inquiry have.

The second section of this report provides three case studies at the country level (Finland, Lithuania and Sweden) based on literature reviews of empirical studies, reports and evaluations. These case studies at the country level provide information about the policies, and examples of the needs of children, parents and other users on the topic of play for children with disabilities, needs that are observed and identified in these societal contexts. 


\section{References}

Barron, C., Beckett, A., Coussens, M., Desoete, A., Cannon Jones, N., Lynch, H., \& Fenney Salked, D. (2017). Barriers to Play and Recreation for Children and Young People with Disabilities. Exploring Environmental Factors. Berlin/Warsaw: De Gruyter.

Bassey, M. (1986). Does Action Research Require Sophisticated Research Methods? In D. Hustler, A. Cassidy, \& E. C. Cuff (Eds.), Action Research in Classrooms and Schools. London: Allen \& Unwin.

Bates, M., Saridaki, M., Kolovou, E., Mourlas, C., Ariu, G., \& Brown, D. (2015). Designing locationbased gaming applications with teenagers to address early school leaving. 9th European Conference on Games Based Learning ECGBL 2015 Nord-Trondelag University College, Steinkjer, Norway.

Besio, S. (Ed., 2008). Analysis of critical factors involved in using interactive robots for education and therapy of children with disabilities. Trento: UNIService.

Besio, S., Bulgarelli, D., Stancheva-Popkostadinova, V. (Eds., 2017). Play Development in Children with Disabilities. Berlin/Warsaw: De Gruyter.

Blanche, E. I. (2008). Play in children with cerebral palsy: doing with-not doing to. In: L. D. Parham, \& L. S. Fazio (Eds.), Play in Occupational Therapy for Children (pp. 375-393). St. Louis: Mosby Elsevier.

Brown, D. J., McHugh, D., Standen, P., Evett, L., Shopland, N., Battersby, S. (2011). Designing Location based Learning Experiences for People with Intellectual Disabilities and Additional Sensory Impairments. Computers and Education 6(1), 11-20.

Bulgarelli, D. \& Bianquin, N. (2017). Conceptual Review of Play. In: S. Besio, D. Bulgarelli, \& V. Stancheva-Popkostadinova (Eds.), Play Development in Children with Disabilities (pp. 9-52). Berlin/Warsaw: De Gruyter.

Butler, C. (1986). Effects of powered mobility on self-initiated behaviors of very young children with locomotor disability. Developmental Medicine \& Child Neurology, 28, 325-332.

Cohen, L., Manion, L. (1994). Research Methods in Education, 4th Edition, London: Routledge.

COST (2013). Memorandum of Understanding for the implementation of a European Concerted Research Action designated as COST Action TD1309: Play for Children with Disabilities (LUDI), https://e-services.cost.eu/files/domain_files/TDP/Action_TD1309/mou/TD1309-e.pdf.

Couch, K. J., Deitz, J. C., \& Kanny, E. M. (1998). The role of play in pediatric occupational therapy. The American Journal of Occupational Therapy, 52(2), 111-117.

Crowe, S, Cresswell, K, Robertson, A., Huby, G., Avery, A., \& Sheikh, A. (2011). The case study approach. BMC Medical Research Methodology, 11:100.

Davies, R. (Ed., 1994). Coming to terms with research. University of East Anglia: Centre of Applied Research in Education (CARE), School of Education.

Davis, Z. T. (1994). Effects of pre-reading story mapping on elementary readers' comprehension. Educational Research, 87(6), 353-360.

Feagin, J. R., Orum, A. M., \& Sjoberg, G. (Ed., 1991). A Case for the Case Study. Chapel Hill, NC: University of North Carolina Press.

Garvey, C. (1990). Play. Cambridge: Harvard University Press.

Geis, G. (1991). The case study method in sociological criminology. In: J. R. Feagin, A. M. Orum \& G. Sjoberg (Eds.), A Case for the Case Study (pp. 200-223). Chapel Hill, NC: University of North Carolina Press.

Ianni, D. (2003). Integrating Internet resources in EFL classes: a case study. Dissertation on the School of Education and Professional Development University of East Anglia.

Mazumdar, S., \& Geis, G. (2001). Case study method for research on disability. In: S. N. Barnartt, \& B. M. Altman (Eds.), Exploring Theories and Expanding Methodologies: Where we are and where we need to go. Research in Social Science and Disability, Volume 2, (pp. 255 - 275), Emerald Group Publishing Limited. 
Missiuna, C., Pollock, N. (1991). Play deprivation in children with physical disabilities: The role of the occupational therapist in preventing secondary disability. The American Journal of Occupational Therapy, 45(10), 882-888.

Myriad Consultants (2005). Case Studies of Employees with a Disability, Policy and Employee Relations. Division Department of Education \& Training Melbourne November 2005 Available online on http://www.eduweb.vic.gov.au/hrweb/diversity/equal.htm.

New Zealand Ministry of Health (2000). New Zealand Disability Strategy discussion document. Available online on http://www.odi.govt.nz/resources/guides-and-toolkits/disabilityperspective/resources/case-studies.html.

Oliver, M., \& Hasler, E (1987). Disability and Self-help: a case study of the Spinal Injuries Association. Disability, Handicap \& Society, 2(2), 113-125.

Stake, R. E. (1995). Case Studies. In: N. K. Denzin, \& Y. S. Lincoln (Eds.), Handbook of Qualitative Research (pp. 236-248). Newbury Park, CA: Sage.

Suryani, A. (2008). Comparing case study and ethnography as qualitative research approaches. Jurnal Ilmu Komunikasi, 5(1), 117-127.

Tsiolis, G. (2014) Methods and techniques of analysis in qualitative social research. Athens: Kritiki (in Greek).

World Health Organization (2001). International Classification of Functioning, Disability and Health (ICF). Geneva: WHO.

World Health Organization (2002). Towards a Common Language for Functioning, Disability and Health: ICF, The International Classification of Functioning, Disability and Health. Geneva: WHO.

Yin, R. K. (1994). Case study research: Design and methods. Thousand Oaks, CA: Sage. 


\section{Methodology: the survey aimed at assessing the children with disabilities play needs from the perspective of parents and children}

Taking advantage of the pan-European nature of the Action "LUDI. Play for children with disabilities" network, a survey aimed to collect the perspectives of parents' associations and individual parents on the children with disabilities play needs was conducted. Given the importance of play for the sake of play in child development and the barriers to play for children with disabilities, it is highly relevant to understand the children with disabilities perspective on their needs regarding play. In their opinion, do they have enough opportunities to play? How about the quality of their play? Do they have the chance of playing for the sake of play, or is it only when play has some secondary goals? Which barriers to play do they perceive? What would they need to improve their play experience?

\subsection{Surveys development and data collection procedures}

Two questionnaires were developed to be applied through the LUDI network in several European countries. One of the questionnaires was directed to representatives of parents' associations and the other to parents of children with disabilities, both aiming for an indirect assessment of the play needs of children with disabilities.

While the questionnaire for representatives of parents' associations contained only multiple choice questions, the one for parents contained only open answer questions aiming at collecting the individual play experiences of their children. Assuming it would be easier to get the opinions of representatives of parents' associations by using a questionnaire that wouldn't take more than 10-15 minutes to complete, a six multiple choice questions instrument was developed, allowing respondents to include additional comments or explanations if they wanted. In contrast, the questionnaire for parents of children with disabilities included mainly open-ended questions in order to collect some anecdotal evidence. This qualitative information on several singular cases may allow for a general description of the play needs of children with disabilities.

Both questionnaires included a cover letter providing brief information about the LUDI network, the objectives of the survey and ensuring confidentiality of the data. No definition of play was provided thus respondents relied on their own definition. The questionnaires were developed by the members of the LUDI network during the first months of the year 2016. The phrasing and concepts adopted in the questionnaire were thoroughly discussed in particular within the LUDI core group, with the purpose of avoiding bias and increasing the fit to the various international contexts. The questionnaires can be found in Appendix. 


\subsubsection{Questionnaire for parents' associations}

In order to allow for subsequent data segmentation and for requiring any further clarification, if needed, respondents were asked to provide their name, the name of the parents' association, the association's country, the associations' website address and/or alternative contact information, the type of impairment/disability and the age range of the children represented, and the number of associates. To collect the information on the type of impairment/disability, the disabilities categorization utilized within the LUDI network was used (Besio et al., 2017), which includes the categories intellectual impairments (mild, moderate, severe, profound); hearing impairments (partially hearing impaired - deaf); visual impairments (partially sighted - blind); communication disorders (language disorders); physical impairments (mild, moderate, severe); autism spectrum disorders; and multiple disabilities. Respondents could select more than one category or specify a different category under "Other".

Question 1 "According to you as a representative, do the children with disabilities have sufficient opportunity to play according to their needs?" was aimed to assess the perceived "quantity of play". Possible answers were "No", "Yes, a little", "Yes, a lot", and "Impossible to say in general", providing three different "quantity levels" of play and the hypothesis of reporting that the reality of the associates was too heterogeneous, not allowing for a general answer.

To assess the perceived "quality of play", question 2 was "Do you think that the parents of the children your Association represents are happy with their children's play?” (yes/no). In case of a negative answer, a justification was requested.

Question 3 - “Is play “for play's sake” important for children with disabilities?” - evaluated the importance attributed by respondents to play activities that have no other goals than play for fun, specifically for children with disabilities. Respondents could choose between "Yes, definitely", "Yes, whenever possible”, "No, play should have a goal", and "No, play is not important".

Perceived barriers to play were assessed by question 4 "What would the children with disabilities that you represent need in order to play (more, better)?”. A four points Likert scale (not important, somewhat important, important, very important) was provided to classify the importance of: toys, high tech tools (assistive technologies, robotic tools), peers (friends, other children), time, adapted or special environments, indoor environments, outdoor environments, a knowledgeable adult, policy measures / financial resources, improved skills needed for play, societal attitudes and behaviors. This list of options was informed by the study on the barriers to play that children with disabilities often face (Barron et al., 2017). Respondents could specify an additional item in the list.

Questions 5 and 6 addressed the perceived play context of the children with disabilities represented by the associations. Question 5 - "Where do the children you represent usually play and with whom?” - aimed for characterizing the environmental 
and social context. For a set of indoor environments (home/other houses, school, culture and leisure centers for children, and rehabilitation center) and a set of outdoor environments (garden/courtyard /street/..., playground, parks and natural environments, and outdoor sport center), respondents could indicate if children usually played alone, alone in the presence of peers, with peers (friends, siblings, etc.), with parents or other family members, or with other adults. An additional indoor environment and an additional outdoor environment could be added. To evaluate the cultural and political context, question 6 - "According to you as a representative, has any change occurred within the last five years that has improved the play of children with disabilities? To what extent?" - gave respondents the possibility of, using a four points Likert scale (no, a little, much, and very much), classifying their perceived recent changes in toys, high tech tools (assistive technologies, robotic tools), indoor environments, outdoor environments, and the attitudes and behaviors of educators, rehabilitators, adults, peers and society in general. It was also possible to add an additional item.

All but question 2 included the possibility of inserting additional comments or explanations.

\subsubsection{Questionnaire for parents of children with disabilities}

Parents were required to fill in the following identification data: country, family relationship (mother, father, guardian), age and gender of the child, and type of impairment/disability. Again, the LUDI disability categorization in was used to collect the information on the type of disability (Bianquin \& Bulgarelli, 2017).

To allow some free thinking about their children's play, the first question requested parents to write down the first three ideas/words that came to their minds when thinking about their children's play. The second question addressed the environmental and social context of play: "Would you like to tell us where does your child usually play and with whom? [e.g., indoor (home, school, leisure centers, etc.), outdoor (courtyard, playgrounds, parks, sport centers, etc.); alone, with peers (friends, siblings, etc.), with parents and other adults, etc.]". The perceived barriers to play were assessed through question 3: "What would your child need in order to play (for more time, more easily, more playfully)? [e.g., specialized or adapted toys, technologies, peers, time, improved skills needed to play, etc.]”. Question 4 evaluated the "quantity" of play: "Could you tell us how much time a day does your child spend playing?”. Finally, parents were challenged to interview their children and a small script was proposed: "If it is possible, would you like to interview your child concerning his/her play? [For example: What do you like about playing, where do you like to play, with whom, and how...? How do you choose your toys? How do you feel when you play? How important is play for you? What would you need to make your play better for you (more fun, more frequent, etc.)?]” 


\subsubsection{Data collection}

One member from each country participating in the LUDI Action was identified to coordinate the survey in the respective country. This coordination involved translating the questionnaires from English to the country's language, using their personal network to contact parents' associations, collecting the responses and translating them to English. Country survey coordinators were asked to contact at least three parents' associations, irrespective of the type of disability of their associates. One representative of the parents' association should complete the parents' associations' questionnaire, and one parent from the association should complete the parents' questionnaire referring to his own particular child. The same person was allowed to complete both questionnaires, assuming the role of a representative of the parents' association and then of a parent of a particular child with disabilities.

31 members in 31 countries participating in the LUDI Action were contacted. The questionnaires were translated into 23 languages $^{1}$ other than English.

The data collection was launched in April 2016 and finished in June 2016. The country coordinators were requested to contact at least three parents' associations and three parents, and ask them to answer to the questions in the survey. The procedure could imply to contact the respondents in various ways by e-mail, by phone or with a personal encounter, but the information provided about the aim and framework of the study should be the same. The respondents' answers were collected by the country coordinator, subsequently translated into English, and reported in a web based platform that would allow afterward to export the collected data to Excel or other formats.

The data collection was managed principally by Pedro Encarnação via e-mail and supported by LUDI Working Group 4 members. The data collection was also coordinated by Tamara Prevendar within the framework of a LUDI Short Term Scientific Mission based at the Department of Special Education at Stockholm University.

The country coordinators that contributed to the data collection were the following LUDI members: Ms Barbara Prazak-Aram (AT), Karen De Maesschalck (BE), Anna Andreeva (BG), Tamara Prevendar (HR), Panayiotis Zaphiris (CY), Jari Jessen (FI), Sonia Sousa (EE), Elina Viljamaa (FI), Odile Perino (FR), Katina Pavlovska (MK), Ursula Winklhofer (DE), Maria Saridaki (GR), Cecilia Sik Lanyi (HU), Dana Cappel (IL), Tamara Zappaterra (IT), Egle Celiesiene (LT), Veronica Montanaro (MT), Rianne Jansens (NL), Agnieszka Landowska (PL), Pedro Encarnacao (PT), Ana Muntean (RO), Natalia Amelina (RU), Miodrag Stankovic (RS), Noemi Rando (ES), Mara Westling Allodi (SE), Sylvie Ray-Kaeser (CH), Hilary Gardner (GB), and Selda Ozdemir (TR).

1 Belgian, Bulgarian, Croatian, Danish, Dutch, Estonian, Finish, French, German, Greek, Hebrew, Hungarian, Italian, Lithuanian, Macedonian, Polish, Portuguese, Romanian, Russian, Serbian, Spanish, Swedish, and Turkish. 
Table 2 lists the number of questionnaires collected per country. A total of 75 responses to the questionnaire for the parents' associations and 129 responses to the questionnaire for the parents of children with disabilities was obtained.

Note from Table 2 that the number of responses in each country is relatively small which, added to the fact that respondents were chosen from a particular network of contacts, does not allow for generalizations at the country level. Analysis at the European level should also be made with great caution since there are many exogenous variables that were not controlled (for example, cultural, economic and political contexts, type of impairments, to name just a few). Nevertheless, it is interesting to analyze the questions in which there was a big majority of respondents choosing one answer. Additionally, it is worth exploring the obtained anecdotal information considering the current scientific beliefs.

Table 2. Number of collected questionnaires per country

\begin{tabular}{lll}
\hline Country & \#Parents' Associations Questionnaires & \#Parents' Questionnaires \\
\hline Austria & 1 & 1 \\
Belgium & 2 & 10 \\
Bulgaria & 2 & 4 \\
Croatia & 3 & 3 \\
Cyprus & 3 & 0 \\
Denmark & 1 & 0 \\
Estonia & 0 & 3 \\
Finland & 3 & 3 \\
France & 4 & 5 \\
FYR Macedonia & 3 & 5 \\
Germany & 4 & 4 \\
Greece & 2 & 4 \\
Hungary & 3 & 6 \\
Israel & 2 & 3 \\
Italy & 9 & 19 \\
Lithuania & 2 & 2 \\
Malta & 0 & 2 \\
Netherlands & 3 & 4 \\
Norway & 0 & 1 \\
Poland & 4 & 19 \\
Portugal & 1 & 1 \\
Romania & 6 & 7 \\
Serbia & 3 & 3 \\
Spain & 5 & 7 \\
Sweden & 3 & 3 \\
Switzerland & 3 & 4 \\
United Kingdom & 0 & 3 \\
Turkey & 3 & 3 \\
TOTAL & 75 & 129 \\
\hline & &
\end{tabular}




\section{References}

Barron, C., Beckett, A., Coussens, M., Desoete, A., Cannon Jones, N., Lynch, H., \& Fenney Salked, D. (2017). Barriers to Play and Recreation for Children and Young People with Disabilities. Exploring Environmental Factors. Berlin: De Gruyter.

Besio, S., Bulgarelli, D., \& Stancheva-Popkostadinova, V. (Eds., 2017). Play development in children with disabilties. Berlin/Warsaw: De Gruyter. 


\section{Appendix}

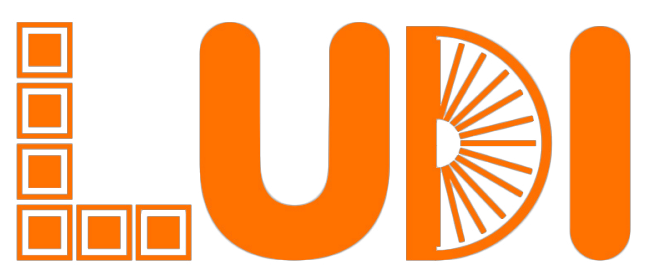

Play for Children with Disabilities

The COST Action TD1309 "LUDI - Play for children with disabilities" (2014-2018) is a pan-European network funded by the European Program COST (https://www.cost. $\mathrm{eu} /$ actions/TD1309) dedicated to the theme of play for children with disabilities, integrating more than 100 researchers and practitioners from 32 countries.

One of the tasks of the Action, managed by its Working Group no. 4, was to gather information about the children's experiences and needs concerning play. To this purpose, a survey had been organized, conducted through the following questionnaire (developed by Serenella Besio and Pedro Encarnação), addressed to Parents' Associations of children with disabilities. This questionnaire has been designed to be completed by a representative of the Association and by a parent of a child with disabilities affiliated to this Association.

If you are going to use the current questionnaire, you are kindly asked to cite the COST Action TD1309 "LUDI - Play for children with disabilities" as the project that developed this tool. Please, also communicate you are using the questionnaire, by sending an e-mail to the Chair of the Action, professor Serenella Besio: serenella.besio@unibg.it 


\section{Questionnaire for a representative of a Parents' Association}

Name of the respondent

Name of the Parents' Association

Country

Website address and/or alternative contact information

Type of impairment/disability represented

Please try and use the following list even if there isn't the precise category of your Association; or, choose "other" and add the category you wish

$\bigcirc$ Intellectual impairments (mild, moderate, severe, profound)

$\bigcirc$ Hearing impairments (partially hearing impaired - deaf)

Visual impairments (partially sighted - blind)

Communication disorders (language disorders)

Physical impairments (mild, moderate, severe)

$\bigcirc$ Autism spectrum disorders

Multiple disabilities

Other

Age range of the children represented

Number of the Parents' Association members

Question 1. According to you as a representative, do the children with disabilities have sufficient opportunity to play according to their needs?

$\bigcirc$ No

Yes, a little

$\bigcirc$ Yes, a lot

Impossible to say in general

Please, use this space for any additional comments or explanation for answers provided

Question 2. Do you think that the parents of the children your Association represents are happy with their children's play?

Yes

No. Could you write why, please? 
Question 3. Is play “for play sake” important for children with disabilities?

$\bigcirc$ Yes, definitely

$\bigcirc$ Yes, whenever possible

No, play should have a goal

$\bigcirc$ No, play is not important

Please, use this space for any additional comments or explanation for answers provided

Question 4. What would the children with disabilities that you represent need in order to play (more, better)?

Please tick the column you prefer per each line

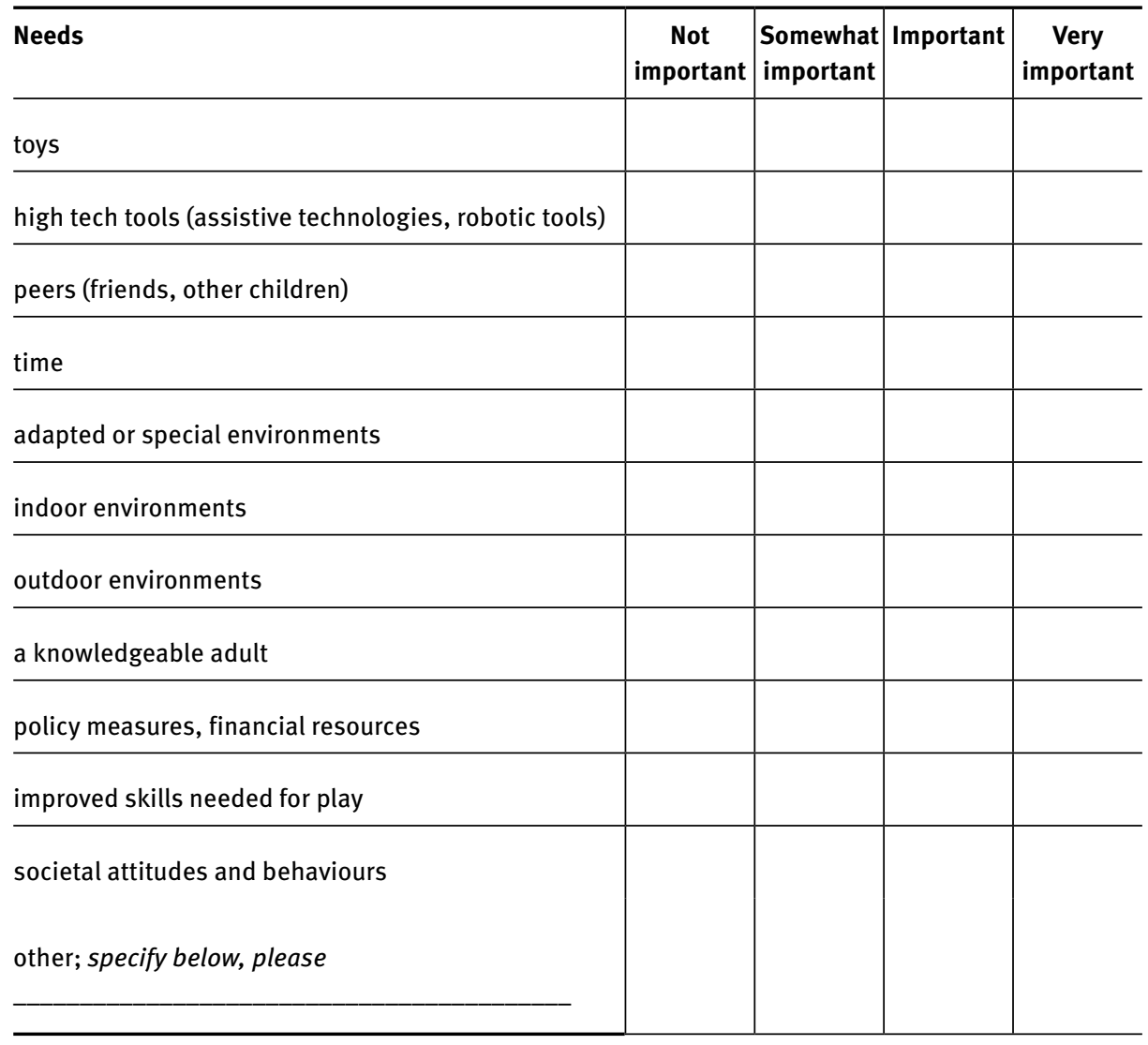

Please, use this space for any additional comments or explanation for answers provided 
Question 5. Where do the children you represent usually play and with whom? Please tick the column appropriate for you

\begin{tabular}{|c|c|c|c|c|c|c|}
\hline \multirow{2}{*}{\multicolumn{2}{|c|}{ Where }} & \multicolumn{5}{|c|}{ With Whom } \\
\hline & & alone & $\begin{array}{c}\text { alone, } \\
\text { in presence } \\
\text { of peers }\end{array}$ & $\begin{array}{c}\text { peers } \\
\text { (friends, } \\
\text { siblings, ...) }\end{array}$ & $\begin{array}{c}\text { parents, } \\
\text { family } \\
\text { members }\end{array}$ & $\begin{array}{l}\text { other } \\
\text { adults }\end{array}$ \\
\hline \multirow{5}{*}{ 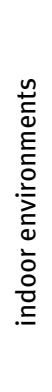 } & home, other houses & & & & & \\
\hline & school & & & & & \\
\hline & $\begin{array}{l}\text { culture and leisure centres for } \\
\text { children }\end{array}$ & & & & & \\
\hline & rehabilitation centre & & & & & \\
\hline & other & & & & & \\
\hline \multirow{5}{*}{ 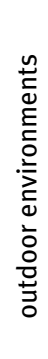 } & garden, courtyard, street, ... & & & & & \\
\hline & playground & & & & & \\
\hline & parks and natural environments & & & & & \\
\hline & outdoor sport centre & & & & & \\
\hline & other _____ & & & & & \\
\hline
\end{tabular}

Please, use this space for any additional comments or explanation for answers provided 
Question 6. [optional] According to you as a representative, has any change occurred within the last five years that has improved the play of children with disabilities? To what extent?

\begin{tabular}{|c|c|c|c|c|c|}
\hline \multicolumn{2}{|l|}{ Change in... } & no & a little & much & very much \\
\hline \multicolumn{6}{|l|}{ toys } \\
\hline \multicolumn{6}{|c|}{ high tech tools (assistive technologies, robotic tools) } \\
\hline \multicolumn{6}{|c|}{ indoor environments } \\
\hline \multicolumn{6}{|c|}{ outdoor environments } \\
\hline \multirow{4}{*}{$\begin{array}{l}\text { attitudes } \\
\text { and } \\
\text { behaviors of: }\end{array}$} & educators, rehabili & & & & \\
\hline & adults & & & & \\
\hline & peers & & & & \\
\hline & society in general & & & & \\
\hline \multicolumn{6}{|c|}{ other; specify below, please } \\
\hline
\end{tabular}

Please, use this space for any additional comments or explanation for answers provided

Thank you very much for your contribution! The LUDI Network 


\section{Questionnaire for a parent of a particular child}

Country

Family relationship (mother, father, guardian)

Age of the child

Gender of the child

Type of impairment/disability

Whilst we are aware that asking parents about the impairment type of their child may be a sensitive issue, we would be most grateful if you were willing share with us the nature of your child's impairment. Please consider which of these options best describes the impairment of your child. If none of these options is a perfect fit for your child please choose "other" and let us know of the particular needs of your child

Intellectual impairments (mild, moderate, severe, profound)

Hearing impairments (partially hearing impaired - deaf)

Visual impairments (partially sighted - blind)

Communication disorders (language disorders)

Physical impairments (mild, moderate, severe)

Autism spectrum disorders

Multiple disabilities

Other

As a parent of a child with disabilities, please write down the first three ideas/words that come to your mind when you think about your child's play

1.

2.

3. 
If you have time to say why these words are important, then please do - this would be valuable information for us

Would you like to tell us where does your child usually play and with whom? [e.g., indoor (home, school, leisure centers, etc.), outdoor (courtyard, playgrounds, parks, sport centers, etc.); alone, with peers (friends, siblings, etc.), with parents and other adults, etc.]

What would your child need in order to play (for more time, more easily, more playfully)? [e.g., specialized or adapted toys, technologies, peers, time, improved skills needed to play, etc.]

Could you tell us how much time a day does your child spend playing? 
If it is possible, would you like to interview your child concerning his/her play?

[For example: What do you like about playing, where do you like to play, with whom, and how...?

How do you choose your toys?

How do you feel when you play? How important is play for you?

What would you need to make your play better for you (more fun, more frequent, etc.)?]

Thank you very much for your contribution!

The LUDI Network 
Mara Westling Allodi, Maria Gladh, Eira Suhonen, Marjatta Takala, and Tamara Zappaterra

\section{Perceptions of Members in Parents' Associations for Children with Disabilities of their Children's Opportunities to Play}

\subsection{Parents' Associations survey}

The Action "LUDI. Play for children with disabilities" developed the survey about the views and needs of users in various contexts in 2016, asking members of Parents' Associations for Children with Disabilities (PACDs) their opinions and views when it comes to their children's opportunities to play. Why the questionnaires were addressed to Parents' Associations? The voices of children should be heard through representatives of associations because they have a wide knowledge on many cases and can report the playing conditions in disability, showing the influence that the political and cultural aspects have on this issue.

The Parents' Associations were contacted to easily get information from a knowledgeable user base which is directly involved in the disability needs.

In each country participating in the Action, a member responsible for the data collection on users' needs was asked to contact parents' associations of children with disabilities in order to elicit the experiences and views within their organisation, concerning the children's opportunities to play and to submit their answers in the web-survey. The national responsible was suggested to collect if possible answers from at least three associations, disregarding the type of disability. The reason for this is because the answers should provide just a snapshot from European context with valuable information about the children's experiences and needs in this field.

It was more important at this step of the Action to get knowledge about general needs of children with disabilities than to inquire about the differences between types of impairments, or about specific cases of children. The answers were reviewed and analysed by members of the Action "LUDI" Working Group 4 and subsequently compiled in the present report.

\subsubsection{Participating Countries}

Countries participating in the survey were Austria, Belgium, Bulgaria, Croatia, Cyprus, Denmark, Finland, France, FYR Macedonia, Germany, Greece, Hungary, Israel, Italy, Lithuania, the Netherlands, Poland, Portugal, Romania, Serbia, Spain, Sweden, 
Switzerland and Turkey ( $\mathrm{N}=24)$. Five more Action "LUDI" countries were asked to participate to the survey but they did not provide answers, during the timeframe of the present data collection, March-June 2016. Numbers of PACD participating from each country varied from 1 to 9, with an average of 3 and a total of 75. Italy and Romania were representing countries with 9 and 6 participating PACDs. Austria, Denmark and Portugal in turn, had 1 PACD per country that answered to the survey.

As a whole, the participating countries show a rather good geographic distribution, with representing countries from East, West, North and South regions of Europe, which indicate that the survey was able to collect opinions from quite different societal contexts.

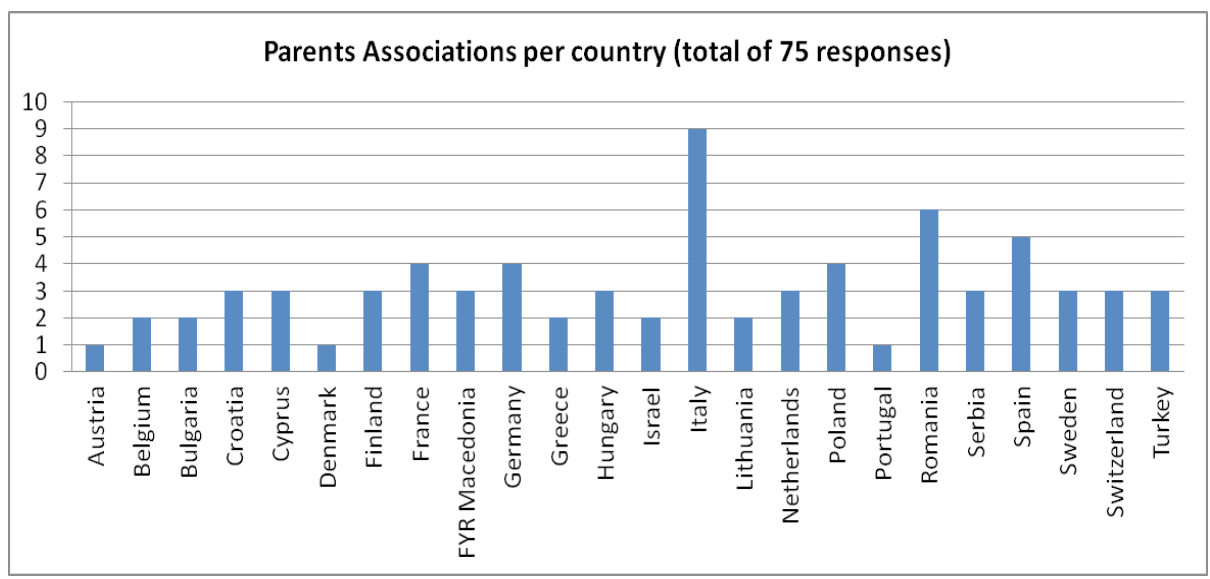

Figure 1. Number of PACDs per country $(\mathrm{N}=75)$ in alphabetical order

\subsubsection{Types of impairment/disability represented and ages}

The knowledge of the type of impairment and of the age of the children gives the opportunity to establish some considerations about these indicators.

PACDs participating in the survey were representing a wide variation of disabilities (Fig. 2) such as intellectual impairments from mild to profound (19\%), autism spectrum disorders (17\%), communication/language disorders (15\%), multiple disabilities (14\%), physical impairments from mild to severe (12\%), visual impairments from partially sighted to blind (9\%), hearing impairments from partially hearing impaired to deaf $(8 \%)$, and other $(6 \%)$. The respondents that reported the alternative "other", in addition to the offered choices or as the only answer, added as specification - e.g. Down syndrome - or other conditions and diagnoses - as developmental disorders, cerebral palsy, dyspraxia, attention deficit hyperactivity disorders, very premature infants, and developmental delay in learning and behaviour. In one case it was 
reported that the children were also deprived, in addition to having disabilities. In this regard the Action "LUDI" focuses on the play of children with disabilities related to category A in the cross-national recognized sense of OECD's (Organization for Economic Cooperation and Development) Centre for Educational Research and Innovation, therefore it caters to children with disabilities or impairments viewed in medical terms as organic disorders attributable to organic pathologies ${ }^{2}$.

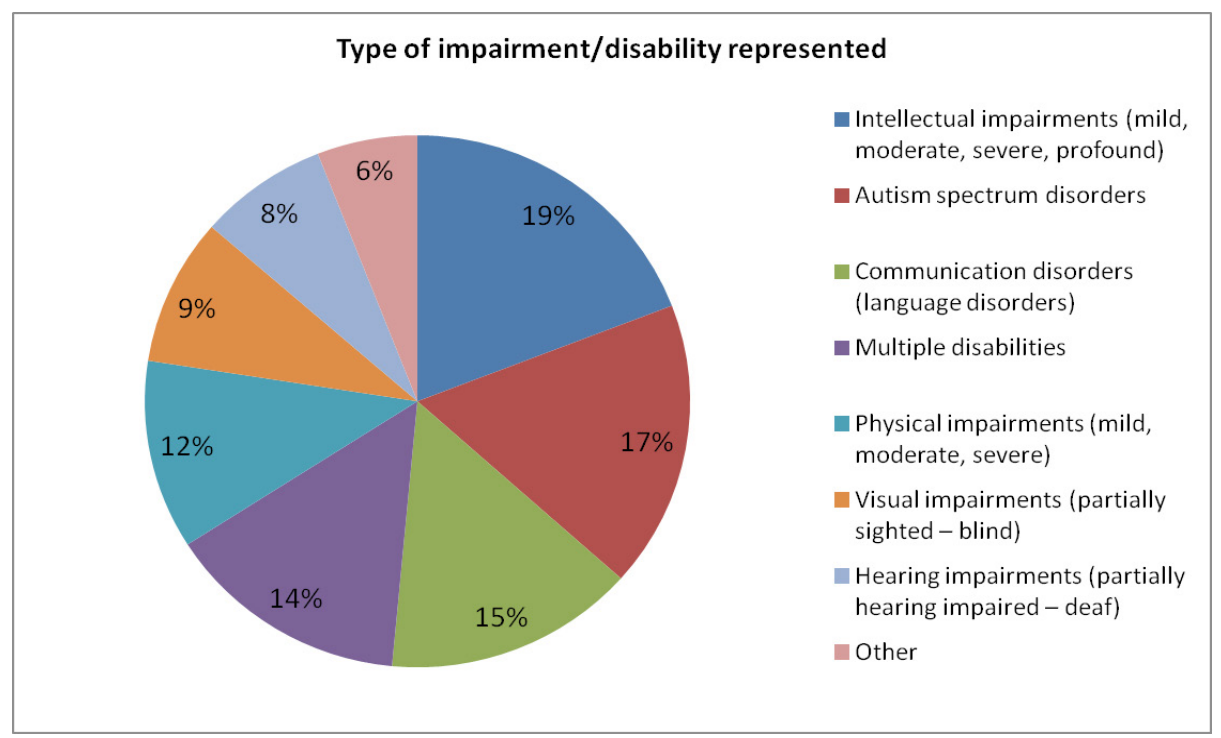

Figure 2. Types of disabilities (percentages) represented by the PACDs $(\mathrm{N}=75)$

The Parents' Associations that participated to the survey represent various types of disabilities, with a rather even distribution between the types. It should be noted also that each association could report that their members included more than one type of disability.

32 Associations reported that they represented persons with disabilities of all ages, while 25 Associations are only in charge of children up to the age of 18.

2 OECD. Students with Disabilities, Learning Difficulties and Disadvantages: Policies, Statistics and Indicators, 2005, 2007. 


\subsubsection{Parents' Association members}

The Associations collect members and operate at a local, regional or national level. Most of the PACDs participating in the survey have a membership of up to 500 participants. Within the countries participating in the survey, 21 PACDs had more than 500 members. All in all, the participating PACDs are estimated to represent at least 87.544 persons with disabilities, with a restrictive estimation.

Table 3. Numbers of members of PACDs

\begin{tabular}{ll}
\hline Number of members & Number of Associations \\
\hline$<100$ & 25 \\
$100-499$ & 21 \\
$>500$ & 21 \\
No response & 8 \\
TOTAL & 75 \\
\hline
\end{tabular}

This number is a lower bound since the estimation builds upon the consideration that the number of members reported in many cases corresponded to the number of families. When an interval was indicated by the respondent, the lower limit of the interval was considered to perform the calculation.

\subsubsection{Opportunities to play according to the needs}

Regarding Question 1, asking if the children with disabilities have sufficient opportunity to play according to their needs, $31 \%$ of the participating PACDs answered that children with disabilities represented in their Association do not have the same opportunities to play as the other children. $42 \%$ of the respondents answered that the children with disabilities had to some extent opportunities to play, while $15 \%$ stated that the children with disabilities that they represent have a lot of opportunities to play. Additionally, $12 \%$ of the respondents reported that it was impossible to give a general answer to this question (Figure 3). This question is aimed at understanding the perception that the Association's representatives have with respect to the needs and the value of play.

\subsubsection{Parents' happiness/satisfaction with their children's play}

Regarding Question 2, about the happiness or satisfaction of the parents with their children's play, a majority of the PACDs (64\%) thought that the parents of the children with disabilities that they represent are not happy with their children's play. A little more than one third of the Associations thought that the parents were happy with their children's play (Figure 4). 


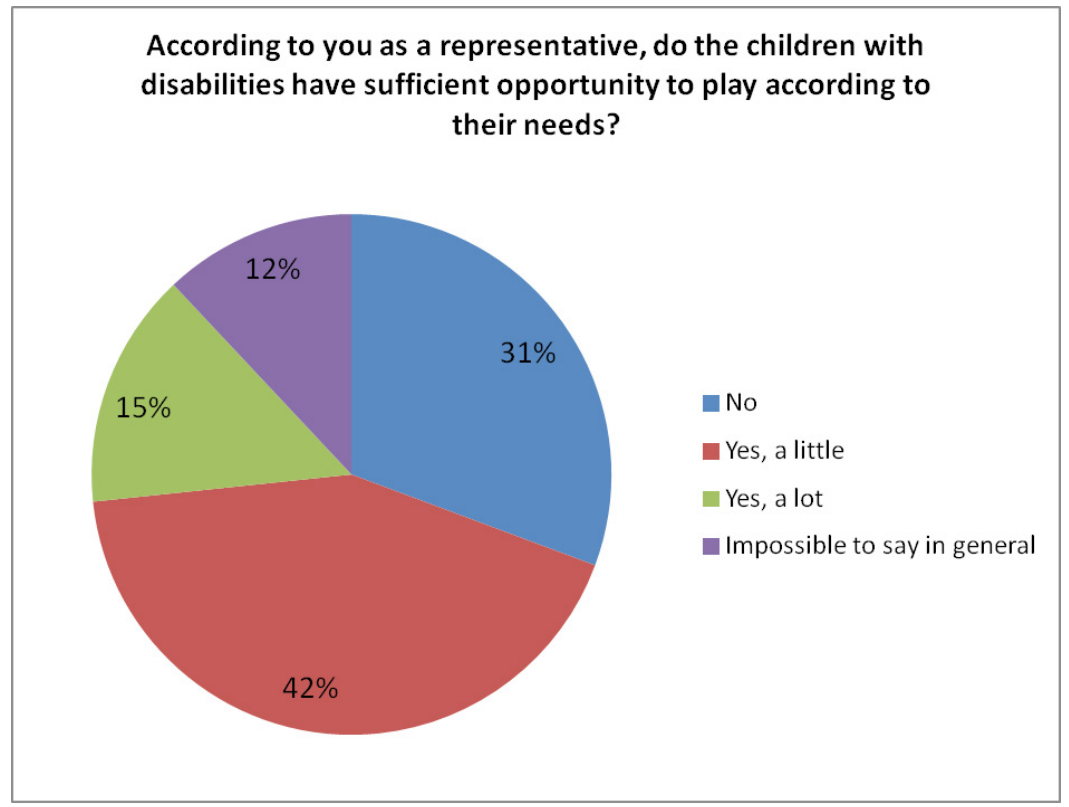

Figure 3. Opportunities to play according to the children's needs represented by PACDs (percentages).

\section{Do you think that the parents of the children your Association represents are happy with their children's play?}

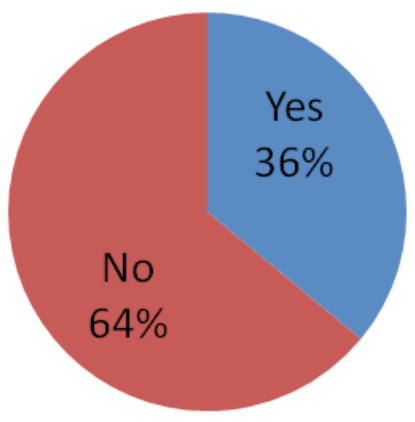

Figure 4. Parents' happiness with their children's play according to representatives of the PACDSs (percentages, $\mathrm{N}=75$ ). 
The respondents could add comments to this question. The comments are analyzed and summarized here and can thus be considered examples, in term of limitations, restrictions, as well as facilitators and barriers, to play for children with disabilities.

Among those that answered that the parents were happy with their children's play (36\%) there were 7 comments. Some comments were linked to toys that were available and adapted: all our children prefer music toys and children can play with many kind of toys, not only the ordinary ones. In one comments toys'library is mentioned and another answer handles parents' inventive to find appropriate play material. In two comments the representatives alluded to resources available through their Association; we have appropriate spaces, facilities and have trained staff and we provide them opportunities for playing.

Facilitators of play were thus mentioned within these comments: specific toys, adapted toys, broad range of available and accessible toys to loan, parents' creativity, purposeful planning and other resources in available space, premises and educated staff.

Among those Associations that answered that the parents were not happy with their children's play (64\%), 44 comments were gathered explaining the motives behind their opinion.

In some answers the parents' dissatisfaction with play was related to activity performance and play preferences: impairments, activity limitations and participation restrictions were viewed as restricting the play activities that a child could take part of and were also impacting a child's play preferences.

One theme related to this category is children's characteristics: in fact, 14 answers related to children's characteristics as reasons for this dissatisfaction were produced. Most of these answers concerned the restrictions that children with autism spectrum may experience in contact with others, as well as their tendency to isolate themselves. The experiences of children with physical and multiple disabilities were also mentioned in this category. Some comments are reported below.

AS [Autism Spectrum] children tend to be alone.

The play of ASD children is lonely, repetitive, lack of diversity and [is] mainly sensory-motor.

[Children with] multiple disabilities cannot enjoy to normal, standardized or frequent play.

Physical barriers were mentioned too: accessibility and usability of the physical setting that may limit play.

The outdoor play environment - both natural and structured - were also cited as entailing barriers to play.

Children have difficulties in playing in natural environments.

Playground are not adapted for children with disabilities. 
The lack of toys as well as the lack of not specifically adapted games may be considered also under this category. The need of games and toys which allow children to play independently is mentioned 10 times. Some examples are reported below.

There are not specific games to some target groups, for example there are no fairy tales or films adapted to sign language.

Grip toys, manipulation toys and movement games can only be applied with support. Independent creative games are not usable or usable only with assistance.

But most of the comments (22) concerned the category: "Social barriers - attitudes and behaviors". They may encompass exclusive or inclusive attitudes and behaviors by peers, teachers, professionals, parents and relatives. Four themes were identified in this area: discrimination, peer relations, parents' skills and human resources.

As to the theme discrimination, the comments included both discrimination imposed by typically developing children and by their parents, as well as discrimination issued by society at large.

The majority of parents having handicapped children avoids the public spaces because of the discriminatory attitudes of parents with healthy children. Some specific behaviors of children with autistic disorders are making the parents with healthy children to not allow their children to play with autistic children.

Negative attitudes of neighbors and of other children.

The older the children, the more difficult it becomes often; exclusion at the playground, e.g. because of unusual behavior.

There is a wide variation, depending on the experiences in educational contexts and socio-cultural context of belonging.

In 8 comments the scarce possibilities of developing peer relations and the lack of friends are considered the cause of children's limited play opportunities.

The parents are partially happy with the children's play with toys and play with an adult. They are less happy with how the children play with other children, in particular free play. It is difficult in the after-school centers / children recreation centers with too high numbers of children. It is a source of anxiety and sadness for the parents and the family, when they realize that the children are not participating in the activities in school, preschool and after-school centers. It is something that the parents talk about as an important issue.

Children with disabilities have not opportunity to peer play with children who have better skills and opportunity to explain how to use the toys.

In this last comment the lack of peers that can act as play role models is regarded as a barrier to play for children with disabilities; this occurrence may depend in turn on 
a lack of an experienced inclusive educational environments, where children with different abilities may freely interact.

There were only 4 comments about parents and their attitudes or skills supporting their children's play. In one comment the respondent said that parents differ a lot, depending on their expectations and abilities related to children's play.

Parents feel helpless in front of the child playing in a way unusual for them, or, [that] apparently, does not play. They experience the difficulty of not knowing how to behave and feel inadequate parents.

2 comments mentioned the lack of human resources that could make play opportunities better to children with disabilities.

It is difficult to organize adequate spaces, needed skills and professionalism are not always available. This is why we also take care of training for both our staff, both support teachers and not least for the parents

\subsubsection{The importance of play “for play's sake” for children with disabilities}

Question 3, asking if play "for play's sake" is important for children with disabilities constitutes the basic assumption on which the whole Action "LUDI. Play for children with disabilities" engages.

The play is a topic widely recognized in education, in rehabilitation and in the context of the rights of children with disabilities: from research we know that children learn a lot from playing, and we know also that play has been established at international level as a right in childhood. However, the play for play's sake is not yet an established theoretical construct nor a cultural fact. For this reason, it is interesting to know the value that the users assign to play in itself.

Following the answers from the participating PACDs we can conclude that the dominant view is that "play for play's sake" is no less important for children with disabilities than for the other children. In this survey $72 \%$ of the respondents share this opinion (54 Associations). From the answers it's also notable that $23 \%$ of the respondents found it important with play for play's sake "whenever it is possible" (17 Associations). These answers may show that there is a common understanding around the fact that play can be hindered, either in favour of training activities, routines and care activities, or due to the lack of availability. Finally, only 5\% of the respondents thought that play always should have a goal, and none considered play as not important.

The comments of those who answered that play should have a goal explain that play in their view should be mainly finalized to achieving educational or rehabilitative objectives. 


\section{Is play "for play sake" important for children with disabilities?}

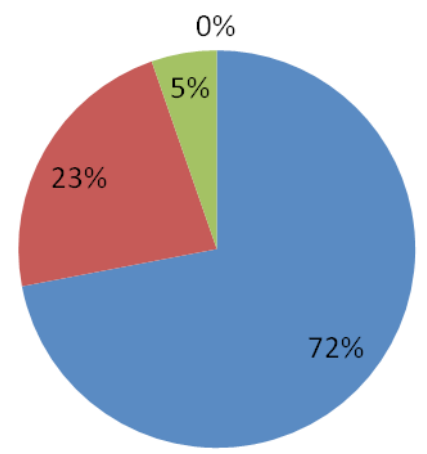

Yes, definitely

Yes, whenever possible

No, play should have a goal

No, play is not important

Figure 5. Importance of play for play's sake for children with disabilities represented by PACDs (percentages, $\mathrm{N}=75$ ).

The comments of those answering whenever possible may indicate that play is certainly supporting children's development, and also that play is considered as oriented to learning. Some comments identify also as barriers some situations related to specific disabilities: for example, that children with autism are trained to play and thus it can be difficult to separate and distinguish their experience of learning from their experience of play; or that children with cerebral palsy may need adapted toys and environments in order to be able to participate in play.

Among the large majority of respondents that answered yes definitely many comments (35) were added that can be grouped around some central themes, as presented in what follows.

9 comments emphasize that play is a very important and basic activity for all children; they used expressions such as: extremely important, very essential for all children, play is children's main activity, a component of a child's natural development, inherent to humans, a basic need like sleep and protection, and as a necessary, not optional, factor for children's growth and development.

13 comments explain that play is related to learning in terms of specific skills (social, relational, emotional skills, basic experiences for daily life) and abilities (cooperation, creativity, communication, logical reasoning) that are practiced through it, and also in terms of more general kind: understanding life, understanding oneself and the world, making experiences of discovery and even the only way to acquire knowledge and skills.

Play is also viewed as a common language with peers, as a medium for communication, friendship and understanding between children, through which the children may experience a feeling of belonging to their peers' group. 
Play is good for children because they become happier as they play, thus it makes the child feel positive emotions: while playing, they experience enjoyment, happiness, pleasure, joy, fun, and also relax, and these emotions are viewed in some comments as important for everyone.

Another reason of the importance of play is that the children as agents elaborate their experiences and express themselves with play, which, among other things, allow people in their environment to understand them and their needs. Play is also defined as a right for all the children.

Some (3) comments point out the importance of play as a tool in preventing difficulties possibly related to a disability. For instance, play can help in preventing and solving some emotional difficulties, or in supporting the development of executive functions, an area that may need intervention. The lack of play is viewed as a symptom of disability itself in another comment.

Other (5) comments involve the role that adults have in relation to children's play. Some comments state that play should be facilitated by the adults, who may adapt the play environment to the interests and the needs of the children; another comment states that the professionals can also take advantage of the pleasure that play originates in the children and use the play activities as mediators to reach other objectives. Furthermore, supervision by adults may be needed in order to avoid risks or repetitive behaviors. One comment identifies also the concern that some parents may not recognize the importance of play, thus prioritizing instead the training of motor and communicative skills in their children.

Summarizing, the largest group of representatives from the Associations considered play for play's sake essential for a wide range of reasons which can be related to socioanthropological, psychological, developmental, and educational theories.

A widely shared belief is that play is necessary and leads to an array of positive outcomes for the child; even if play is mainly experienced as a free activity without specific objectives.

The answers from the parents' Association give a strong support to the conception of play for play's sake as very important for children with disabilities. This conception seems largely shared among the participating Associations.

\subsubsection{Needs of the children in order to play (more, better)?}

The Question 4 investigates the experienced play needs and their nature. The respondents were given several options and were asked to indicate the perceived level of importance.

In order to let children with disabilities play more or better $93 \%$ of the respondents answer that peers are essential (very important/important). Societal attitudes and behaviours are referred as an important or very important factor ( $87 \%$ of the respondents), when it comes to facilitate play. An equivalent answer (87\% of the 
respondents) considers important or very important to have access to a knowledgeable adult. As much as $84 \%$ of the participants in the survey regards time as a necessity, to make children be able to play. Other quite high ranked aspects, making it possible for children with disabilities to play, are: adapted or special environments (79\%), policy measures/financial resources (79\%), outdoor environments (77\%), improved skills needed for play (72\%), toys (69\%), indoor environments (68\%), high-tech tools/ assistive and technologies/robotic tools (59\%).

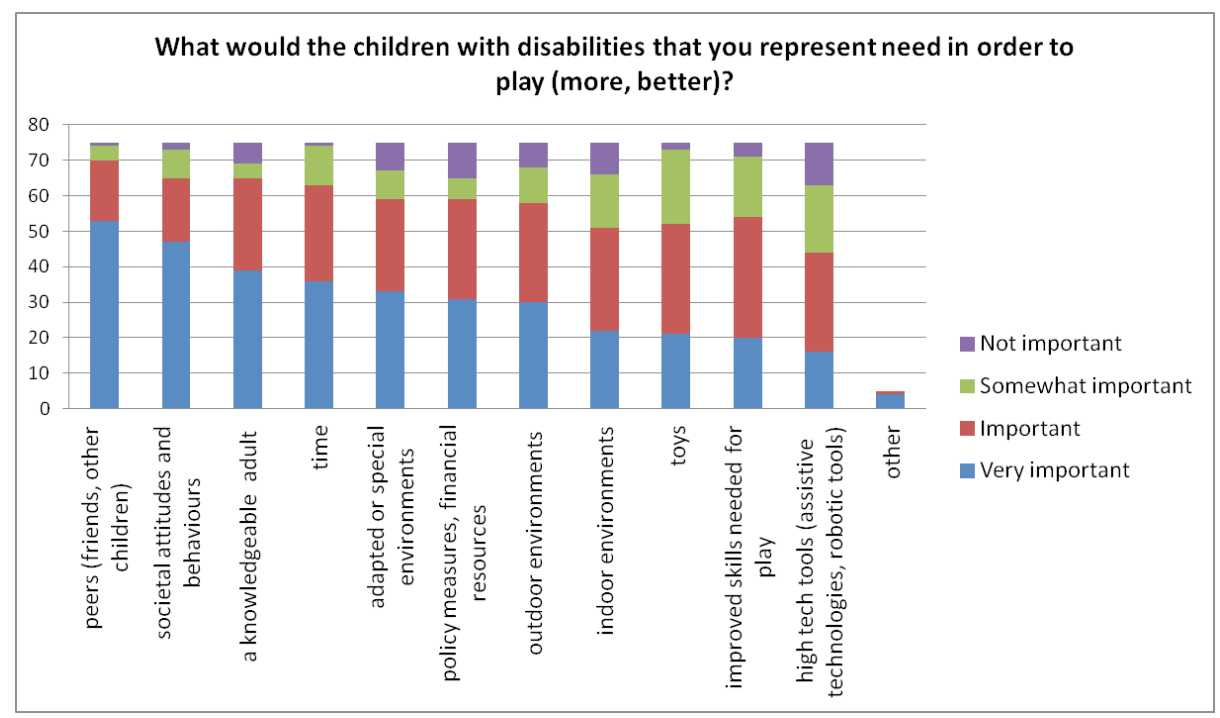

Figure 6. Needs of children with disabilities in order to play more or better, according to the representatives of PACDs $(\mathrm{N}=75)$.

5 respondents added some contents that they considered important or very important in order to allow the children with disabilities that they represent to play more, or better. One thing that is needed is the availability of adapted, age-appropriate toys, that are adapted to a user at an early-stage ability but that are illustrated with pictures that are age-appropriate and thus not with infantile subjects; thus a broader range of toys are needed that are suitable for users, whose developmental needs and interests follow a pattern that is not a 'mainstream' one. Another answer says that providing information to the parents about the importance of play for children with visual impairment would be very important. Research on play and ludic behaviour is also very important for another respondent. Activities and qualified people, rehabilitation services and support to the families are mentioned by two respondents and are grouped together as similar, since they both ask for qualified and supportive services to the families. Something that stands alone and is needed according to one respondent is the motivation to play as a prerequisite to engage in play. 


\subsubsection{Play environments and play partners}

The survey gave the opportunity to get a picture about the contexts and the situations where children with disabilities usually play as well as about their play companions. In fact, Question 5 investigates which are the most used play contexts of children with disabilities (formal/non-formal, outdoors/indoors) and who are their playmates (children, adults, family members, others).

Current indoor environments are: homes and other houses, schools, culture and rehabilitation centres as well as leisure centres for children. Current outdoor environments are: playgrounds, parks and natural environments, gardens/ courtyards/streets and outdoor sport centres. Looking at whom children with disabilities are most frequently used to play to (in combination with where) it seems to be more common playing with parents or family members at home than with peers or friends in schools. The survey shows also that children with disabilities are more often used to play alone, even in presence of peers, than to play with peers or friends in outdoor environments, such as playgrounds, parks and natural environments and gardens/courtyards/streets. In outdoor sport centres instead, children in this survey seem to play a little bit more with other children and youth, rather than alone.

Table 4. Environments and playmates for the play activities of children with disabilities according to the PACDs.

\begin{tabular}{|c|c|c|c|c|c|c|}
\hline & \multirow[b]{2}{*}{ WHERE } & \multicolumn{5}{|c|}{ WITH WHOM } \\
\hline & & $\stackrel{\frac{0}{0}}{\frac{5}{\sigma}}$ & 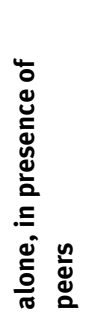 & 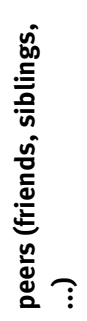 & 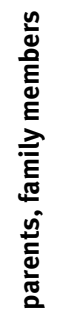 & 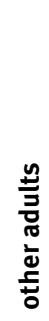 \\
\hline indoor & home, other houses & 30 & 12 & 27 & 49 & 15 \\
\hline \multirow[t]{4}{*}{ environments } & Schools & 14 & 28 & 39 & 2 & 22 \\
\hline & $\begin{array}{l}\text { culture and leisure centres for } \\
\text { children }\end{array}$ & 5 & 16 & 24 & 14 & 18 \\
\hline & rehabilitation centres & 15 & 16 & 18 & 5 & 28 \\
\hline & Other & 0 & 1 & 1 & 0 & 1 \\
\hline outdoor & gardens, courtyards, streets ... & 21 & 23 & 26 & 27 & 8 \\
\hline \multirow[t]{4}{*}{ environments } & Playgrounds & 18 & 26 & 27 & 27 & 13 \\
\hline & parks and natural environments & 17 & 21 & 26 & 37 & 15 \\
\hline & outdoor sport centres & 12 & 11 & 28 & 18 & 22 \\
\hline & Other & 2 & 2 & 2 & 2 & 2 \\
\hline
\end{tabular}




\subsubsection{Changes in the play of children with disabilities}

The Question 6 investigates whether according to the perceptions of parents' Associations there have been any developments about play of children with disabilities and in which fields (technologies, policies, educational sciences and rehabilitation, but also cultural attitudes and behaviors).

According to the respondents to this study, there have been more or less improvements, when it comes to play for children with disabilities within areas such as attitudes and behaviours among educators $(\mathrm{N}=42)$, adults $(\mathrm{N}=44)$, society in general $(\mathrm{N}=47)$ and peers $(\mathrm{N}=46)$. Even more noticeable improvements were reported in areas such as high tech tools $(\mathrm{N}=61)$ and outdoor environments $(\mathrm{N}=53)$. In hightech tools was reported the higher numbers of very large changes $(\mathrm{N}=13)$ by the respondents. Toys were also perceived as having improved much or very much by a relatively large number of respondents. In the other topics there were rather small numbers of respondents that were reporting very large or large improvements.

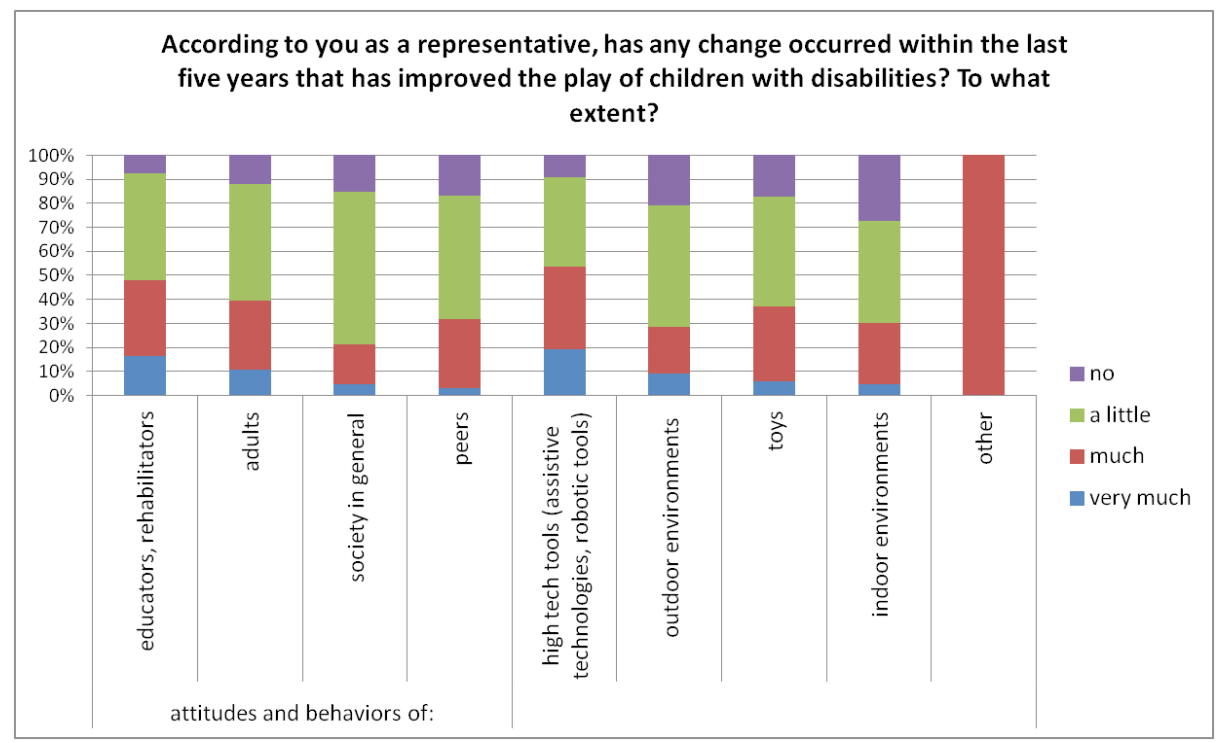

Figure 7. Changes occurred in play for children with disabilities in the last five years, according to the PACDs (percentages). 
Mara Westling Allodi, Tamara Zappaterra, Marjatta Takala, Elina Viljamaa, Eira Suhonen and Alisa Alijoki

\section{Parents of a child with disabilities and their views about their child's play}

\subsection{Participating Countries}

Members from various countries participating to the Action "LUDI. Play for children with disabilities" coordinated the collection of answers from parents of children with disabilities in each country. Parents were contacted by members through local and national parents' and disability Associations and through other networks. In many cases they were informed in advance about the survey via phone and e-mail and asked for their willingness to participate. The members were asked to collect answers from at least three parents from their country, without any other specific selection criteria. Members from 31 countries were asked to participate.

The members from 26 countries collected in total, 129 questionnaires were received from parents with an average of about 5 questionnaires per country ( $\mathrm{SD}=4.65 ; \mathrm{min}=1$, $\max =19$ ). The views of parents from some countries are better represented than others due to the higher participation of parents in these countries. Anyway, the recruited questionnaires represent quite a satisfying geographical distribution.

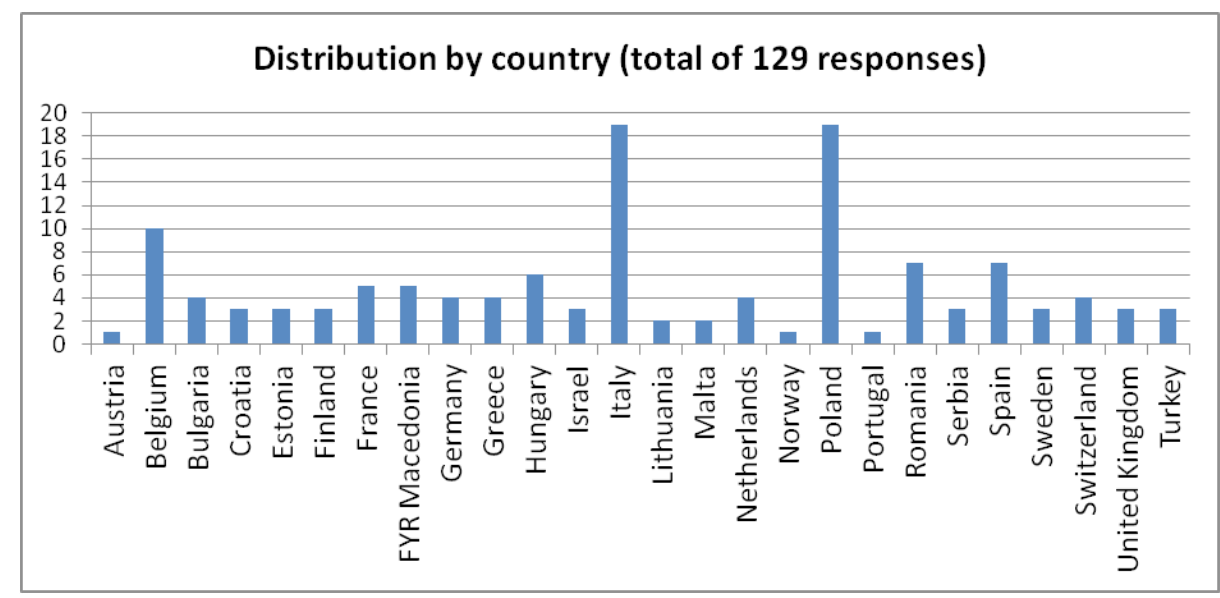

Figure 8. Number of questionnaires received per country participating to the survey on parents' views of play $(\mathrm{N}=129)$.

(c) BY-NC-ND $($ C) 2019 Mara Westling Allodi, Tamara Zappaterra, Marjatta Takala, Elina Viljamaa, Eira Suhonen, Alisa Alijoki This work is licensed under the Creative Commons Attribution-NonCommercial-NoDerivs 3.0 License. 


\subsection{Family relationships}

The majority of the responses were given by mothers $(n=112)$ while fathers gave 10 of the answers. A few answers were provided by other family members and others (1 sibling, 1 grandmother, 5 therapists/guardians).

\subsection{Characteristics of the children}

\subsubsection{Age of the children}

The parents reported the age of the child whose experience they were thinking about. The majority of the children were reported being in the age range 6-9 years (33\%), while the other age groups were rather evenly represented, with the younger children being represented in $21 \%$ of the answers, the adolescents aged 10-13 years being the $24 \%$ and the older adolescents $14-18$ the $22 \%$. Thus, the received questionnaires include opinions about experiences from a broad range of ages, with a slight major representation of primary-school-aged children, as described in Figure 9.

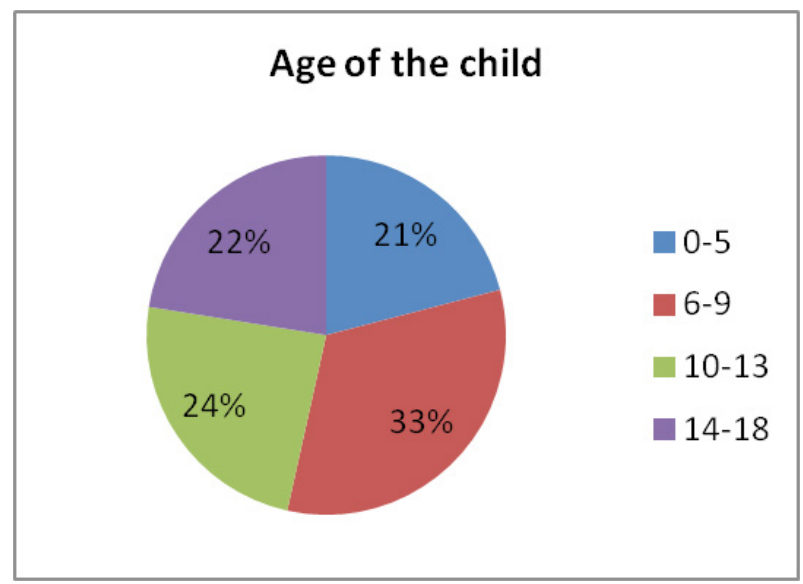

Figure 9. Reported age range distribution in\% of the disabled child among the respondents to the Parents' survey $(\mathrm{N}=129)$.

\subsubsection{Gender distribution}

The majority of the children were boys (63\%), the girls were $37 \%$. 


\subsubsection{Type of impairment/disability}

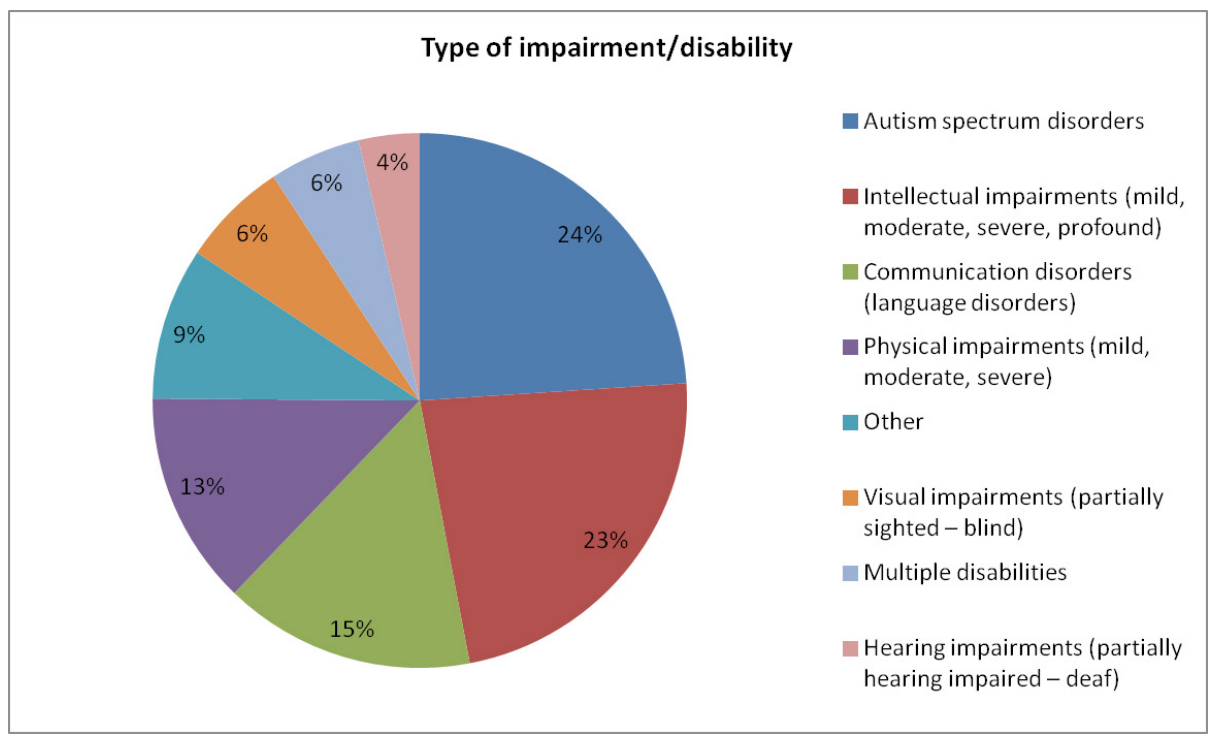

Figure 10. Reported type of impairment / disability among the respondents to the Parents' survey

As to the disability, the two major groups of children represented in the survey were those with ASD (Autism Spectrum Disorder) (24\%), and with Intellectual impairments (23\%). Taken together, these two types represented almost half of the respondents.

As reported in Figure 10, the next common types of impairments in the group of participants were Communication disorders (15\%) and Physical impairments (13\%). These two types together represented a little more than one fourth of the answers. The last quarter consisted of answers indicating the option Other (9\%) - where also intellectual impairments such as Down syndrome were cited, together with epilepsy, ADHD, dyspraxia -, then Visual impairments (6\%), Multiple disabilities (6\%), and Hearing impairments (4\%).

\subsection{Parents' words about play}

The parents answered also to the question: As a parent of a child with disabilities, please write down the first three ideas/words that come to your mind when you think about your child's play? This open-ended question is addressed to know what the most important issues are in play and disability, without suggesting specific perceptions to the parent, but leaving freedom to draw from imagination and personal experience. 
Parents were also asked to explain the meaning of the words chosen in the following question. If you have time to say why these words are important, then please do.... Almost all (121 respondents in 129) have reported on this additional section, to explain the choice of the 3 words they have mentioned in their answer to the previous question.

The answers to these questions are analysed in this section using content analysis.

The parents used overall 146 expressions about their children's play in their responses.

They could be categorised into six categories: Positive expressions, Negative expressions, Expressions about type of play or activities, Expressions about objects and items; Expressions about other people; Expressions about development.

Some expressions were quite clear, in relation to these categories (e.g., "happy" is interpreted as a positive expression), whereas a few might have more than a unique interpretation, such as "play alone"). Some expressions might possibly fit in more than one category (like the sentence "She loves company, talking, physical contact, and variety" which refers to positive expressions, expressions of actions and expressions about others). These expressions have not been considered in this report.

The emotions involved in play are strongly positive for the majority of the answers regarding emotional states (84 cases): in fact, the words that were chosen most often by the respondents in terms of feelings and emotions related to play, regarded fun, enjoyment, creativity, pleasure, enthusiasm, well-being. These concepts suggest that the play activity is conceived as very important and meaningful to the child.

However, parents wrote also 55 words or sentences which were categorized as negative expressions. Restrictions were seen in attention, in children's play and in peer relations, the frustration experienced on failure, the frustration when the play situation or the toys are not suitable for the child, and trouble as an outcome when the relationship with peers are not working well. Box 1 contains a list of the concepts that were used in the responses.

\footnotetext{
Positive emotions

Relax, calmness, curiosity, stimulating, enthusiasm, enthusiastic, bustling, cheerful, creative, fun, funny, free, surprise, pleasure, concentration, joy, happy, laughing, laughter, enjoyment, smile, smiling, well-being, imaginative, imagination, interest, distraction, love, parents love child, happiness and pleasure, shared moments of joy, like, vivid, tolerance, respect.
}

\section{Negative emotions}

Stubborn, father's anxiety, not exciting, boredom, mischief, frustration on failure, loneliness, monotonous poor, rejecting, lack of concentration, alone with assistant or parent, solitude, isolation.

Box 1. Concepts used in the responses

Expressions referring to type of play or activities were mentioned 41 times. We categorized these activities with reference to the Classification of the types of play 
adopted by the Action "LUDI. Play for children with disabilities" (Bulgarelli \& Bianquin, 2017). Within this framework, according to the parents' answers regarding their children's play, the most representative type of play reported is practice play. The children are capable of experiencing simple activities such as repeating gestures and phrases, listening to the music, often accompanying with body movement, or touching and handling stimulating sensorial materials and colourful toys with different textures. For instance, children with intellectual disabilities are more interested in the physical characteristics of play materials, than in their representational possibilities (Lender, Goodman \& Linn, 1998).

There are also many activities that involve the whole body, such as motor activities in playgrounds, exercises as walking, running, climbing.

The second type of play more represented is play with rules which includes videogames or technological tools, such as tablet, i-Pad, PlayStation. These devices have a wide range of applications in the case of children with motor impairments or with autism spectrum disorders and in general they strongly attract all children (Weiss, Bialik \& Kizony, 2003; Reid, 2004).

Symbolic play is the third type of play cited by parents. This includes simple symbolic play such as play with shapes and drawing, but also more sophisticated activities as for example playing with alphabet, with cards or role play and pretend play with toys and friends.

As to its cognitive dimension, construction play appears rarely in the parents' answers. The parents mentioned widespread materials of building play, such as Lego bricks. One father said that his child was not capable in doing construction play, but was able to disassembling materials, indicating the difficulties that may be experienced at the symbolic level of play: children with intellectual disabilities are delayed in the emergence of symbolic play (Bulgarelli \& Stancheva-Popkostadinova, 2017).

In the social dimension of play it is difficult to distinguish among the different types (solitary, parallel, associative or cooperative) from the parents' answers. Solitary play and onlooker play are mentioned. The parents said in some cases that their children play also with animals. Some mentioned play activities fall unambiguously under the cooperative play type, such as play with the ball freely or with rules (as in the case of football), or play with cards, or simply dealing with rules. The parents cited also generic activities from a social point of view such as talking, smiling, laughing, and having company.

Objects or items, like a ball, a tablet or toys, were mentioned 18 times. Play is thus also playing with something or handling objects. What is needed for playing are toys and other objects like tablets, scissors, and mobile phone. Some parents (16) connect play with different kind of activities, like dancing, running, singing, doing things on the PC. The fact that so many objects other than toys and so many activities other than playing with toys or role play are mentioned by the parents, shows that the concept 
of 'playing' is understood quite broadly, and in some answers has been interpreted as close to the concept of leisure time.

Other people, adults and children, or the lack of them, were associated with play 32 times. Issues such as assistance, inclusion and solitude were categorized here. Play needs the presence of peers, sisters, brothers, adults. Sometimes parents reported that children with disabilities do not have the opportunity to play with their peers, but instead there are adults who play with them. Parents express clearly that playing is doing something with others. Thus, the lack of play can be related to the lack of other people to interact with.

Many parents acknowledged the need that the adults lead or supervise the play of a child with disabilities. In addition, the adults should also socially act to increase the awareness of the need for play companions for children with disabilities. Some other aspects may be added. For instance, several parents mentioned that their children need often to change play activity and that they ask for a wide variety of play activities. This occurrence may be related to the lack of concentration that characterizes some types of disability or to the lack of awareness or capacity in peers to interact with the child with disabilities, or to the adults' lacking skills to support or lead the child's play.

Sometimes these situations are evaluated as a low level of culture of inclusion, as the following words show:

The non-disabled children are not prepared by adults to accept diversity. This leads inevitably to isolation of children with disabilities.

In some cases the play is compromised by the intrinsic difficulties due to a specific type of disability:

The deaf child needs to understand the play proposed and sharing his playing experience with peers rewards and makes him feel included.

In another case the child doesn't speak:

He is dependent on communication partners.

The last category of this content analysis, that connects play with development, includes 12 expressions, which were relating play for example to learning and educational goals. Some parents in fact connect play to development by talking about cognitive skills, strategy play, where play is seen as allowing the integration of discovering skills and learning. One father underlined the rhythm of play, and called it "action-reaction". He understood in this interactive dialogue an important developmental aspect that must be introduced, supported and sustained in some kinds of impairments - such as severe intellectual disabilities. In many cases play does not occur spontaneously, because of the child's lack of initiative and concentration. In 
these cases, it is fundamental that the child's play is supported by a competent adult. When involved in structured situation, defined by adults, children with intellectual disabilities show higher levels of pretend play (Nader, Grosbois \& Vieillevoye, 2012). The previous limitations in playing alone have been then overcome, but this result needed a purposeful pedagogic intervention:

He was taught how to play with focus on sharing, playing with others. His spontaneous play was schematic and alone.

The child needed one-to-one relationship, a condition cited by several parents:

Playing with too many children does not work: it is too chaotic and she'd get overstrung.

The play was defined by parents in various ways. Some parents pinpointed that play was an important occasion of communication between the caregiver and the child, and a main medium for the child to express his/her own feelings. One mother said:

Playing is the main way to communicate with him, and for him to express his feelings.

Others referred that through play the child acquires a self-marking behaviour, an element known in the studies of play and disability, which may have positive or negative aspects, depending on the specific situation. So a mother said:

She has an incredible need to make a mark. Being very smart she suffers more the lack of dexterity than the fact of not walking.

Another mother said:

He wants to gain more exclusive attention.

Summarizing, parents seem to think at play as a positive and valuable experience for the child, and to consider that their child's play wakes up positive feelings, like enjoyment, happiness and fun. But this attitude is not shared by all the parents involved in the survey. Many comments have been collected underlying the negative side of the child's play: why the play doesn't succeed, the lack of peers to play with, the fact that the only play activity that might be practiced is destroying objects, and that sometimes it reveals limited and difficult.

Finally, since play is generally seen as an activity that may fulfill important needs of the child, parents feel frustrated and unhappy when their children experience shortcomings and limitations to their play. 


\subsection{Places and companions for play}

With the second question the respondents were asked to explain where and with whom their child plays. A large number of parents (70) answered that the child plays at home, sometimes in specific rooms, and they added often the type of activities preferred, which could be pretend play, role play, play with various toys (cuddly toys, dolls, educational toys, computer games, tablet, board games, Lego bricks), play with sounds, music and dancing, colours, puzzles, motor play. Some examples:

She plays fantasy play at home, so she plays most by herself. Or with one friend at a time. My daughter feels that she easily ends up outside the play situation, when several friends play together. She plays gladly fantasy play with an adult too. She plays a lot of games, both with friends and with adults /parents.

Usually she plays alone at home. She interacts with her little sister and enjoys a lot.

One's own home is often one of several places in which the child plays, but sometimes the home environment is the only place where the child plays, due to health issues or other circumstances:

The girl is playing exclusively at home with adults, care must be taken to infection because she is immunosuppressed.

Many parents (51) answered that their child plays at an educational environment like school, preschool, kindergarten, nursery, and day-care centre. In these places the children play with peers and classmates.

At school he plays with some selected class mates.

My daughter plays alone at home and she does not rely on adults' attention. She does not always take part in the games with her peers at the kindergarten (mainstream). Unfortunately, she does not speak yet and that is why she has difficulties to play with other children, but she is never isolated. My daughter is part of the group and she feels good playing with her peers.

At school with a few peers.

Some parents (14) mentioned also other particular indoor environments for learning, play and leisure time attended by the child after school: play therapy, after-school therapy, leisure centre, rehabilitation centre, playroom, speech-language therapy group, institute, extracurricular activities, ludoteque, non-profit youth organisation:

She has friends in the speech and language therapy group.

In rehabilitation centre - with therapists and peers.

She goes to a non-profit youth organisation [...] weekly. 
Other environments for play are sport centres (6):

(...) on the street, sport centres, shopping centres; she is very sociable.

In the sport centre with adults, but she loves going to the gym and be with the older girls.

Others answered (13) that the child usually played indoor without further specification.

My daughter plays most indoor. She has never liked physical activities very much. Indoors he likes to play computer plays or play with Lego with his friends.

Some parents (7) told that child liked to play with and in the water, swim in the swimming pool or in the sea.

Water is the element that attracts him [...]

He likes playing with water.

She likes to swim in the swimming pool.

Many parents answered that the children played outdoor in various environments. Sometimes the answers reported outdoor without any additional specifications (16). Most of the time outdoor places are clearly close to home - such as in the following cases: yard, backyard, courtyard, and garden (18) - where the children can play for instance ball games, with the assistance of siblings or other family members.

With assistance they play games in the yard like tag and things like that.

Outdoor in garden with adults, very rarely with other children.

Outside in the garden with brother, parents, sometimes with the uncle and frequently with other kids (not from school).

Other environments where the child is going to play are playgrounds. They are mentioned by 29 parents, also to underline that they are not always suitable to the child.

He likes playgrounds, especially swings and slides. He enjoys any physical activity in which he can jump and move.

At playground with friends or neighbours.

He loves to ride his bicycle and to swing outdoor or on playground (there are not many playgrounds and the existing ones are in bad condition or inappropriate for children with disabilities). She went on the swings when she was a little child. She has some difficulties with the gross motor activities, so she has difficulties with the balance, and she does not dare to run around so much.

My son prefers to play outdoors: on a play set with a slide, going down and up on the stairs, riding wild with his wheelchair on the terrace.

Outdoors the game experience is almost non-existent. Playgrounds and sports centres are not equipped and not properly accommodate children with disabilities especially in cases of multiple disabilities. 
The children also use to play outdoors in parks (18), or in equipped parks alone or with siblings, peers and parents.

Outdoors she plays sometimes hide and seek, but not often.

My son loves to play outdoor but it is quite difficult to allow that without supervision. Traffic can be really dangerous.

[...] to the park with mates

[...] at the park with parents and rarely with peers.

Some parents (10) describe outdoor activities, games and objects that the child plays with, in the open air and in natural environments. The objects are for example sticks, branches, trampoline, bikes. The activities may be: climbing trees, swinging, jumping and playing sports, like football, soccer, basketball, go-kart etc.

Also plays on her own, in her own way. Spinning or bouncing, climbing, jumping around.

He likes to be outside. Climbing trees, contact with animals.

Outside he plays with different kinds of branches or sticks and balls, a swing was quite classy.

He likes to play football or floorball outdoors with his friends [...]. He also enjoys playing (football) with his father and brother.

Another more general type of outdoor environment is mentioned by few (3) parents with the term country, or countryside.

The same question asked also the parents information about the child's play companions.

Several children (60) were reported to play alone. For most of the time the solitary play is reported by parents together to play with partners, but for about one third of the children playing alone is the only type of play reported (18) by parents. The literature as well reports a higher proportion of solitary play in children with intellectual disabilities (Guralnik et al., 1996) with respect to the typically developing ones; deaf children spend more of their time as onlookers and in solitary play (Slade, 1994); blind children spend the majority of their play time playing alone (Shneekloth, 1989).

Playing alone may be something that the child wants to do, an activity that is part of a broad repertoire of various play activities in different contexts involving partners and companions in other situations. In some cases, the parent adds that playing alone is not a problem, but it is instead a preference, or a condition caused by disability.

Most of the time he plays alone at home or I play with him. He does not want to play with other children.

Friends are not that important, being alone is not the problem, it gives him a permission to go and immerse himself in the privacy of his own autistic world.

She does not always take part in the games with her peers at the kindergarten (mainstream).

[...] but a lot of time he plays alone - autistic features. 
In some cases, they use to play alone because they like it, in other cases because they are rejected by peers, or also because there is a lack of time and opportunities to play with others during the leisure time. The lack of children to play with is also mentioned (5).

[...] since he cannot/ he doesn't talk, other children reject or avoid him.

Usually he plays alone, by lack of others.

One parents referred derisive attitudes by other children, which is a sign of inadequacy in dealing with a child with disabilities and more generally of lack of inclusive culture:

He plays with children, who sometimes laugh at him, which induces frustration.

Sometimes (3) the parents tell that the child likes observing the other children's play:

He usually plays alone, he just watches other children, he does not really join them in their games.

She likes very much observing her older brother play with his peers.

In many cases different play situations are associated with specific persons: playing with peers at school, playing with brother /sister at home and at the playground for example are often associated. Both siblings and friends are often reported as playing with the child.

At home she plays with her siblings and at school with her friends.

At school, kindergarten and preschool the child is reported to play with peers (28): school friends, selected classmates, peers in "ordinary conditions", children with similar limitations, a few peers, a limited group of peers, older children, and small children.

At school he plays with some selected classmates.

My daughter is part of the group and she feels good playing with her peers.

Our daughter likes to play at school (school for 4-20 years with physical and cognitive disabilities) where children with similar limitations can play with her.

She plays at nursery with peers in ordinary conditions proposed by the educators.

[She] prefers to play with parents or older children, feels safer that way.

Other types of mentioned play partners are: friends (18), other children (5), children living in the neighbourhood (2).

[He plays] during free time with friends.

Sometimes he plays with friends, two friends, always the same ones.

At school, he shares games with friends. 
Siblings are often (41) mentioned as play partners and also as play supporters.

[He plays] possibly with the older brother and his friends (it is a big happiness when he can be with these friends).

[She plays at] home, with her brother and sister.

With her sister she plays less structured games and runs around being silly.

Besides brothers and sisters there are other young relatives that are mentioned (5) as play companions: cousins, niece, and nephew.

[He] plays also with the 12 year old cousin, alternate play, quarrels and pampering.

Outside [...] with nephew or sister: go-karting, biking, let herself be guided in fantasy play, she enjoys being led.

The parents (44) and other adult family members (4), i.e. uncle (1) are mentioned often as playmates. Both mothers and fathers are reported to be involved in playing.

[He plays] at home with us.

She usually plays home in her room, sometimes alone, sometimes with other family members.

[...] primarily with family members.

Home - with her mother; in the playgrounds - with her mother.

[...] on playing places with brother and father.

[Mother] I like to play a game with her, but this is difficult with (her) limited concentration. So mostly I sit next to her colouring as well.

Often at home with me and his brother, outdoors often with his dad and peers, he also practices basketball.

The play situation may involve the extended family, where the grandparents may have an important role. Grandparents, grandmother, grandfather (10) are mentioned.

Adult family members: mother, father, grandma alone both at home and in the garden.

[She plays] at playgrounds with her parents and grandparents.

[We play] everywhere we can. School, parks, playgrounds, home, in the yard, with peers at school, with us at home or her grandparents, and also with her caregiver.

Playing with parents or other family members could be one of many developmentally appropriate play activities, but in several (26) cases the child was reported as playing with family members only.

Other adult companions that were reported (9) to play with the child were defined as: teachers, instructors, therapist, trained professionals, volunteers, supervisors, reference adult. These adults are involved in working at the preschool, school, kindergarten, playground, speech-and language therapy centre, play therapy and they were not child's relatives. 
[Play] in rehabilitation centre - with therapists and peers.

[Play] with children and therapists in kindergarten.

Learning and play happen with the instructor and the teacher are together or (when) the instructor assists in the group.

[Play] indoor alone or with assistant - outdoor alone or with assistant.

In the playroom with trained professionals, volunteers and friends.

There is always a reference adult who helps him with peers both in indoor and outdoor environments.

Besides specified professionals, also generic adult persons were reported (16) to be involved and supportive in play activities with the child.

And he wants to say hello to all the adults too.

For cycling he needs adults help, he can't go cycling alone. Cycling with a tandem is something he enjoys a lot. He's happy to work with adults [...].

The children were also reported to play with their pets, and enjoying having contact with animals: in particular dog, horse, cat, chicken were specifically mentioned (5).

[He] plays with dog and cat. [...] chatting with the chicken, plays a game of fetch with the dog with ball or stick [...]

[...] outside playing with the ball, the dog [...]

$[\mathrm{He}]$ likes to be outside. Climbing trees, contact with animals.

\subsection{The child's needs about play according to the parents}

The questionnaire asked the parent (third question) to describe with their own words what the child would need in order to play for more time, or more easily, or more playfully. The free answers of the parents about what their child's needs were coded below within the same categories that were defined to discuss the Associations' survey. Besides these categories, some concepts emerging from the parents' formulations were added.

The need that was reported most frequently (43) was the company of friends, peers, play mates, partners for play. In Box 2 a collection of expressions taken from various obtained answers is presented.

\section{Peers}

More peers mostly; Peers without disability integrated in residential areas; Peers are really important for her but most of the time she cannot find friends; Friends who like to play with him; peers to model (imitate); Playmate; Interactions; Playmates who give pleasure to play, encouraging imitation, interaction; Friends who could adapt their play to him and play structured games; More peers; Needs playmates, even in the family; Playmates of the same age; Share play with peers; Patient playmates respecting time and difficulties; Companions sensitive to inclusion; Some company; Welcome by peers; Friend, brother that support him; Most of all share play with peers. 
According to the parents' views, peers are needed for various reasons: for instance, because they could be models for the child to imitate in play. The interaction with peers is seen as very cherished, since their fellowship can give pleasure to the child, and encourage interaction. The peers should be accepting and able to understand and adapt their play to the child's needs and behaviours, they should like to play with the child, and be sensitive to inclusive issues. They should also be patient and respect the child's difficulties and his/her need for more time to play. The experience of sharing play with other children is considered very important, as if playing only with adults was not good and satisfying enough for the child.

Some answers suggest that playing with other kids is not easy to realise for some children with disabilities. As a consequence, social play with peers is a key experience which some children with disabilities are deprived of. According to the literature in the field, children with intellectual disabilities have difficulty starting to play (Luttropp \& Granlund, 2010); children with hearing impairments engage in less associative or cooperative play than the other children (Antia \& Dittillio, 1998); in children with motor impairments the different levels of cognitive and verbal competences affect the quality of playing with peers (Stoneman et al., 1989; McCluskey, 2002).

He needs no special toys. He needs peers.

[...] above all he would need to share the play with peers. It is playing that develops skills, especially playing with others.

I think for a deaf child to age my son is important to share the plays with peers, understand the play proposed.

Probably a playmate would be good for him, with whom he could play [...]

Many parents (40) think that their child would need toys, in order to play more easily, or for more time. Box 3 contains various expressions taken from the parents' answers.

\footnotetext{
Toys

Adapted toys; Specialized toys; Toys that turn or pop-up with a cause and effect; Toys producing sounds; Easier games, if it is too difficult he stops playing; Toys with noise and music, but soft, ball with handles; Cards with bigger letters; Materials adapted to needs; Special swing; Adapted toys that allow to play independently; Creative toys; Toys to activate pressing a button: soap bubble machine; Soap bubbles; Affordable toys to guarantee variation, diversity; Interesting toys; Toys from favourite series; Adapted to the ability and age-appropriate looking; Games, puzzles, jigsaws; Letters in all colours and shapes; Favourite toys; Toys for playing in the sand; New toys; Engaging toys taking account of physical and cognitive peculiarities.
}

Box 3. Quotes related to the need of Toys

The toys that the child would need should be adapted and specialized. They should take account of child's physical and cognitive peculiarity. They should be adapted to their ability on a difficulty level, but should be also age-appropriate-looking, that is, not looking as toys for young children, if the child is a teenager. 
More toys with sounds and music would be needed, and they should be soft so that the children would not hurt themselves. The adaptation should be done so that the child can perform an activity more easily and independently. The toys should be designed with devices (i.e. buttons) so that the child is able to play autonomously and to interact with the environments; in addition, they should be made of various materials.

The toys should be interesting, engaging, motivating and relating to the child's interests in narratives, stories and themes. They should allow the child to perform actions, make sounds, to make an effect happening with his /her actions.

There is a need of not too expensive toys, so that it is possible to have many toys, which would guarantee more variation and novelty for the child.

The adaptation of the toys would allow the child to play autonomously:

She would need toys to play independently, because the existing ones are either too large or too hard. For example, if she wants to play with the kitchen, the oven door is too rigid and she fails to open.

She is eager to play with all toys and games she comes across while shopping but they are not adapted to her needs.

For some child however, there is no need of toys adaptations, according to the parents.

He doesn't need special toys - ordinary toys are enough.

Adapted toys are often boring. She needs toys which she can activate with pressing a button. The soap bubble machine is wonderful. There should also be a machine to feed the ducks when going to the park, just by pressing with one hand.

For many parents (20) there is also a need of technological toys, of which the literature has amply demonstrated its effective use in supporting development and playfulness especially in children with motor disabilities and with autism spectrum disorders (Besio, Bulgarelli, Stancheva-Popkostadinova, 2017). Box 4 below presents some examples.

\section{High-tech toys}

Smartphone, iPad, touch screen are easy to use; Specialized toys and technology; Sounds of computer games, colourful graphics; Adapted games; Adapted technologies; Toys that makes music; Mini robots; A tablet not so sensitive; Computer games; Better designed video games; Visual remote control; Tablet with Internet; Remote-control toys; She needs to be able to access her tablet games.

Box 4. Quotes related to the need of High-tech Toys

Devices such as computer, tablets, and smartphones are needed, and in all cases the respondent suggests that they should be adapted and accessible, designed in ways 
that allow the participation of everyone. These toys should also be motivating and interesting with the use of music, colours etc. Technologies as Internet and remote control are also needed by some children.

Definitely she would need technological tools appropriate to her condition that is aggravated to frequent dystonia which is affected that do not allow to have a constant control using writing, play and communicating tools.

He needs toys that help develop his creativity. New technologies [he] also likes, touch screens because they are easy to use.

Adapted toys to awaken her sensorial capacities, musical toys and technological devices as mini robots which provide sound and movement at the same time which imitate a real person because each parent has not always the time, the energy and the patience to initiate the play time. My child would also need a tablet not too sensitive and able to receive knocks with applications which do not require precise gestures on the screen.

One parent expresses the opinion that high tech toys are related to learning at school, not to play situations, and that playing alone is an important activity.

I do not approve the technological tools that instead I think are important at school in teaching. It is important to have playmates, but also engage in playing activities alone: my son, for example, builds with Lego and I see those moments of concentration relax him.

According to the respondents, many children (24) need to improve skills that are involved in play. The skills may be related to motor ability, language, cognitive ability (attention, concentration), social skills, emotional self-regulation and also motivation to play. In Box 5 some examples are reported.

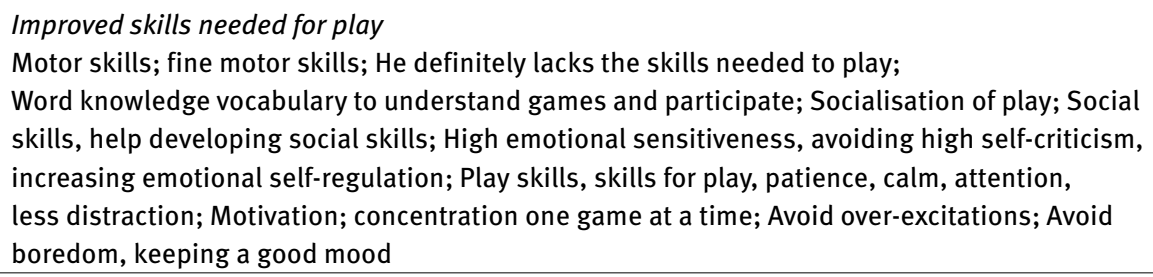

Box 5. Quotes related to the need of Improved Skills

The improvement of social skills is viewed by these parents as a very important goal.

My child needs improvements of play skills and socialisation of his play.

His social skills are not as good as others in this age and he does not 'make a number' of himself but more likes to get out of the situations where are a lot of people together. He has challenges to get new friendships. My child is very sensitive and can cry if he feels that someone insults him. He is very critical of how he himself behaves. 
Some children have reported to have a lack of concentration or other intrinsic limitations, so these conditions limit the play and a good feeling in playing, such as in these reports:

She needs more concentration.

Other children are reported to experience a condition of boredom, indicating that the environment is not capable to offer suitable stimuli. Some mothers wrote:

The disabled child is bored.

Fantasy is very important for her.

A large number of various outdoor environments were needed by the respondents (24) and a few other indoor and specialized environments. Box 6 contains some excerpts from the answers.

\section{Outdoor environments}

Structured space; Adapted playground with tools that give sounds; More fun at physical activities would have improved her motor skills; Specialized playgrounds; More playgrounds; Special and not crowded spaces; Accessible locations spaces; Affordable adapted bicycles; Playgrounds without so many dangers; Inclusive accessible environments without barriers: specifically designed for disabled children to promote the encounters suitable and equipped spaces; Inclusive playgrounds; Accessible playgrounds equipment; Off-road walker-rollators

Indoor environments

Extracurricular activities in specialized centres focused on integration; Large spaces, leisure sites.

Box 6. Quotes related to the need of Outdoor and Indoor Environments

Playgrounds should be inclusive and adapted to children with disabilities. If adaptations and specific designed scenarios were available, the child could be more active in her play and could do more social and motor experiences.

When she was younger it should have been valuable to have a disability adapted playground in the vicinity, so I believe it would have been more fun to her to be physically active, for example to follow a path, when she was learning to go/walk. Or if there have been (in the play spaces) outdoor more tools that give sounds to play with, adapted to her age.

Surely they lack the indoors and outdoors environments designed specifically for disabled children where promote the play and the encounter with the other.

The outdoor environment should be accessible, inclusive and safe.

My son would need [...] proper outdoor space without too many dangers.

(...) more accessible spaces [...] 
He would need to be in inclusive environments for every type of disability, where the child can achieve certain goals and [feel] unhindered.

[...] we need suitable and equipped spaces.

Someone (3) stresses the need to play within safe environments in the case of children with disabilities.

Security is the first thing that must be offered to children with intellectual deficits, which often are not aware of dangerous situations for their safety. The communication must be guided from a reference adult in cases of lack of verbal language.

Another important need that emerges among the needs reported (20) by the parents is the need of more time. Box 7 includes some examples.

Time

Needs more time to understand the play plot; Time to respond; Time for discovery, mess around, lot of time; More playtime during the day; She needs free time, the leisure time is a little and she is tired.

Box 7. Quotes related to the need of Time for play

The child may be involved in many activities and therapies that may limit the time left for leisure time and play.

She needs free time, after school and therapies the leisure time is a little and she is tired.

The child may need more time in the play situation in order to understand and take part to what happens around him/her. The other children would also need to be patient and wait a bit longer for the disabled child to respond to their questions and invitations. There should be more time also for unstructured play.

He needs to mess around to discover materials. For learning about the materials, toys he needs time, a lot of time. Activities, time for free discovery and explorations.

Some parents (15) reported that their children needed a knowledgeable adult in order to play more easily and for more time. The role of a competent adult in play is mainly declined in three functions, sometimes with some overlaps in meaning: the adult as a facilitator, the adult as a mediator, and the adult as a supervisor (Zappaterra, 2018).

The adult could support the play process and promote participation, help to solve conflicts, help to understand rules. See the box below for examples from the parents' answers. The support of the adult is something that may be always needed.

She always needs support from an adult. 
Some examples are reported in Box 8 below.

\section{Competent adults}

Songs and movements of the hands are interesting and are imitated; Adult to supervise the play; Parents' involvement; People that entertain him, move, swing, hold; Adult supporter, trainers; Support in play so that she stays; Adult that explains new things and introduces people; Someone that directs his attention to play, makes play easier, gives lot of encouragement; Adults with professional training in ACC; A coach who could train him to play in another way than repetitively; A person who could provide him with ideas of adapted games and play; A person who could mediate the interaction between him and others: parents should and must learn how to play better with our children, learn mediation of play; Help from other parents and blog; Adults or companions with whom to interact, get involved and accepted with the time and manner of what their need; Competent adult people with an open mind that would help the peers of the autistic child to play with him; Specialized staff to facilitate the approach to the play and relationships; Competent adult who involve him and help others understand him; Need specialized personnel able to make appropriate proposals; Parents that have fun playing, and share the fun with the child; Assistance while playing concerning the rules, dealing with others.

Box 8. Quotes related to the need of Competent Adults

The adult's role as a play facilitator is widely recognized in the research. The role of the adult in this case is to offer the child educational interactions and pedagogical framing linking play with positive learning outcomes and taking a proactive role in creating play scenarios and supporting their realization (Sylva et al., 2007; Wood, 2009; Besio, 2017).

The adult could have the role of a mediator between the child and his/her peers, by involving the child, supporting the interaction with the play environment and the relations with the others and also by helping the other children to understand the child. According to Haight (1998), pretend play in interaction with the adult has an important role in the acquisition of social skills. Garvey (1982) emphasizes the importance of the adult in the home environment to prompt and elicit social skills through pretend play.

She is afraid of unusual things so I think she needs someone to explain new things to her, such as new objects or people.

Furthermore, the role of the adult in the play of children with disabilities assumes the characteristics of a specific expertise, a skill to positively cope with intrinsic difficulties. In this sense an adult can be qualified as a play supervisor when he/she is able to establish, support and evaluate play and play scenarios oriented to specific purposes. The adult would also provide ideas of adapted play and games. The adult should keep explaining, help the child in communication, for example to understand the play rules and to deal with negotiations with the others, with situations of winning and losing games, etc. 
He needs a competent adult who involves him and help others to understand him. If my son meets cosy atmosphere can participate in almost everything, it is very sensitive and sympathetic. What matters is the contact.

The adult should have competences and skills in specific areas, such as alternative communication, activity adaptations, educational planning (e.g., to suggest activities that offers the optimal level of difficulty, and that would expand the child's play experience). The parents may need to learn how to play better with their children.

It also lacks specialized staff to facilitate the approach to the play and relationships.

A parent has given a very comprehensive response saying that the child needs a playmate able to adapt to him/her and to his/her characteristics, he/she needs someone who can support the child's progress towards more and more complex levels of play and who can bridge the relationships with the other children.

Friends who could adapt their play to him and play structured games, a coach who could train him to play in another way than repetitively, a person who could provide him with ideas of adapted games and play, a person who could mediate the interaction between him and others.

The parents must also discover how to have fun playing, instead of prioritizing training, and they should learn to share fun with their child.

The kids really enjoy when they learn something new and gross with the excitement of fun. What 'pass' to the child is the joy of parents who are in touch with the "inner child" of themselves, but the parent of a blind child does not select a fun play, but a therapeutic play. The aim would be to see the child have fun playing and have fun yourself playing with your son.

Other parents (8) underlined instead the need for changes in societal attitudes and behaviours in order to make play easier to a child with disabilities. Some examples of this occurrence are reported in Box 9 below.

\section{Societal attitudes and behaviours}

The children tend to end up a bit outside; More togetherness with seeing peers at school; Integration into society; Social inclusion in school;

Acceptance from peers; Kind look of others in public places

Box 9. Quotes related to the need of inclusive attitudes and behaviors

The attitudes in schools may make the child with disabilities end up outside the group of peers, if the school staff do not work for intentionally promoting and introducing inclusive practices. These practices would not happen without intentional pedagogical interventions. Attending a mainstream educational environment is not sufficient to guarantee full participation and inclusion into the school community. The presence 
of the child with disabilities within the educational setting may be accepted, but there might be a lack of attention for his/her specific needs.

When it comes to other children, our children tend often to end up a bit off, outside of the group, regrettably. I think that it is this way for most of the children. My daughter has a couple of seeing friends, that she meets once or two in a week, after school. She is not bullied at school, but she is neither entirely together, if you know what I mean. In school she is often with her adult resource person.

In another response, the parent indicates that there may be a - more or less openly negative attitude in the social context, which may be transmitted through disapproving, curious, or even hostile looks, for instance when the child is playing outdoor the simple play activity he/she likes. This situation could be regrettable for the parents, and could contribute to make them feeling restraints in joining these public social situations with their child.

My child finds fun playing, long [time], with simple and repetitive plays. It would need the kind look of others, children and adults to play in public places.

Some parents talked about the importance of a setting with a good relationship, good feeling, and a positive disposition as a turning point to develop a favourable situation of play for the child with disabilities.

If my son meets cosy atmosphere he can participate in almost everything, he is very sensitive and sympathetic.

Acceptation from peers and good mood.

Another suggestion related to attitudes among educators and parents is to make efforts in suggesting and thinking out activities that are more fun, which would also increase the child's motivation to play.

Making activities more fun, thus experiencing positive feelings in activities.

[...] so I believe it would have been more fun to her to be physically active.

The last theme reported (8) concerns policy measures and resources at the community level. Examples are referred to in box 10 below.

Policy and resources

Organized sport for disabled children; integration into society; accessibility; better links to the community; inclusive playgrounds; clear visualisations and step-by step sheets; museums; barnyard.

Box 10. Quotes related to the need of Policy and resources for playing 
There should be more opportunities to play organized sport activities for children with disabilities. The regular play environments should be made accessible to all children. It should be possible for children with motor impairments for example to access various environments, with other walking resources. Methods that make it easier for children to participate should be adopted, i.e. through visualisations.

I think there should be more sport activities organized by the cities / municipalities. I think this would be important.

Assistance while playing concerning the rules, dealing with others, dealing with winning and losing. Clear visualisations and step-by-step sheets.

Handicapped accessible playground equipment (stairs to slide, not only a jungle gym with ropes or similar); off-road walker-rollators.

More accessible spaces, better links with the local community.

However, some parents express a desire for self-determination of their own children about the play and the desire that logistical difficulties are overcome.

Our daughter is a very active child and it is evident that she needs a lot of active play. Moving around gives her pleasure and it makes her happy. Free style play, with no rules, except for not getting hurt stimulates her and then relaxes her.

Besides playgrounds, there could be other public places that the child could visit for playing and having fun, according to the child's interests, as history museums and barnyards:

He would love to go on a barnyard and be together with the animals. But this is not possible, we don`t know someone.

\subsection{Children's experiences of play}

The final part of the questionnaire was designed to collect the perceptions of play of children themselves, giving them the opportunity to make their voices heard.

Examples and ideas about the needs of children with disabilities about play have been gathered through the mediation of the parents. In fact, the last question of the questionnaire asked the parent to interview - If possible - their children, asking them to tell about their play, and collecting their experiences and preferences. In this section the contents of the answers are reported according to some prevailing themes that were identified through the answers provided.

Before presenting the results of the analysis it is necessary to point out that in some cases the views of the child could not be collected, due to extensive communication difficulties; 27 parents answered that they could not report the child's answer because 
the child for example could not speak, or because the child would not understand it. Furthermore, 12 parents did not answer to this question.

My child does not speak.

She cannot say useful answers due to her conditions.

Some parents (16) reported that their child could meet difficulties in communicating his or her experiences and will. However sometimes the parents knew what the child liked and they reported these activities, preferences and needs, on his/her behalf.

My child is not able to answer but I would say that she likes dolls, musical toys and to follow our dog and play hide and seek with it. She prefers to play with her younger brother.

My daughter is not verbal, but I know the answers - she loves the computers, music and animals. She likes to watch films, videos, listen to sounds and melodies, drawing. My daughter loves walking in the park and playing with the dogs, riding her favourite horse Universe.

Sometimes the parent reported that the child found it difficult to express an evaluation of play.

It is hard for him to define what he likes and why.

The respondents' answers display a range of circumstances, from those in which it was not possible to provide the child's views concerning play, to situations in which the parent interpreted the child's preferences and provided the child's views by proxy, again to situations in which a particular type of verbal explanation or evaluation was difficult to perform for the child, and to situation in which the child's own utterances are reported. In the following analysis of the answers both the parents' proxy and the children's reports (83) are reported. To distinguish these last, they have been put into Italic.

The themes identified are Activities and Events; Partners in play; Emotional states; Agency in play; Evaluations; Places.

Activities and Events. The children - or the respondents that report on the child behalf -describe which play activities they like to do and engage with.

There are varied play activities that give her pleasure: games, physical exercise (sliders, swings, ball, etc.), dolls, little houses, puzzles, etc.

My daughter is not verbal, but I know the answers. She loves the computers, music and animals. She likes to watch films, videos, listen to sounds and melodies, drawing. My daughter loves walking in the park and playing with the dogs, riding her favourite horse Universe.

I prefer playing in my room with dragons and other animals, creating stories [...]

Play activities vary a lot: many types of toys are mentioned, both traditional - as dolls and Lego bricks, while the practice play is reported 18 times - and digital toys and games provided by new technologies (16 times). 
She likes games with new technologies (tablet, console) and play with dollhouse, with dolls [...] I do not play very much, I play X-box, football, floorball and I swim [...]

A type of play that is mostly cited among the other ones is symbolic play (8).

She likes to play veterinary game. She likes to set up the table for dinner.

He likes moving toys like cars and trucks.

I like to create different fantasy worlds, I play about what I hear on the TV or in the real life. For example I like to play Harry-Potter inspired plays.

Some children (8) like to listen to sounds and melodies and someone has a clear preference for these games.

He prefers music games.

I listen much to music and sometimes I make my own songs.

Many children (13) are also fond of many physical activities outdoor, both gross motor activities like sliding, swimming, horse riding, bike riding and games with balls (like football, or basketball).

She likes hide and seek, playing tag. Blowing soap bubbles and playing with water and sand is also popular.

He likes playing outside and being sporty.

Another theme is Partners in play. Play activities may be performed on one's own (8), but a great extent of activities imply being and interacting with others and many children seem to like staying with their peers, friends (22) and siblings (9):

She enjoys playing [...] in park with other girls.

Most I like to be with my friends.

The best is to play with my big brother and his friends.

He likes to play with other children.

He feels very important when he is in the play with other children.

I prefer playing in my room [...] alone or with one friend.

She prefers to play with her younger brother.

I like to play with my friends, mostly with my best friend Liv.

In some cases, watching others when they play is reported as a play activity (2).

Besides she likes watching others playing, e.g. taking the slide.

She says that she likes playing alone and watching others playing.

It seems that the child's pets (3) should also be considered play companions.

My child is not able to answer but I would say that she likes [...] to follow our dog and play hide and seek with it. 
Another theme is Emotional States. Playing is often associated in the reports with strong often positive emotions and excitement: play is reported many times (34) to be associated with great happiness, pleasure, joy.

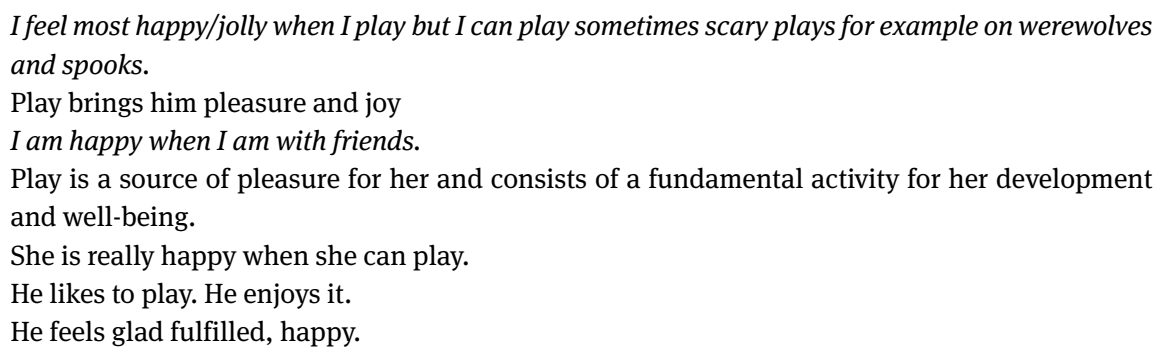

The answers indicate that play is immensely appreciated and longed for by the child as a source of joy and happiness, a fact that the parents seem often well aware of. These positive emotions and the pleasure that the child feels when playing may show play as an intrinsically motivated activity and its importance as an engine for development.

Sometimes the answers mention even negative emotional states, as sadness. This is related to what happens when the child cannot participate in play or cannot keep up with others in play situations, or when the play situation is not adapted to the child's needs:

When she plays with others she doesn't like it that often as it's going too fast, she can't keep up with them. This makes her sad. It's also often too busy/too much.

But the overall attitude of feeling in playing for the majority of children is very positive. The play is associated to fun, peace, cheerfulness, happiness, freedom, relaxing. Many children (13) said that play is very important for them and they would like to have more time to dedicate to this activity. One child used a suggestive metaphor, saying that play empties his head. It is extraordinary to see these testimonies of different children using the same words:

When I play I feel great, I am very good at football. And I laugh a lot.

I choose my toys watching the game that I like more, when I play I feel good, peaceful, serene, concerned, playing is very important.

I feel good while playing. Play is important. I would like to spend more time playing.

Being with friends and have fun.

I feel good when playing. Play is important for me.

When I play I feel free. For me it is very important to play. I would play better if I had more models, models, so my car racing is more exciting and fun.

When I play I feel good and I am happy. I wish I have more time to play and a larger garden to go on a segway.

To play is not having to feel pressure. Relaxing. To have and to make fun. It is important because it empties my head. If I have to stop playing, because of homework or having to study, I get very upset. 
Another kind of feeling emerges when the type of play is not suitable or satisfying for a child, depending on the age or the capacity to understand the rules. A child said:

I like playing. But it depends on rules. I do not like childish games.

Sometimes the adults insist using the same tools or materials, disregarding the age of child. Other times the play need a presence of an adult to vehiculate good feeling and a sense of security. A mother said:

Playing alone is relaxing for her. Sometimes she prefers to play with other children. Playing with many children should not last too long because that would be too oppressive and she would need an adult to protect her.

In other cases, the type of impairment does not allow to understand the feeling of the child towards the play. A mother said sadly:

I would like to know as a mother what he likes about the play, and what he feels when he is playing.

In other cases, these feelings can be perceived from a specific behaviour of the child, such as in this testimony:

We know that he likes the sound games, toy trains, the wheelchair swings. You can understand why he laughs happy.

Another theme identified is Agency in play: the answers here grouped (10) contain statements on the child's will and choices, from which the child emerges as a subject, as an autonomous protagonist. The child - or the parent on his/her behalf - decides, explains needs, preferences, interactions, negotiations and expresses a feeling of power and the competence of problem solving.

I choose my toys according to my interests and capacity to use them by myself, independently.

I like to be leader of my toys. It is I who command.

When I get new Play Mobil toys, I always like the figures most of all. I give them names, so that they will become the characters.

Usually she chooses her own toys, but sometimes I also make suggestions that she accepts or proposes an alternative.

She prefers choices and she always wants to choose the play.

He wants to play with the same objects over and over. He seeks sameness in his play.

In one answer the child's agency displays itself in the child's request to be supported by an adult, who gives the right prompts during particular activities. This circumstance may appear paradoxical under the point of view of the child's agency, but on the contrary it shows the child's competence in expressing his awareness on what he is 
able to do by himself and what - outdoor activities in this case - needs the adult's support to be accomplished.

From an educational perspective, on the other side, it would be an issue in the future, for the adults, to decrease eventually and if possible the provided support, so that child may enjoy higher levels of autonomy:

He wants to know what to do all the time, when he is outside. He "wants"/needs an adult to tell him what to do/ to instruct him.

A further theme has been called Evaluations: the child - or the parent - expresses likes and dislikes and personal opinions about play. In many answers (15) the appreciation of friends as well as the wish to have more playmates is expressed.

Nice [with] more peers.

I would like buddies.

He does not like to play on his own he likes to play with peers and children in the neighbourhood. The game is very important for her. Perhaps she would need more (same) age peers.

A certain number of evaluating statements (13) relate to time for play and its duration, signalling the child's desire to play for a long extent of time, and more often, or regularly, not just now and then. Some phrases may indicate that the time for play may be experienced by the child as too limited sometimes or not granted.

He would like to play every day, if it is possible several hours.

She likes playing all day long.

I would like to do it every day.

In other answers (6) also other limitations and shortcomings in play are described. Some activities may have become difficult for the child and the play environment may be not adapted. Particular games may be too complicated for the child.

But she likes to slide, to swing herself. However, this is not possible anymore: too heavy, too fragile, too disabled.

She loves playing so much but she needs safe outdoor environments to play.

A few games are too difficult because they have too many rules. I would prefer board games with less rules in order to easily play with them.

Another experience is expressing a need for more safety in the educational environment:

She would also like if the boys would not slap her in the kindergarten.

The evaluation theme indicates that play is an important activity where some shortage or complication may emerge sometimes according to the children. It could be a lack 
of time to play and a lack of occasions to play properly and effectively with friends that are not living close. Some children want more playmates and buddies to play with. The conflicts that may arise with other children can also hinder play. Lack of adaptations in the play environment may also create unnecessary limitations to the child's play experience. But some children seem aware of these circumstances and try to adopt strategies and self- advocacy in order to deal with these issues.

The last theme that has been singled out is Places: play takes place in various locations: at home (9), in the child's room and in other environments. Children play in educational sites like preschools, kindergartens, schools (3) and outdoors in natural environments (8) or in playgrounds (2).

He wants to play in playing spaces.

He wants to play outside, to ride the bicycle.

In park with peers.

At home with sister.

I play most at home in my room [...] In the summer I play more outdoor. 


\section{and Parents' Surveys}

The 75 Associations for persons with disabilities that were selected by the national coordinators in 24 countries and that answered to the survey represented a wide range of disabilities and precisely: intellectual impairments (19\%), autism spectrum disorders (17\%), communication/language disorders (15\%), multiple disabilities (14\%), physical impairments (12\%), visual impairments (9\%), hearing impairments (8\%), and other (6\%). The Associations have been chosen among the most meaningful ones within each country, however the research sample can not be considered statistically significant because it has been created thanks to the professional network of national coordinators of the research and it is not representative of the totality of existing Associations of persons with disabilities. Nevertheless, a third of the types of disability in the sample of the survey concerning the Associations (36\%) and almost the half of the sample concerning the parents' survey (47\%) represent the autism spectrum disorders and the intellectual disabilities. As a total, the Associations represented at least 87.000 members. 31\% answered that children with disabilities in their organisation do not have the same opportunity to play, and $42 \%$ answered that they can play a little. Only 15\% answered that they can play a lot. $64 \%$ thought that the parents were not happy with their children's play. These results may be considered as higly important, in terms of barriers and facilitators, a construct adopted by the International Classification of Functioning, Disability and Health and embraced within the COST Action "LUDI. Play for Children with Disabilities" as a theoretical and methodological model to achieve scientific, social and technological purposes (WHO, 2001; COST, 2013).

According to the comments of the Association's representatives, the facilitators of play for children with disabilities may be: adapted toys, accessible toys to loan, association resources that have appropriate spaces, facilities and trained staff, parents' creativity, purposeful planning. That is, on the one hand, the Associations require accessible and equipped environments and call for improvements of the tools of play and their greater availability and affordability. On the other hand, they emphasize the importance of a more general educational training about play of both parents and professionals. In fact, the barriers reported by the Associations are related to the lack of the same items listed among the facilitators: physical barriers, lack of accessibility and usability of the physical setting that may limit play, lack of accessible and not specifically adapted toys and games, accessible outdoor play environment - both natural and structured. Also the characteristics of the child due to his/her impairments are referred to as barriers. For this reason it would be important a widespread awareness among professionals about the developmental

(c) BY-NC-ND $(2019$ Mara Westling Allodi, Tamara Zappaterra and Donatella Fantozzi

This work is licensed under the Creative Commons Attribution-NonCommercial-NoDerivs 3.0 License. 
characteristics of children with the different kinds of impairments, in relation to the play needs and types (Besio, Bulgarelli \& Stancheva-Popkostadinova, 2017).

Most of the comments of Association's representatives about happiness/ satisfaction with their children's play concerned social barriers, attitudes and behaviors. They may encompass exclusion by peers, attitudes held by teachers, professionals, parents and relatives. Four themes were identified to groups the obtained answers: discrimination, peer relations, parents' skills and human resources.

In several comments the scarce possibilities of having peer relations and the lack of friends is considered the cause of children's limited play opportunities. This assertion is confirmed by the answers to the central question of the questionnaire, related to the play needs: in fact, playmates, peers, friends are the largest reported need in both the questionnaires.

Play for play's sake was considered important for children with disabilities as it is for other children (72\%). This question represents the basic assumption on which the whole COST Action “LUDI” engages, even if play for play's sake is not yet an established theoretical construct nor a cultural fact. The largest group of representatives from Associations considered play for play's sake essential for a wide range of reasons which can be related to socio-anthropological, psychological and developmental theories. Anyway, only one comment reported a concern in that some parents may not recognize the importance of play and prioritize the training of motor and communicative skills instead of play. In the perception of Associations, play is related to learning in terms of specific skills (social, relational, emotional skills, basic experiences for daily life), and it is considered as an opportunity to develop abilities (cooperation, creativity, communication, logical reasoning); it is also viewed as a common language with peers, a medium for communication, a tool for preventing difficulties in relation to a certain type of disability. The lack of play is viewed as a symptom of disability itself. Associations reported also that play makes the child feel positive emotions, a statement strongly tuned with the Action "LUDI" assumptions (COST, 2013).

Furthermore, various comments involved the role of the adults in relation to children's play. The role of a knowledgeable adult in children's play has been specifically investigated by the survey through a multiple choice question contained in the questionnaire of the Associations and an open-ended question in parents' questionnaire.

According to the Association's representatives an important improvement to the play of children with disabilities may be obtained thanks to availability of peers, changes in societal attitudes and behaviours and supportive adults. Other measures are mentioned - less numerous than the previous ones - and are related to: more time, adapted or special environments, policy measures and financial resources, outdoors and indoor enviroments, toys, improved skill of children, high tech tools. 
The same contents about the needs of children to play have been found through the answers to the parents' questionnaire, but their respective importance was reported in a slightly different order.

In fact, the child's needs according to the parents were most frequently: to have friends and peers to play with, adapted and specialized toys, even technological toys, improved skills necessary to play, accessible outdoor environments; only on a second place they remark the need for knowledgeable adult in order to play more easily and for more time, then societal attitudes and behaviours, policy measures and resources. Thus, one of the most important needs expressed by several parents and children is the need to experience play with other children: many parents in fact express that their children use to play alone, not always as a choice, but because they lack friends and peers to play with. Having access to a variety of adapted toys should also be carefully considered; in fact, they might facilitate or broaden the play activity, or make it more fun. Knowledgeable adults, in addition, may have an important role in facilitating, supporting and sustaining the play activity of the child, his/her interaction with peers or with objects.

From a cross tabulation that connects the data related to the play needs to the type of impairments of the children emerges that the greatest need reported by Associations and parents connected to children with autism spectrum is represented by toys, and the same happens in the case of children with language/communications disorder and with multiple disabilities. In the case of children with intellectual disabilities the playmates are the most important need, but more than for children with hearing impairments, who often play alone. The children with physical disabilities would mostly need toys able to generate improved skills.

Another cross tabulation - concerning the children's age and their play needs - reveals that in the age range $0-5$ the most common need is represented by toys; in the age range 6-9 instead different needs emerge with the same number of answers: a competent adult, playmates and time to play; in the age range 10-13 the priority is given to playmates; in the age range 14-18 there is a need of toys, especially technological ones. The 4 age ranges are fairly equally represented, so we assume that this distribution may be representative of the needs related to play at different ages of children with disabilities, regardless of the type of impairment.

Concerning where the child with disabilities plays, the Associations reported homes and other houses as indoor environments, and then schools, rehabilitation centres and leisure centres for children. Cited outdoor environments are: parks and natural environments, playgrounds, gardens/courtyards/streets and outdoor sport centres.

As to the playmates of children with disabilities, who most commonly play with them, these data has been put in combination with where this happens. It seems for example to be little more common that the children play most often alone or "in presence of peers" rather than "with" peers or friends in schools, or than in culture and leisure centres for children. 
The Associations' survey also shows that children with disabilities more often do play alone or "in presence of peers" than with peers or friends in outdoor environments such as playgrounds, parks and natural environments and gardens/courtyards/ streets. The opposite situation is verified in the case of outdoor sport centres, where children considered in this survey seem to play a little bit more with other children or youth, rather than alone.

Regarding the places of play, the parents involved in the other survey answered that the child plays at home, at school, in outdoor environments, as a park, especially in playground, in other indoor environments as rehabilitation centres or sport centres. About the playmates, several children were reported to play alone. This condition of play the majority of time is reported by parents together to play with partners, but for about a third of children playing alone is the only type of play reported by parents. The reasons that are at the basis of this situation are, according to the parents, related to: a preference of the child, or a condition caused by disability, or a rejection by peers, or also because there was a lack of time and opportunities to have some playmates. Other playmates reported by parents are: parents themselves, siblings, friends or peers in general, professionals, grandparents.

The 129 parents who answered are located in 26 European countries. They represented children of different ages and the various age groups were quite evenly represented. The boys were a majority (63\%).

The parents were asked to express their perceptions and opinions related to the play of their children. They used as much positive as negative expressions. Positive words used were, for example: intense, joy, delighted, happy and fun; many positive emotions and fun were stressed about their children's play. Examples of negative expressions adopted to describe the same topic are: rejecting attitudes, childish or monotonous. Restrictions were identified in lack of attention and of peer relations.

Generally speaking, parents think that play is a positive and valuable experience for the child. It means enjoyment, happiness and fun, even if there are also experiences of shortcomings, for instance lack of peers to play with. Play is seen as an activity that fulfill important needs of the child: therefore parents declare to feel frustrated and unhappy when their children experience failure and limitation to their play.

The responses by parents of children with disabilities from many different contexts indicate that play is an essential activity for children with disabilities, as for all children. It is highly enjoyed by their children and makes them happy. At the same time, it may be restricted by environmental and social barriers and limited by developmental delays, and lack of skills related to the impairments. In order to make it possible and to enhance the participation of children with disabilities to play activities, adaptations, positive attitudes in the social contexts, available resources, and adequate policies are needed.

Some additional reflections that are inspired by the parents' answers concern the emerging of other play experiences that could be investigated and possibly included in the existing adopted models of play. 
Within the framework of the Classification of the types of play adopted by Action “LUDI” (Bulgarelli \& Bianquin, 2017), the parents' answers regarding their children's play refer to practice play as the most representative type: the children touch handle different materials, and repeat gestures with body movement.

The second type of play more represented is play with rules which includes videogames or technology tools as tablet, i-Pad, PlayStation, with a wide range of applications useful for children with motor impairments or with autism spectrum disorders.

Symbolic play is the third type of play cited by parents. This includes simple symbolic play such as play with shapes and drawing, but also more sophisticated activities, such as playing with cards or role play.

In the cognitive dimension construction play appears only seldom. Sometimes the children are not capable in construction play, but they can disassemble materials (that, of course, is a "practice play" activity and not a constructive one).

As to the social dimension of play, it is difficult to distinguish - within the answers to the questionnaire - among the different types (solitary, parallel, associative or cooperative). Some more precise information in this regard may come from the answers to the question dedicated to playmates. When it comes to the open question about play, only few mentioned play activities fall unambiguously under the cooperative play type, such as play with the ball, also with rules as football, or play with cards, or simply dealing with rules. Parents cited also generic activities from a social point of view such as talking, smiling, laughing, and have company.

Furthermore, some parents report an activity of observation of other children's play, which is called "onlooker play". ${ }^{3}$ If the child is not actively playing, the observation of other children while playing, could be considered as an activity in which the child understands and learns, through watching what to do and what happens in play. During onlooker play the child spends most of the time «observing other children playing, sometimes asking questions, commenting, or responding but not overtly engaging in the play activity» (Parten, 1932, quoted in Barton, 2016, p. 268). This activity could be a step that the child experience before joining the play situation, or imitating it.

There is another type of play that some parents report in their answers and was not immediately found in the classical definitions of play: it could possibly receive more attention in future mappings of play activities. It is the play activity with pets, for instance with a dog, which is reported in more than one occasion. It is possible in a way to consider these activities as play activities for the dog and not for the child, but it is also possible to consider these activities as play for both the parts involved in the interaction. The relationship between humans and nature, is something that

3 Within the framework of the LUDI Classification of the types of play, "onlooker play" is part of the "parallel play" (social area). 
has been overlooked, since the dominant approach in many theoretical frameworks has been anthropocentric (Wilson, 1984; Kahn, 1997; Keller \& Wilson, 2013) but an analysis of the child's interest about and relationship with the nature, particularly with living creatures, could provide further elements to a theoretical model of human development (Lee, 2012), perhaps also of play. This is a general theme that could be possibly explored further and then related to the experience of children with disabilities.

When possible, parents interviewed their children about their concrete experiences of play and their related feelings. The direct voice of users has been thematised as Activities and Events; Partners in play; Emotional states; Agency in play; Evaluation and Places. Play emerges in the children's experiences as a meaningful and pleasant activity that they can engage in, that they can observe, communicate, share; through it, they can experience participation in social relationships. In playing, they feel positive emotions such as joy, happiness, relax, fun, excitement. Children may also experience agency, as they can decide and act as powerful persons, thus showing to be in control of the play situation. With reference to the evaluation theme, several children expressed their wish to play for more time, to have more options and adaptations for play, and that barriers and limitations to play may be overcome.

In conclusion, the children's direct voice reports that the play encourages positive emotions, expands the range of social interactions, and support their agency.

\section{References}

Antia, S. D., \& Dittillo, D. A. (1998). A comparison of the peers' social behavior of children who are Deaf/Hard of Hearing and Hearing. Journal of Children's Communications Development, 19, 1-10.

Barron, C., Beckett, A., Coussens, M., Desoete, A., Cannon Jones, N., Lynch, H., \& Fenney Salked, D. (2017). Barriers to Play and Recreation for Children and Young People with Disabilities. Exploring Environmental Factors. Berlin/Warsaw: De Gruyter.

Barton, E. E. (2016). Critical Issues and Promising Practices for Teaching Play to Young Children with Disabilities. In B. Reichow et al. (Eds.). Handbook of Early Childhood Special Education. New York: Springer International Publishing.

Besio S. (Ed., 2010). Gioco e giocattoli per il bambino con disabilità motoria. Milano: Unicopli.

Besio, S. (2017). The Need for Play for the Sake of Play. In: S. Besio, D. Bulgarelli, \& V. StanchevaPopkostadinova (Eds.), Play Development in Children with Disabilities (pp. 9-52). Berlin/ Warsaw: De Gruyter.

Bianquin, N. \& Bulgarelli, D. (2017). Conceptual Review of Disabilities. In: S. Besio, D. Bulgarelli, \& V. Stancheva-Popkostadinova (Eds.), Play Development in Children with Disabilities (pp. 58-70). Berlin/Warsaw: De Gruyter.

Bulgarelli, D. \& Bianquin, N. (2017). Conceptual Review of Play. In: S. Besio, D. Bulgarelli, \& V. Stancheva-Popkostadinova (Eds.), Play Development in Children with Disabilities (pp. 9-52). Berlin/Warsaw: De Gruyter. 
Bulgarelli, D. \& Stancheva-Popkostadinova, V. (2017), Characteristics of play in children with intellectual disabilities. In: S. Besio, D. Bulgarelli, \& V. Stancheva-Popkostadinova (Eds.), Play Development in Children with Disabilities (pp. 88-93). Berlin/Warsaw: De Gruyter.

Brambring, M. (2005). Assessing developmental differences in Blind versus Sighted children, key-note speech, ICEVI European conference, Chemnitz, Germany, 14-18 August 2005, Conference proceedings/report, 2005, 18-23.

COST (2013). Memorandum of Understanding for the implementation of a European Concerted Research Action designated as COST Action TD1309: Play for Children with Disabilities (LUDI), https://e-services.cost.eu/files/domain_files/TDP/Action_TD1309/mou/TD1309-e.pdf

Guralnick, M. J., Connor, R. T., Neville, B., \& Hammond, M. A. (2006). Promoting the peer-related social development of young children with mild developmental delays: Effectiveness of a comprehensive intervention. Journal Information, 111(5).

Haight, W. (1998). Adult Direct and Indirect Influences on Play. In: D. P. Fromberg, \& D. Bergen (Eds.), Play from Birth to Twelve and Beyond: Contexts, Perspectives, and Meanings (pp. 259-265). New York \& London: Garland Publishing.

Kahn, P. H. (1997). Developmental Psychology and the Biophilia Hypothesis: Children's Affiliation with Nature. Developmental Review, 17(1), 1-61.

Kellert S. R., \& Wilson E. O. (2013). The Biophilia Hypothesis. Island Press.

Lee, P. C. (2012). The Human Child's Nature Orientation. Child Development Perspectives, 6(2), 193-198.

Lender, W. L., Goodman, J. F., \& Linn, M. I. (1998). Repetitive activity in the play of children with mental retardation. Journal of Early Intervention, 21(4), 308-322.

Luttropp, A., \& Granlund, M. (2010). Interaction-it depends-a comparative study of interaction in preschools between children with intellectual disability and children with typical development. Scandinavian Journal of Disability Research, 12(3), 151-164.

Nader-Grosbois, N., \& Vieillevoye, S. (2012). Variability of self-regulatory strategies in children with intellectual disability and typically developing children in pretend play situations. Journal of Intellectual Disability Research, 56(2), 140-156.

Organisation for Economic Co-operation and Development (OECD) (2007). Students with Disabilities, Learning Difficulties and Disadvantages: Policies, Statistics and Indicators http://www.oecd. org/education/innovation-education/studentswithdisabilitieslearningdifficultiesanddisadvantagespoliciesstatisticsandindicators-2007edition.htm

Reid, D. (2004). The influence of virtual reality on playfulness in children with cerebral palsy: A pilot study. Occupational Therapy International, 11(3), 131-144.

Schneekloth, L. (1989). Play environments for visually impaired children. Journal of Visual Impairment and Blindness, 83, 196-201.

Slade, A. (1994). Children at Play: Clinical and Developmental Approaches to Meaning and Representation. Oxford University Press.

Sylva, K., Tagart, B., Melhuish, E., Sammons, P., \& Siraj-Blatchford, I. (2007). Changing Models of Research to Inform educational Policy. Research Papers in Education, 22(2), 155-168.

Stoneman, Z., Brody, G. H., Davis, C. H., Crapps, J. M. (1989). Role relations between children who are mentally retarded and their older siblings: Observations in three in-home contexts. Research in Developmental Disabilities, 10, 61-76.

Weiss, P. L., Bialik, P., Kizony R. (2003). Virtual reality provides leisure time opportunities for young adults with physical and intellectual disabilities. Cyber Psychology and behaviour, 6(3), 335-342.

Wilson, E. (1984). Biophilia: The human bond with other species. Cambridge: Harvard University Press.

Wood, E. (2009). Developing a Pedagogy of Play. In: A. Anning, J. Cullen, \& M. Fleer (Eds.), Early Childhood Education: Society and Culture (pp. 27-38). London: Sage Publications, 
World Health Organization (2001). International Classification of Functioning, Disability and Health (ICF). Geneve: WHO.

Zappaterra, T. (2018). The Role of Knowledgeable Adults in Children with Disabilities' Play. An Exploratory Research in Europe. Today Children Tomorrow Parents, 47-48, 74-85. 

Section 2. Case Studies Based on Literature Reviews from three Countries 


\section{Egle Celiesiene and Marjatta Takala 6 Introduction to the Section}

EU Strategy 2020 highlights sustainable and integration growth priorities, and the socio-educational innovation is directly related to a smart growth priority and to implement flagship initiative "Innovation Union". This initiative, dedicated to promoting communication, abandons the traditional approach to innovation and it is recommended to follow the broad-based innovation to promote not only technological, but also socio-educational innovation, which highlights the importance of understanding different groups of users' needs.

Smart specialization strategies and scenarios are modelled in preparation for the new European Union financial programming cycle and are prepared by all European Union countries. Some of them, such as Lithuania, prepare their specialization strategy for the entire country. Smart specialization calls for a review of existing policies and practices to ensure compliance with inclusive and creative public education priorities. That is the main premise of holistic assessment of specific social groups, in this case - specifically of children with disabilities who need to play.

\subsection{Topics of relevance and novelty}

According to Cmirnova et al. (2012), the nineteenth and the twentieth century beginning successor in the early game theory, for example, the excess energy (Surplus Energy Theory, Spencer, 1878), recuperation or relaxation (Recreations or Relaxation Theory, Lazarus, 1883) recapitulation (Recapitulation Theory, Hall, 1920), was used to explain play and its purpose. The modern play research era developed the Psychodynamic play theory (the psychodynamics of Theories of Play, Freud, 1961; Erikson, 1985), Cognitive development play theory (Cognitive Developmental Theories of Play, Piaget, 1962; Vygotskij, 1966, 1997) which examine the links between child development and play. Researchers tend to agree that the child develops by playing. Play allows the children to develop their intellectual, emotional and social skills and how pleasant the child's activities are, paving the way to learning (Brėdikytė \& Hakkarainen, 2011; Brėdikytè, 2012; Lillard et al., 2012; Whitebread, 2012; Brèdikytė et al., 2013, Brandišauskienė \& Maslienè 2014). Researchers stress the importance of positive peer relationships in childhood and later life (Brèdikytè et al., 2013, Kvieskienè, 2014).

Children can experience a variety and/or a combination of disabilities that can affect their ability to play. Disabilities can be physical, intellectual, or emotional and can range in severity from mild to profound; nevertheless, all of these children have some capacity to engage in play.

Play is important for all children. Although play research on children with disabilities is lacking in some areas, much has been learned about how children with 
disabilities play and how their play possibilities can be expanded. As more is learned and newer advances are made in all types of play environments, more opportunities will be possible for children with disabilities to participate in play. Many technological solutions have been promoting this in the 21st century.

The task of the LUDI WG 4 is to collect data on the users' needs, related to play for children with disabilities. We collected data on the users' needs and reported them with case studies from different countries. All LUDI members were invited to contribute to the mapping of users' needs, making a review of relevant literature and documents from the respective context. The second section of the report presents results from literature reviews about children with disabilities and play performed in three countries, namely Sweden, Finland and Lithuania during the year 2015. These countries are situated a bit north from central Europa and they have relatively small populations. Sweden has 9.6 million, Finland 5.5 million and Lithuania about 3 million inhabitants. All these countries aim toward inclusive education and embrace a social model of disability, away from a deficit approach.

The case studies summarize several studies and reports published in these countries. The situations reported in these studies should be considered as examples from different contexts of the play needs of children disabilities. However we cannot generalize aspects regarding play of children with disabilities. Each child has his or her own way of playing as well as own demands for play. Children with disabilities face a bit different situations than those of typically developing children. Having one or more impairments can mean that play might demand adaptations or support from the adults around or from the environment. How the society and the environment support children with disabilities and their families may differ in these three countries.

When discussing play, there is usually a person to play with, meaning that several persons are engaged. It is often a peer or a sibling. In a study (Diamond, Hong \& Tu 2008) typically developing children evaluated the possibilities to play with children with physical disabilities. In that study the typically developing children saw barriers but also possibilities. Parents' importance seems to be a common issue in these three countries. Scaffolding the play of young children with disabilities was also underlined in a review by Childress (2011). Play was used as an important source of interaction. Parents learned about their child during the play, and it seemed that most parents could adapt their play according to the needs of the child. So the play is difficult to study or to talk about without taking account the environment and the relationships around the child.

Education of children is today based on inclusion in most countries. How that is done in practice, varies in these three countries. The basic principles of inclusion are participation, equality, fraternity and liberty (see Hausstätter, 2013). These are also the guidelines regarding opportunities to play for children with disabilities in Finland, Sweden and Lithuania. 


\subsection{Methodology}

A literature review was made with relevant terms and various strategies (disability, children, play, special educational needs, special needs, children's rights etc.) in order to identify reports, thesis, scientific papers, documents from governmental bodies, international and national agencies, Non-governmental organizations, parents' associations, Universities, that have relevant contents about the needs of parents and children related to play for children with disabilities from chosen country. The literature was found both with web-searches in various databases and looking directly at the publications from various stakeholders and agencies. The scope was to identify at least 10 relevant documents, up to 20. A group of interested colleagues or students in the literature review and data extraction were involved. An analysis of the results (case study of the users' needs about play for children with disabilities in three countries) was prepared. The report contains a short description of the policies and stakeholders in context, and the results from the literature review, concerning needs, barriers, facilitators and recommendations.

\subsection{Short project description}

The case study represents three countries: Sweden, Finland and Lithuania. Every country studied their policies, mapping of the users' needs, barriers, facilitators and finally concluded with recommendations.

The Swedish project gives recommendation to the school to focus on the need of children with medium and high impact disability and in particular children with autism spectrum disorders and attention deficits. Welfare providers should give support to their families, follow-up their needs (Statens Folkhälsoinstitut, 2014) and also give a leisure subvention to the families so that they can afford more activities (Handisam, 2014).

Finnish legislation tries to promote early childhood education and welfare by offering kindergarten services with low prices for all families with young children. In addition, teachers in kindergarten are well educated, carrying either a bachelor or master degree. Services are available all over Finland. However, not very much research on play exists.

Lithuanian scientists conclude that the situation is slowly improving with more and more methodological tools introduced into the educational system, which are created in response to the need by teachers and special needs educators, who were seeking to gain knowledge about effective and inclusive work with children who have Special Educational Needs. Including play as a method and as a learning tool represents one step towards a more inclusive and open education. There were a stack of studies in Lithuania about play in the lives of children with disabilities. This study helps to improve knowledge and gives the background for other studies. With more 
resources and good practice models, promoting positive socialization and individual support for children with SEN, the needs will be understood and addressed better, thus promoting the need for various forms of play. Having opportunities to play improves various abilities and helps children with disabilities also in future life.

\section{References}

Brandišauskienė A., Maslienė D. (2014). An overview of developed forms of pretend play situation in Ecec institutions in Lithuania. Vilnius: Lithuania University of Educational Science. Retrieved from http://zaidimolaboratorija.leu.It/store/tinymce/Brand_Masl_straipsnis_2014.pdf

Brèdikytė, M., Hakkarainen, P., Jakkula, K., \& Muntter, H. (2013). Adult Play Guidance and Children's Play Development in a Narrative Play-world. European Early Childhood Research Journal, 12(2), 213-225.

Childress, D. C. (2011). Play Behaviors of Parents and Their Young Children with Disabilities. Topics in Early Childhood Special Education August, 31(2), 112-120.

Smirnova E.O., Sokolova M.V., Sheina E.G. (2012). Approaches to the notion of a play in contemporary foreign psychology. Journal of Modern Foreign Psychology, 1, 53-64. Retrieved from http://psyjournals.ru/en/jmfp/2012/n1/51438.shtml

Diamond, K. E., Hong, S-Y. \& Tu, H. (2008). Context Influences Preschool Children's Decisions to Include a Peer with a Physical Disability in Play. Exceptionality, 16(3), 141-155.

European Commission (2019). EU Strategy 2020. Retrieved at https://ec.europa.eu/info/ business-economy-euro/economic-and-fiscal-policy-coordination/eu-economic-governancemonitoring-prevention-correction/european-semester/framework/europe-2020-strategy_en

European Commission. (2010). Accompanying document to the Europe 2020 Flagship Initiative Innovation Union. Brussels: Commission staff working document, COM(2010)546/SEC (2010)1161. Retrieved from http://ww.w.xploit-eu.com/pdfs/Europe\%202020\%20Flagship\%20 Initiative\%20INNOVATION.pdf

Hausstätter, R. S. (2013). An article concerning romanticism, nationalism and the moral argument in special education. Scandinavian Journal of Disability Research, 15(4), 299-310.

Kvieskienė G. (2014). Pozityvioji socializacija visiems [Positive Socialization for All]. Vilnius: Vilnius Pedagogical University.

Lillard, A., Pinkham, A. M., Smith, E. (2011). Pretend Play and Cognitive Development. In: U. Goswani (Ed.), The Wiley-Blackwell Handbook of Childhood Cognitive Development (pp.85-311). Hoboken: Wiley-Blackwell.

Vygotskij, L. S. (2016). Play and its role in the mental development of the child. International Research in Early Childhood Education, 7, 2, Retrieved from https://files.eric.ed.gov/fulltext/ EJ1138861.pdf

Whitebread, D. (2012). Developmental psychology and early childhood education: A guide for students and practitioners. Los Angeles: Sage Publishers. 


\section{Eira Suhonen, Marjatta Takala, Alisa Alijoki, and Elina Viljamaa 7 Children with and without disabilities in Finnish early childhood education}

This chapter focuses on the Finnish system with regards to early childhood education and deals with research on special needs and play.

\subsection{Public health care services for children with disabilities}

In this section we introduce the main public health care services to all families in Finland.

\subsubsection{Child and family policy in Finland}

Pregnant mothers are available to start maternity leave from 50 to 30 working days before the delivery and the duration of maternity leave is 105 working days. After that either the mother or the father is able to stay at home with the parental allowance for 158 working days. Also fathers have the possibility to take the entire 54 working days of paternity leave when the mother is not on maternal leave. (Ministry of Social Affairs and Health, 2013.) Every pregnant mother gets a maternity grant. They can choose if they want to have it cash or as a maternity package which contains clothes and child care items needed for a new-born child. In addition to this, a child benefit is paid by the state every month to all children under the age of 17. The amount of it depends on the number of children in the family. Depending on family's size and income some families can get housing support or social assistance from Social Insurance Institution (Ministry of Social Affairs and Health, 2013.)

\subsubsection{Child welfare clinic}

In addition to a well-organized and rather cheap daycare system, we have a wellstructured child welfare clinic-system, where all parents with small children visit regularly and receive advice how to promote the development of their child. It has existed from 1920 on and it is totally free. Pregnant women receive advice and the progress of the pregnancy is followed there. Fathers are also welcome to the welfare clinics. After the child is born, the parents and the child visit the clinic regularly until the child is at school age (7 years) (Ministry of Social Affairs and Health, 2013).

In Finland children ages 1-5 attend regularly child welfare clinic where children who might be at-risk for learning disabilities are identified. Central Union for Child 
welfare has summarized the services for the child with special needs and his/her family (Ministry of Social Affairs and Health, 2013).

According to the Finnish law (Finnish Disability Act 1987) about services and support based on disability, a disabled person is someone who has difficulties in daily issues because of an illness or a disability. The responsibility to organize the services in the extent that is needed is given to municipals (3§). In addition we have a law regulating the support given to persons with intellectual impairment (Law about special services for Intellectually impaired 1977/519).

Social welfare and health care professionals provide support and information for the parents of children with disabilities. Child health clinics follow children's development at regular intervals. We consider it important to identify delays and challenges in development as early as possible (Ministry of Social Affairs and Health, 2013).

Children's medical, educational and social rehabilitation begin immediately when children have got diagnosis. Child health clinics support also children's families. Children with severe disabilities are entitled to medical rehabilitation organized by the social Insurance Institution. The authorities draw up a service plan together with the parents, covering all the services and assistance needed by the child and serving as the basis for making decisions. The parents of children with disabilities are eligible for various financial benefits from the Social Insurance Institution. Family's size and income determine the fees of day care (Ministry of Social Affairs and Health, 2013).

Early intervention services take place in child care (mainly kindergartens and family day care), in child welfare clinics, in social work and in therapy. (Rantala, Uotinen, McWilliam 2009). Finnish children with disabilities attend all those different daycare forms mentioned before, depending on their own situation, on the possibilities the municipal has to offer and on parents' wish.

In addition to the official systems, we have several associations that also promote the wellbeing of young children with disabilities. The Finnish Association on Intellectual and Developmental Disabilities (FAIDD) is a non-profit, nongovernmental organization that promotes good life, equality and participation for persons with intellectual disabilities and others who need support with learning, understanding and communicating (FAIDD, 2015).

\subsection{Early childhood education services}

In this section we are presenting children's possibilities to take part to early childhood education as well as preschool education. In Finland preschool takes only one year when children are at the age of six. 


\subsubsection{Daycare and preschool education services}

Organization of day care and early childhood education and care (ECEC) is guided by the Ministry of Education and Culture. In 2015 we have received a new law to ECEC, but its precise content is still preliminary. The ECEC includes elements of education, teaching and care. Our National Curriculum Guidelines on Early Childhood Education and Care in Finland (Finnish National Board of Education, 2016).

All children under school-age have a subjective right since 1996 to early childhood education and care (ECEC). Local authority has to provide to every child under compulsory school age opportunity to day care, once the parental leave period ends. That right lasts until the primary school (at the age of seven) starts. The fees are based on family size and income level. The options families can choose form are a) municipal or b) private day-care center or c) in the home of a family day care provider. The pre-school year, which is one year before elementary school, is free of charge (Finnish National Board of Education, 2016.) Families can also take care of their child at home themselves and in this case they receive child home care allowance. This implies to children until the age of three (Ministry of Social Affairs and Health, 2013).

Preschool education is organized in day care centers and schools. The length is one year before the basic education. Education is based on a local curriculum drawn up within the framework of the National Core Curriculum for Pre-primary Education (2010). From August 2015 it has been compulsory for all children. Children who have elongated compulsory education have two years pre-primary school and they can start it at the age of five. Most of these are children with severe disabilities (Finnish National Board of Education, 2016).

\subsubsection{Some statistics}

In 2013 together 58.134 children were born in Finland. Finnish population was 5471753 inhabitants in 30.12.2014. Together 229000 children were at a municipal daycare $(74 \%)$ or privately taken care (8\%), mainly at home or in private settings in 2013. Children in day care attend it mainly the whole day. Children under 1 year old are mainly taken care at home (Figure 1).

In 2010 8,3\% of children who attended day care had some special needs. The support services offered for them consisted of following: pedagogical support, special education group in day care, the child or the group has an assistant or the services of early special educator are available (Laaksonen \& Lamberg, 2014).

We don't have exact statistics regarding children with disabilities in Finland. For example, in our capital city Helsinki of all children in day care we had $5.7 \%$ of children with special needs in 2013. According to an ongoing study (Suhonen et al., 2015) about $20 \%$ of children with special needs have different kind of disability. 


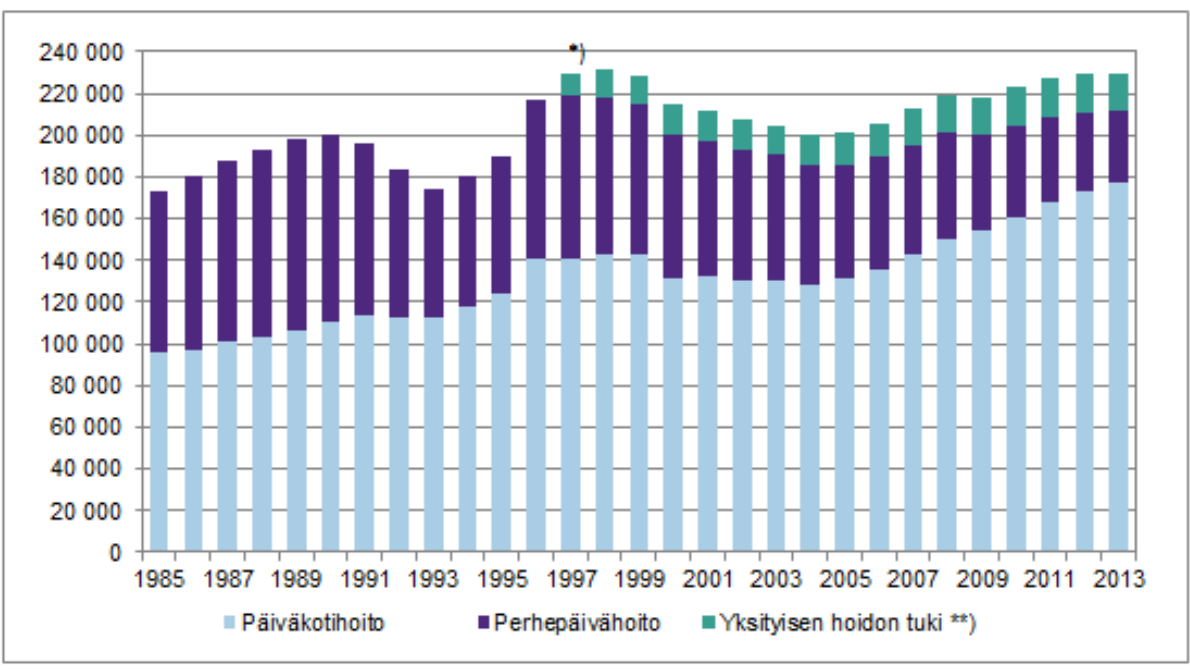

Figure 1: Amount of children in municipal (light blue), family day care (violet) or at private care (green, usually at home) during 1985-2013

There are some figures of certain groups of disabled children born yearly: about 70 children with a Down syndrome, around 600-1000 children damaged by mother's alcohol use, about 500 children with a heart disease, 100-120 children with CP, 50-60 deaf children are born yearly. All these children have different needs and their development has special features. However, all children want to play in one way or another.

\subsection{Early childhood special education}

In this section the focus is on play and children with special needs just on the age group who receive early childhood special education.

\subsubsection{Inclusive education}

Inclusive education is an approach to educate students with special educational needs in regular daycare and in regular school. Early Childhood Education (ECE) is also committed to the inclusive philosophy and the model to support children in ECE based in the model of The New Special Education Strategy which was launched by the Ministry of Education in 2007 (Ministry of Education 2007). It concerns mainly basic education not directly the early childhood education, but the inclusive principle 
is central in both. Municipals have made their own strategies of inclusive early childhood special education based on this Strategy of Special Education (2007).

The strategy in education including Pre-primary Education introduces a 3-tiered student support model (general, intensified, special support) which includes a new phase intensified support between general and (officially decided) special support (Ministry of Education 2007; KELPO, 2011).

High quality basic education refers to the support that every child receives in schools. The idea behind is that good quality education perceive variation of children's needs. If that is not enough and the child needs something more and somewhat different, the teacher has to do a pedagogical evaluation and discuss with colleagues, parents and the child what kind of support is needed. Then a personal learning plan needs to be written. This means the child starts to receive intensified support. If the child still needs more intensive and different support in addition to what is described in the pedagogical evaluation, it is possible to do a psychological or medical evaluation. Based on their results and discussions with all stakeholders, the child has the right to receive special support. $\mathrm{He} / \mathrm{she}$ is also entitled to an individualized learning plan (IEP) (see also Suhonen \& Nislin 2012).

According the law of Early Childhood Education (2015) all children in early childhood education would have an individualized education plan including the child's special needs. The model of three step support system is used in Finland also in early childhood education although it is not prescribed by the law of Early Childhood Education.

\subsubsection{Some examples of assessments and interventions programs}

In this section we are focusing in some assessments and interventions program which are using in Finland in early childhood education.

\subsubsection{Intervention program focusing all children}

In inclusive settings we have developed Pedagogical Sensitive intervention (PedaSens). Previous research has demonstrated that a child seems to benefit from a number of day care-group relationships that are fostered in co-operation with other children and adults (Grossmann \& Grossmann, 2008; Siegel, 2014). Positive relationships are formed when the adults stay in interaction with the child and responds sensitively to the needs of the child as well as to the whole group. PedaSens consists of providing theoretical information and video guidance about sensitive interaction, and supervision between the trainer and professionals of early childhood education (Harkoma, 2016).

Another program we have used in children from five to seven based on the MindUp ${ }^{\mathrm{TM}}$ program (Sconert-Reichl \& Lawlor, 2010). In Finland it is called Young 
Learning Mind (POM) ${ }^{4}$. The program is designed to improve children`s understanding about their functional brain; to enhance awareness of changes in internal states, to expand the ability to regulate stress response induced behaviors, to boost social collaboration, empathy, and kindness. The program lasts for 30 weeks and is implemented as a part of municipal early education curriculum (Sajaniemi, Nieminen, Suhonen \& Harkoma, 2016).

\subsubsection{Intervention programs focusing children with special needs}

There are some intervention programs as $\mathrm{Kili}^{5}$ (Isokoski et al. 2002) which are made to combine language and motor skills training. In Kuttu ${ }^{6}$ (Kähkönen et al. 2002) children use pictures as a support of the communication and play. These programs have been evaluated so that they are effective, there is a response to intervention. In the study of the effect of KILI (Sajaniemi at al. 2010) a significant and positive effect on non-verbal performance and play behavior was found.

PRT (Pivotal Response Training) is used with autistic children. In this program the main aim is to practicing communication, behavior, play and social skills in children's natural learning environments (Koegel \& Koegel 2006). In Finland we have had a project (started in 2005) by Honkalampisäätiö, where PRT program has been modified to Finnish circumstances and new supervisors have been educated (Hyytiäinen, Kinnunen, Timonen, \& Ylönen, 2008).

Finnish legislation promotes early childhood education and welfare by offering services with low prices. Services are available all over Finland. However, not very much research on play exists.

\subsection{Some examples of assessment and intervention programs}

The Portage Programme is one of the services offered by the Child Development Programme. This program is originally a home-based teaching programme for children ages birth to four who have special needs. In day care centers we use the The Portage Programme in Day Care (Saarela \& Pietiläinen, 2001) which is developed in FAIDD and it based on The Portage Classroom Curriculum (1978).

The program VARSU (Kovanen, 1998) is based on the Assessment, Evaluation and Programming System for Infants and Children (AEPS) (Bricker \& Pretti-Frontczak, 1996). This program is a curriculum-based assessment/evaluation system designed

\footnotetext{
4 POM comes from Finnish words Pieni Oppiva Mieli (Young Learning Mind)

5 Kili (young goat) comes from Finnish words "kieli" (language) and "liikunta" (physical exercise)

6 Kuttu (young sheep) comes from Finnish sentece "kuvin tuettu leikki" (supporting play with pictures)
} 
for use with children from birth to 6 years who have special needs or are at risk for developmental delays.

\subsection{Summary of the nine play studies in Finland}

In this section we will present nine Finnish studies about play. In all of them play is somehow in a focus and the perspective is in the children with special educational needs.

\subsubsection{Background of the studies}

The findings represented in this report are based on Finnish research between years 2006-2015. Four of them are PhD dissertations (Alijoki, 2006; Suhonen, 2009; Korkalainen, 2009; From, 2010) and two are peer reviewed research article (Pihlaja, 2009; Suhonen et al. 2015). In addition, there are two master thesis (Heiska \& Kallio, 2008; Niska, 2015) and one large report of children's participation in early childhood education when they have special needs (Hujala, 2011). Participants in these studies were mainly young children from three to seven (66.7\%). Both infant and toddlers as well school children were represented in a same level (both 22.2\%). Methods that had been used in these studies were interviews, surveys, observations, questionnaires and videotaping. One of the studies was a meta-study of scientific articles and one was a narrative study.

\subsubsection{Users' needs}

All in all we could say that children with special educational needs (SEN) express desire to play with others. However, they felt lonely. This might be due to the lack of social competence, lack of opportunities meeting and contacting other children or some other reason. Results clearly revealed that children with SEN had significantly less social communication, more reticent behavior and more solitary passive play. In some studies SEN children in mainstream groups did not feel they fit in. Many of the children with SEN needs use Augmentative and Alternative Communication (AAC). When using pictures or picture folders the children were more motivated and more engagement to play. 


\subsubsection{Barriers to play}

Children with SEN need more positive feedback and assurance that they are accepted. Children played significantly more in special groups than in mainstream groups. Teachers in mainstream groups did not recognize play interventions and they did not understand the meaning of play in rehabilitation as well as special teachers did. The lack of knowledge and lack of theoretical background of play influenced that kindergartens teachers had not enough skills to support and guide the play of children with SEN.

In many studies the meaning of sensitive adult seems to be one of the main issue to support children's play. The practitioners' sensitiveness to child's initiatives had twofold meaning; it is both preventing way to support children's participation to play and it helps children with SEN to engage in play.

Most of the children had poor language skills or they did not speak at all. Also the skills of social communication were weak. Children with SEN had difficulties to join the play and often they just looked at others' play or they withdrew from the play completely. Because of these reasons they had very few possibilities to rehearse the skills needed in play. Children with SEN needed also more instruction how to use toys.

\subsubsection{What facilitators help children to play?}

In Finnish studies it seems to be very a common recommendation that we need to increase play possibilities between children with and without special educational needs. Inclusive early childhood education might be the best way to do that. That demands well educated staff in early childhood education (e.g. day care centers). Educators in mainstream groups need more support for their own work.

In many studies the highlights were in adults' competence. These studies suggest more training to educators and more knowledge about special education and special needs for those who work in early childhood education. More attention should be paid to the fundamental task of early childhood education; how to guide children in play. Teaching should be an interactive process where, in joint play episode, turn taking, questions, requests and comments are jointly shared. Also some of the recommendations expressed that interventions should focus on increasing adults' sensitivity to notice children's initials and observe children's' needs in play.

In one study (Suhonen et al., 2015) they recommend more Developmental SocialPragmatic approaches (DSP), where the focus is on social communication including both verbal and non-verbal communication and social engagement. How to do things together needs to be taught to many children with SEN. 


\subsubsection{Concluding remarks}

The reliability of the quality of these studies varied from medium to high. Even the master theses were quite high level according to their evaluation criteria. Many kinds of methods had been used and also the mix method approach had been employed in some studies. In all these studies the ethical issues were identified and discussed. One of the studies had quite a high bias because only few people were interviewed and they all come from the same institute (Korkalainen, 2009).

\subsection{Discussion}

Parents of children with and without disabilities in Finnish early childhood education have several options to choose. The child can stay at home until the age of seven when it is time to go to school. The child can also attend an ordinary, an integrated or a special day care group. All this is quite cheap and the majority of families prefer municipal day care. However, there are also private day care centers, together $8 \%$ of children attending day care were in a private center in 2012 (Laaksonen \& Lamberg, 2014). Some choose them. Nevertheless, in all these institutes the staff has been trained so that the value of play is unquestionable. The pedagogy needs to be childcentered and continuous contacts with parents are underlined.

The inclusive principles like participation, equality, liberty and democracy are underlined and form a basis of the action (see Hausstätter, 2013). Of course individual institutes or people working in them can sometimes act in a different way, but these are the common guidelines. However, it is not always easy to make inclusion and equal paly opportunities come true. There are still barriers for playing, many of them invisible, on attitudes of adults around. Our task is to remove these attitudes.

\section{References}

Alijoki, A. (2006). Erityistä tukea tarvitsevien lasten polut esiopetuksesta alkuopetukseen tukitoimet ja suoriutuminen. [The different Paths of Children with Special needs from Pre-school to Elementary School - forms of Support and Achievement. Doctoral Thesis] Helsinki University Press. Retrieved at https://helda.helsinki.fi/handle/10138/20014

Bricker, D., \& Pretti-Frontczak, K. (1996). AEPS measurement for three to six years (Vol. 3). Baltimore: Brookes.

FAIDD (2015). The Finnish Association on Intellectual and Developmental Disabilities. http://www. kehitysvammaliitto.fi/in-english/homepage/

Finnish Disability Act 1987. Laki vammaisuuden perusteella järjestettävistä palveluista ja tukitoimista 1987/380. [Act regarding services and support based on disability]

Finnish National Board of Education, 2016. http://www.oph.fi/english

From, K. (2010). "Että sais olla lapsena toisten lasten joukossa" - Substantiivinen teoria erityistä tukea tarvitsevan lapsen toiminnallisesta osallistumisesta toimintaympäristöissään." ["To 
be a child just as the others". The substantive theory of activity-based participatory of the child with special educational needs]. Department of education/special education. University of Jyväskylä, Jyväskylä University Press. Retrieved at https://jyx.jyu.fi/dspace/bitstream/ handle/.../22736/9789513938017.pdf

Grossmann K. E., Grossmann, K. (2008). Universality of Human Social Attachment as an Adaptive Process. In: C. S. Carter, L. Ahnert, K. E. Grossmann, S. B. Hardy, M. E. Lamb, S. W. Porges, \& N. Sachser (Eds.) Attachment and Bonding. A new Synthesis. (199-228). London: The MIT Press. Harkoma, S. (2016). Aikuisen pedagogisen sensitiivisyyden kehittäminen taaperoryhmässä toteutetun PedaSens-intervention avulla. [Developing adults' pedagogical sensitivity in toddlers' kindergarten groups. Master thesis] Pro-gradu. Helsingin yliopisto. Retrieved at https://helda.helsinki.fi/handle/10138/168186

Hausstätter, R. S. (2013). An article concerning romanticism, nationalism and the moral argument in special education. Scandinavian Journal of Disability Research, 15(4), 299-310.

Hyytiäinen, M., Kinnunen. K. \& Ylönen, J. (2009). PRT-projekti 2005-2008. Loppuraportti. Joensuu: Honkalampi-säätiö. [PRT-project. Closing report]

Isokoski, M., Lindholm, L., Lindholm, R., \& Vepsäläinen R. (2004). KILI -kieli ja liikunta. Ryhmäkuntoutusohjelma kielihäiriöisille lapsille. [Language and physical activities . Group rehabilitation for children with SLI] 2nd edition. Helsinki: Early Learning.

KELPO (2011). Developing good Education. Retrieved at http://peda.net/veraja/kalajoki/hankkeet/ kelpo

Koegel, R. \& Koegel, L. (2006). Pivotal Response Treatments for Autism: Communication, Social, and Academic Development. Baltimore: Brookes Publishing Company.

Kähkönen, A.-M., Lindholm, R. \& Hannele Tahvanainen, H. (2006). KUTTU - Kuvin tuettu leikki. [Picture supported play] Helsinki: Early Learning.

Laaksonen, R. \& Lamberg, K. (2014). Varhaiskasvatuksen historia, nykytila ja kehittämisen suuntalinjat. [Early childhood education according to statistics]. In The History of early education, current stage and future development. Ministry of Education and Culture. Reports and clarifications 2014:12, 61-136. Available at http://www.minedu.fi/export/sites/default/ OPM/Julkaisut $/ 2014 /$ liitteet/tr12.pdf?lang = fi

Ministry of Education (2007). Strategy of Special Education. Ministry of Education and Culture. Helsinki. Retrieved at http://www.minedu.fi/export/sites/default/OPM/Julkaisut/2007/ liitteet/tr47.pdf?lang $=\mathrm{fi}$

Ministry of Social Affairs and Health (2013). Child and Family Policy in Finland. Tampere: Finnish University Print Ltd. Retrieved at www.stm.fi/en/publications

National Institute for Health and Welfare, (2005). https://www.thl.fi/en/web/thlfi-en

Niska, I. (2015). Erityistä tukea tarvitsevien lasten leikki ja kommunikaatio päiväkodin integroidussa erityisryhmässä. [Play and communication in children with special needs in an integrated special group of kindergarten. Master thesis] Pro-gradu. Helsingin yliopisto. Retrieved at https://helda.helsinki.fi/handle/10138/156135

Pihlaja, P. (2009). Erityisen tuen käytännöt varhaiskasvatuksessa - näkökulmana inkluusio. [Practices in Early Special Education - inclusion as a viewpoint]. Kasvatus [Education] 49(2).

Rantala, A., Uotinen, S., \& McWilliam, R. A. (2009). Providing early intervention within natural environments. A cross-cultural comparison. Infants \& Young Children, 22(2), 119-131.

Sajaniemi, N., Suhonen, E., \& Kontu, E. (2010). Verbal and nonverbal development in SLI children after early intervention. Early Child Development and Care, 180(4), 519-534.

Sajaniemi, N., Nieminen, S., Suhonen, E. \& Harkoma, S. (2016). Research report from Finnish Mind UPTM Program 2015-2016. University of Helsinki, Finland. Retrieved at https://mindup.org.

Sconert-Reichl, K., \& Lawlor, M. (2010). The effects of a mindfulness-based education program pre- and early adolescents' well-being and social and emotional competence. Mindfulness, 1 , 137-151. 
Siegel, D. (2014). Brainstorm: The Power and Purpose of the Teenage Brain. New York: Penguin Group.

Suhonen, E. (2009). Erityistä tukea tarvitsevan taaperon sopeutuminen päiväkotiryhmään. Monitapaustutkimus vuorovaikutussuhteista ja niiden rakentumisesta. [How toddlers with special needs adjust to the day care setting. A multiple case study of how the relationships with adults and children are built] Doctoral Thesis: Helsinki University Press. Retrieved at https://helda. helsinki.fi/handle/10138/20030

Suhonen, E. A., Nislin, M., Alijoki, A., \& Sajaniemi, N. K. (2015). Children's play behaviour and social communication in integrated special day-care groups. European Journal of Special Needs Education, 30(3), 287-303.

Suhonen, E., \& Nislin, M. (2012). Inclusive models in early childhood intervention in Finland. In R. S. Haustätter (Ed.), Inkluderende spesialundervisning [Inclusive Education]. Bergen: Fagbokforlaget.

Suhonen, E., \& Sajaniemi, N. (2012). Enhancing children's learning through intent participation understanding relationship between pedagogical sensitivity and stress regulation. Teoksessa Technical creativity in schools' curricula with the form of project learning "From idea to the product" - from the kindergarten to technical faculty. (pp. 56-61). Ljubljana: Ministry of Education, Science, Culture and Sport.

Taipalus-Suominen, I. (2012). Oppimisen tueksi kuvitettuja leikkejä kehitysvammaisille lapsille. [Pictured plays to intellectually impaired children in order to support learning] Degree Programme in Social Services. Diaconia University of Applied Sciences. Helsinki 


\section{Egle Celiešiene, Giedrẻ Kvieskienė and Angelẻ Kaušylienė \\ 8 Play for children with disabilities: the users' needs in the Lithuanian context}

\subsection{Introduction}

According to Lithuanian Ministry of Social Security and Labour, in 2015 Lithuania had 253.400 persons with disabilities, who are receiving welfare from the state, of which $48 \%$ were men and 52\% were women. Out of this number, 15.000 were children. The main reasons for children's disability (and special education needs, SEN) in Lithuania are mental disorders, behavioural disorders, hereditary problems, deformations, anomalies of chromosomes and nervous system diseases.

The report by Lithuanian Education and Science claims that the number of children with SEN is increasing in general in higher educational institutions $(6,6 \%$ in universities and $19,3 \%$ colleges in 2006, compared to 2005). And yet, the number of children with special needs in educational system declines with each stage of education (most - 15,1\% - of the SEN children are in pre-schools, with only 0,3 going to universities, in comparison with general number of children and young people in schools and universities).

Statistical data points out that even though the general numbers of inclusive education are growing, the tendencies overall are not showing positive results in the long run. Even though the number of children with SEN in educational institutions is growing, they have a pattern of falling out of the system in their young adulthood, thus resulting in decrease of socialization, communication problems and limited career options.

This tendency points out a structural, holistic problems in Lithuanian social care and educational systems, opening such flaws as insufficient resources, not adequate inclusion process, lack of good practice model for social care professionals.

Research by Lithuanian College of Democracy concludes that the users' needs about play for children with disabilities and with special education needs (SEN) are not met in Lithuania.

This claim is met by the following case study. The first part of this case study discusses the current situation and statistical data relevant to the topic of children with disabilities, the second part of the study discusses the improvements and upgrades done in recent years, and the last part of the study describes the rare positive examples of how play is included in daily schedules of children with disabilities and SEN. 


\subsection{Outline of Lithuanian social security and education of children with SEN}

The report by Lithuanian Education and Science ministry summarizes the possibilities of social integration of persons with special needs and the statistics about availability for them to learn (formal and non-formal education) and work. The report concludes that the number of children with special needs in educational system declines with each stage of education (most - 15,1\% - of the SEN children are in pre-schools, with only 0,3 going to universities, in comparison with general number of children and young people in schools and universities).

The report concludes that the number of children with SEN is increasing in general in higher educational institutions (6,6\% in universities and 19,3\% colleges in 2006, compared to 2005). It recommends to attend more carefully social inclusion and integration programmes, dedicated for people who finish high schools, because there is a huge risk that children with SEN are not adequately included to the job market and educational institutions after they complete their secondary education.

The report can be used to see the main tendencies of educational needs for children with SEN, and, while having data about the decrease of children reaching one or another stage of education, include more non formal education tools (including play) as a method for better experience in educational process for children.

The report by Lithuanian Children Rights Protection Office describes a current situation of children disability and with SEN in Lithuania, presenting statistical data about the amount of children in general and in various educational institutions, including special care schools.

The paper describes the main problems providing social care services, including:

1. General intolerance in the public regarding persons with SEN.

2. Lack of funding for basic needs of the children.

3. Lack of specialists who could work with persons with SEN in schools and other institutions.

4. Lack of specialists working with children with SEN on a district and local levels.

5. Not adequate funding for making public spaces available for persons with SEN.

6. Lack of specialists in rural areas.

7. Limited amount of social care institutions.

8. Not enough available transportation options.

9. Lack of funding for leisure activities and support for necessary tools for inclusion (toys, educational materials).

10. Poor system for inclusion in public schools, not adequate qualifications for educators.

11. Limited career options for young persons with SEN.

12. Lack of coordination between different institutions. 
Both of the reports conclude that that special needs are not addressed properly in Lithuania, the inclusion process is complicated. The institutions working with children who have special needs focus on improving the basics (transportation, accessibility, materials and tools, availability of specialists), and at the moment, has very limited resources to focus on the content, individual programmes or socialization, including play.

\subsection{Case study: good practice models and improvements in Lithuania}

Even though the general situation is not showing too much positive results, small but steady progress is made. Using experience from countries with advanced social security, learning from good practice models and adapting them in Lithuania has become one of the main goals for upcoming years.

Center of special education and psychology in 2010 has prepared a research paper.

"Variety of educational forms of People with SEN". Using situation analysis, analysing good practice models in Denmark, the Netherlands, United Kingdom and case studies they made a recommendation to use in Lithuanian educational schools.

The goal of this chapter is to describe what kind of educational assistance is provided for children with SEN in Lithuania and in Denmark, the Netherlands, United Kingdom, and what kind of experience is provided for these children in educational institutions.

The research does not focus on the play, but describes general experiences of children with SEN and possible recommendations for improving the situation while adapting the good practice models of Denmark, the Netherlands and United Kingdom through interviews with 18 experts.

The paper relies on 4 case studies of Lithuanian children, who were educated both in state primary and middle schools and in schools for children with special needs. The paper claims that main difference between two types of educational institutions is the individual support for the children. Their behaviour is changed to the positive side, according to the parents and the teachers, when they are placed in a special needs school. There, according to respondents, they have more positive experience, without possibility to be bullied or left behind academically. They also state that home-schooling provides even more positive results.

The role of play in the research is rudimentary, it is seen as additional leisure activity, with little to no focus on it in children's schedule.

The case studies in this paper offers a viewpoint on special needs education in Lithuania, which emphasizes not inclusion but a certain level of marginalization (sending children into special care home instead on working individually with them in local communities). 
To solve this, a methodological tool "Individualizing educational programmes for students with SEN" was created. It's a set of recommendations for teachers, who work with children with different needs and abilities.

The paper summarizes the recommendations for preparing an individual plan and differentiated education for children with SEN. The text argues that schools should not use a general plan and educate each child individually, according to their own needs and abilities.

It is structured to reflect these points and creates an elaborate recommendation for making an individual plan for each child. The text introduces play as a tool for learning, and encourages teachers to use play as a tool for active research, productive group work.

The methodological tool is created in response to the need by teachers and special needs educators, who were seeking to gain knowledge about effective and inclusive work with children who have SEN. Including play as a method in it as a learning tool is a one step towards a more inclusive and open education.

It is one of the first methodological tools, dedicated to the topic, in Lithuanian language, which shows that the situation is improving and that the good practice models are gaining more accessibility and availability.

\subsection{Socialization and daily activities of children with disabilities and SEN}

In the last segment of this paper we are going to discuss examples of positive socialization and daily activities of children with SEN.

In an "Analysis of children with SEN in public schools" participated 164 teachers, 50 children with SEN, 66 parents who have children with SEN. All participants come from middle schools in 1 district.

Methods used in the research were: structured interview with SEN children, SEN child parents, questionnaire with teachers. Data processed using statistical methods.

The research concluded that almost half of the children with SEN are living in families at social risk, half of the participants were not participating in after-school programmes, spend their time passively, usually - watching TV. Data gathered by the research has contradictions - teachers are insisting that families that have children with SEN are taken care of, has individual help, while parents argue on the contrary.

Parents spend very little quality time with children (either watch TV together or do chores), and make little effort for helping children with their homework. Children with SEN and their parents claim that they receive no or not enough care from special pedagogues, social educators, speech therapists. Teachers claim that their help for children with special needs is adequate, yet they also mention that the lack of time, good practice models, knowledge and methodological tools are the main problems, why the help for children is not of good quality. 
Children and parents agree, that they receive less than adequate help from teachers, and that the help they receive is not enough for quality education. Teachers claim, that there is not enough possibilities offered by school administration to improve their qualifications to offer quality education for children with SEN.

The research focuses on the basic needs of children with SEN, and does not cover play as a method and tool for improved educational quality. The research results provide information that children with SEN are offered not enough leisure or educational possibilities due to lack of qualifications, methodological tools and good practice models.

Another research paper, called "Socialization model of children with SEN" is dedicated to summarizing the socialization possibilities of children with SEN. It introduces the main factors and conditions needed for creating a model for positive inclusion.

Research objects were 4-21 year old children with SEN socialization process in social care institution.

Organizing, carrying out and analysing the research took 10 years. 60 children with SEN and 120 educators from 4 different institutions were included in this longitudinal study. The goal of the research was to provide a model for socialization, created according to the socialization strategies, sources, good practice models and previous research. Analysis of previous research/content, statistical data analysis, empirical observation methods were used during the time of the research.

The article claims that the main threats for positive socialization for children with SEN is the attitude of general society, but current tendencies of creating inclusive socialization models provide opportunities for children and young persons with SEN to have in general more positive experience socializing.

The research states that skills related to play offers improvement in social behaviour, and that creating an environment where play is encouraged is important in order to empower children for positive socialization. Social games are also important as a formative force for positive behaviour.

The research states that play and other leisure activities are directly correlating with the developmental issues - the more delayed is the development, the less the child is interested in play, common activities, socializing; also, they have more expressive style of communication and lack of abstract thinking. The research recommends creating an environment where play is encouraged as a tool of improving and forming child's behaviour.

"Emotional development of children with mental disability through didactic games” presents a pedagogical experiment which was carried out from October, 2007 to February, 2008 in NGO "Vilties spindulelis" with 6 visitors of the NGO. It describes children's needs for appreciation, support from an adult and being a leader. The researcher analysed quarterly plans of work with special needs children, it noticed that no plan included such goals as "to develop empathy", all of them were concentrating on simpler tasks (to develop love for nature and animals; to learn how 
to take care of plants; get to know more about birds). Thus pointing out that educators who are described in the research paper focus on specific tasks, not a holistic strategy. During the interviews, none of the staff members describes didactic games or play as a method for developing empathy or other positive outcomes, its function is limited for breaks and energizing. That should be seen as a barrier.

The paper focuses on didactic games to:

1. Develop empathy through mimicry

2. Express thoughts and developing communication skills

3. Develop empathy through music

4. Learn about expressing emotions through pictures

5. Learn about helping others

Paper recommends to:

1. Improve the education programmes and include more complex tasks for educators

2. To introduce play gradually and in small groups.

Results of an experimental research convince us of that, didactic games influence not only emotional development of children, but also on development of the person as a whole. Thus, under influence of a purposeful management in didactic games children with mental disabilities have an emotional progress more intensively.

"Emotions of children who have average cognitive development disorders through theatrical games observes closely the impact on children of theatrical games. Methods used in the paper is the analysis of literature and previous publications, content analysis, conversation, case study.

The overall topic is: developing emotional intellect in children with average cognitive development disorders through theatrical games.

The paper argues that using various arts (painting, music, dance, storytelling and theatre) is essential in teaching children with SEN on how to communicate their emotions, because usually, average cognitive disorders go hand in hand with aggression and other socially disruptive behaviour.

Behaviour of 4 children was analysed during the research, providing that children are more responsive, calm and trust themselves better if theatrical games are introduced in their daily routines. Conditions for positive socialization is encouraged, because children are learning to express their emotions in positive and non-disruptive ways, to relate to others better, to communicate more in general.

The paper notices that theatrical games are used as a tool for inclusion less than other art forms (music, dance, visual arts). Theatrical games relatability to playing, the natural activity of children, offers a wide array of possibilities for education and socialization.

Another study, "Deaf and blind children, communicating through games" takes a look into the communication of 6 children with disabilities. She uses such methods as analysis of literature and previous publications, quality research, case study. 
The study reveals that deaf and blind children communicate through body language and through acoustic methods - gestures, mimics, touching. Research concludes that children who are deaf and blind, during game time communicates only directly with their teacher. They need to have a constant structure and repetition - routine helps them to communicate better. Children do not communicate between themselves, only with their teacher, without using verbal cues.

"Inclusive education using play therapy in pre-school" discusses children's need to express themselves and own feelings and having a safe environment where they can explore their surrounding and understand themselves better. Overall, the paper discusses the importance of play for development of a pre-school age child.

The specifics of the play therapy method application under the inclusive education conditions in the pre-school education group.

Barriers for children to have a full experience in play are described as: not enough different forms of support and help for children with disabilities and lack of new methodologies and learning of how to teach for educators.

The facilitators for improved experience for children are not rushing the child the child has to feel safe and take initiative. Also, using different types of play therapy:

- Psychoanalytical play therapy (letting the child to forget their problems)

- Expressive play therapy (letting the child to express their feelings)

- Interpersonal play therapy (letting the child to develop their relationships)

- Non-directorial play therapy (play without structure)

The recommendations for improving the experience are:

- Being a part of a community

- Having social relationships and forming friendships

- Partnership between family, specialists and community

- Implementing human rights

This paper defines a good practice model of using play as a tool for inclusion of children with disabilities.

\subsection{Conclusions}

The number of children with special needs in educational system declines with each stage of education (most - 15,1\% - of the SEN children are in pre-schools, with only 0,3 going to universities, in comparison with general number of children and young people in schools and universities).

The number of children with SEN is increasing in general in higher educational institutions (6,6\% in universities and 19,3\% colleges in 2006, compared to 2005).

Attending more carefully social inclusion and integration programmes, dedicated for people who finish high schools, is essential, because there is a huge risk that 
children with SEN are not adequately included to the job market and educational institutions after they complete their secondary education.

Special needs are not addressed properly in Lithuania, the inclusion process is complicated. The institutions working with children who have special needs focus on improving the basics (transportation, accessibility, materials and tools, availability of specialists), and at the moment, has very limited resources to focus on the content, individual programmes or socialization, including play.

Special needs education in Lithuania emphasizes not inclusion, but a certain level of marginalization (sending children into special care home instead on working individually with them in local communities).

The situation is slowly improving with more and more methodological tools introduced into educational system, which are created in response to the need by teachers and special needs educators, who were seeking to gain knowledge about effective and inclusive work with children who have SEN. Including play as a method in it as a learning tool is a one step towards a more inclusive and open education.

The basic need to play of children with SEN are not met in most cases in Lithuania, and does not cover play as a method and tool for improved educational quality. The research results provide information that children with SEN are offered not enough leisure or educational possibilities due to lack of qualifications, methodological tools and good practice models.

With more resources and good practice models, promoting positive socialization and individual support for children with SEN, the needs will be understood and addressed better, thus promoting the need for various forms of play.

\section{References}

Aleksiene V., Zviceviciene S. (2009). Lietuviu etnochoreografija autistiskiems vaikams: ugdymo ir terapijos aspektai [Lithuanian ethnochoreography for autistic children: aspects of education and therapy]. Vilnius: Ciklonas.

Alisauskas, A., Jomantaite, R. (2008). Bendrojo lavinimo mokyklų mokinių specialiuju ugdymosi poreikiu tenkinimo analize [Analysis of satisfaction of special education needs of pupils in general education schools]. Siauliai: Siauliai University.

Alisauskas, A., Alisauskiene, S., Gerulaitis, D., Melienė, R., \& Miltenienė, L. (2010). Specialiuju poreikiu asmenu ugdymo(si) formu ivairoves tyrimas [Study on forms of special needs education]. Siauliai: Siauliai University.

Kisoniene R., \& Dudzinskiene R. (2005). Mokiniu, turinciu specialiojo ugdymo(si) poreikiu, ugdymo turinio individualizavimas [Individualisation of curriculum for students with special educational needs], Vilnius: Via recta.

Ignatovskaja, J. (2008). Intelekto sutrikimus turincio vaiko emocine raida didaktinio zaidimo metu, [Emotional development of a child with intellectual disabilities during didactic play]. Vilnius: Vilnius Pedagogical University.

Piliciauskas, A. (2005). Neigaliuju meninis ugdymas. Metodikos ir terapijos aspektai [Students with Disabilities in the art education. Methodology and aspects of the therapy]. Vilnius: Vilnius Pedagogical University. 
Segalovicius, A. (2007). Specialiuju poreikiu turinciu asmenu mokymosi apreptis: ataskaita [Report on the learning needs of special needs students], Vilnius: Factusdominus.

Pranckeviciene, V. (2010). Inkliuzinio ugdymo organizavimas taikant zaidimo terapijos metoda pries mokyklinio ugdymo grupeje [Organizing inclusive education through a game therapy approach in a preschool group], Kaunas: Vytautas Magnus University.

Vaicekauskiene, V. (2006). Specialiuju poreikiu vaiku socializacijos modelis [Socialization model for children with special needs]. Vilnius: Vilnius Pedagogical University. 


\section{Play for children with disabilities: the users' needs in the Swedish context}

\subsection{Background}

The task assigned to the Working Group 4 within the EU COST LUDI Network was to contribute to a mapping of the users' needs on the topic on play for children with disabilities.

The members of the Working group 4 including representatives from Finland, Italy, Lithuania and Sweden contribute to the description of the users' needs by mean of a mapping of available literature on this topic, from the respective countries. The members from the other countries in the LUDI network were also invited to participate to the mapping of the users' needs from various contexts.

In this report the results from the mapping of policies and studies from the Swedish context are presented.

\subsection{Aims and method}

The aim of this study is twofold: firstly the aim is to give a short description of the policy context of Sweden, which is relevant for the topic of "Play for children with disabilities", through a presentation of the legislation and the policies; of stakeholders, the national and local agencies and authorities with responsibilities in this field; and of other non-governmental organizations. Secondly, the aim is to perform a mapping of the users' needs concerning Play for children with disabilities, which are emerging from available research from relevant disciplines, reports and investigations made from the authorities and organizations that have responsibilities in this field, and other relevant stakeholders in Sweden. The content of the mapping effectuated are the users' needs, the barriers and the facilitators that are described in the identified reports.

The data collection followed a procedure in several steps. The information about the stakeholders, agencies, authorities and organizations was made by means of open web searches with combination of terms as disability, impairment, children, youth, adolescent, play, leisure time, in the Swedish language (funktionsnedsättning, funktionshinder, barn, ungdomar, lek, fritid). Once the organizations and the 
authorities were identified, the publications available on the web-sites were title- and summary- checked. If the content were judged potentially interesting for the purpose of the mapping, the publication was collected in a shared web BOX folder (Westling Allodi 2015a) that would be available for all the participants in the mapping; about 30 publications were collected. Databases for scientific publication in English (SCOPUS, EBSCO) were also searched for relevant publications with the same search terms and with the addition of search terms about users' needs of play, children experiences, parents' views etc. A Swedish publication database for scientific publications and thesis was also searched with the search terms "lek for barn med funktionsnedsättning” (play for children with disabilities) resulting in 10 student thesis. The publications were checked by the first author and a certain number were assigned to master-, $\mathrm{PhD}$ students and colleagues that were invited and agreed to participate to the mapping. The group of reviewers consisted of seven people from the Department of Special Education at Stockholm University, all of them with large experiences as researchers and/or educators of childhood, disability and special educational needs. The reviewers contributed with a number of one to four data extractions to the mapping. Fifteen reports are included in the mapping.

At the same time, a web survey was developed with Survey \& Report, a tool available at Stockholm University, which was employed in the data collection (Westling Allodi, 2015b). The content of the survey on users' needs were discussed with the member of the LUDI WG4. The final survey contains 19 questions, including: name of the reviewer, type of publication, reference, information on number of participants, their age and disability, methods of data collection, users' needs, barriers, facilitators, recommendations, evaluation of credibility, ethical issues and bias. The participants in the mapping accessed the documents assigned on the shared folder and performed the review answering to the web survey. The results were summarized in a web-report (Westling Allodi, 2015c).

\subsection{Description of the Swedish policy and context}

The legislation that concerns the topic of play for children with disabilities comprehends various Acts: the Education Act (Skollagen, 2010:800) the Social and Health Act (Socialtjänstlagen), and the Support and Service Act for persons with disability (1993:387). The Swedish government has adopted the UN Declaration of Rights for persons with disability (SÖ 2008:26). The Swedish Parliament has ratified the UN Convention of the rights of the child in 1990, but the convention is not yet incorporated in the Swedish legislation, although the issue is the object of an inquiry.

The national agencies that are involved in the services and development of practices on the topic of play for children with disabilities are:

- National Agency of Education (Skolverket, 2015) is responsible for the curriculum for preschool and school, the official data collection on resources and results, the 
development of in service training for teachers, the publications of guidelines and other reports and materials for schools.

- The National Board of Health and Welfare (Socialstyrelsen, 2015) is responsible for guidelines and support materials for the Health and Social services providers, the evaluation of services and analysis their outcomes, for instance concerning persons with disabilities and their families, and also the definition and diagnostics criteria of impairments and disabilities.

- The National Agency for Special Needs Education and Schools (Specialpedagogiska Skolmyndigheten, 2015) has a responsibility for the development of learning materials and resources for children with disabilities as alternative communication tools. SPSM runs the special schools for children with multiple disabilities, gives support and consultation to the staff from the various municipalities in matters that concern the children with disabilities that attend regular schools, organizes workshops and training for teachers, publish reports and guidelines on special educational needs.

- The Swedish School Inspectorate (Skolinspektionen, 2015) evaluates regularly the quality of the preschool and schools in all the municipalities, by means of inspections, surveys, audits; it investigates also particular issues, and complaints, for example concerning the lack of adequate support to children with special educational needs.

- The Swedish Agency for Participation (Myndigheten för Delaktighet, 2015) works to ensure that the disability policy has an impact on "all the corners of the society" develops guidelines, disseminates knowledge, publications and materials to increase accessibility and participation and reduce various types of barriers in the society; the agency evaluates regularly how other agencies are developing praxis and routines to guarantee access and participation for persons with disabilities.

- The Ombudsman for Children in Sweden (Barnombudsmannen, 2015) is a national agency with the mission of monitoring, and pushing the local authorities to apply the Convention on the rights of the child; it may propose changes to laws and ordinances and reports regularly to the government.

- Equality Ombudsman (Diskrimineringsombudsmannen, 2015) is a national agency with the mission of combat discrimination in the society on the basis of sexual differences, age, and for ethnic, religious, or disability reasons. It investigates citizens' complaints on these matters.

- the Swedish Agency for Youth and Civil society (Ungdomsstyrelse, 2015) is a national agency that is concerned with the needs and welfare of children and youths and the organization of the civil society, such as associations for leisure activities.

- The Public Health Agency of Sweden, (Folkhälsomyndigheten, 2015) has a responsibility for the development and evaluation of the health and wellbeing in the population in a broad framework, including monitoring and taking initiatives 
for reducing the risks for disadvantaged or vulnerable populations, publishing evaluations, guidelines, participating in international comparative studies (WHO), collaborating with universities in research projects. The Public Health Agency of Sweden works also to identify and highlight public health issues where effective interventions can be made.

The various agencies perform investigations, evaluations of practices, collect the views of users, publish guidelines for practitioners, and contribute to the further training of teachers and other professionals.

There are a vast number of service providers that are involved in providing play opportunities to children with disabilities. The social services and educational services in Sweden are decentralized to local authorities, the 290 municipalities. The Health services are decentralized to 21 Regions. Another actor is the Swedish Association of Local Authorities and Regions (SKL).

Besides the public providers, there are also private providers of services (as for example independent schools) but all the providers are coordinated by the local authorities and they are funded with tax revenues, at least in the case of educational and health services. The municipality may develop own policies on these matters, for instance in order to improve the accessibility of playgrounds, or increasing the leisure activities for children with disabilities (e.g. culture, music, arts, sports, see e.g. Nacka Kommun, 2015) in public or private associations, that are accessible for children with disabilities.

The Health services in the various regions offer also provisions to facilitate play for children with developmental delays and disabilities and their families: Habilitering (2015) (Child Rehabilitation services) offers support and consultation services of various kind to families of children with disabilities and Lekotek (2015) offers activities to support play activities for children with disabilities. Places where there are enhanced opportunities to play and where the families may borrow toys may also be organized by parents' associations. The quantity and quality of the provisions offered in the various districts and regions however may vary.

There are also many associations and non-governmental organizations that take initiatives in the field of children's rights, children with disabilities, parents' organizations, and disability and rights organizations: for example, Lika Unika (Equal Unique) and Funktionsrätt (2019) a federation of 39 organizations for persons with various disabilities and diseases; and Foundations (e.g. Stiftelsen Funka). The topic of play is recognized in the media. The Swedish television has produced films for teachers and parents on the topic of play for children with disabilities in preschool (UR, 2009).

Play for children with disabilities may be a topic for various professions: preschool teachers, special needs educators, leisure time educators, teachers in physical education, occupational therapists, psychologists, and therefore may be treated in the study of early interventions, language and speech therapy, special educational 
needs, inclusive education, developmental psychology, psychomotor development, neonatology, disability studies, assistive technologies, ICT, etc.

The Swedish policy states clearly that the children with disabilities and their families have rights to get support and services in order to participate in activities and to develop optimally. The right to leisure activities is recognized in the Social service act. The families may apply for economic support in order to allow the children to participate in such leisure activities. They have right to participate in education and leisure time activities, right to assistance when required and right to receive assistive technologies and equipment, for example to use the transportation services for the disabled. They have right to a priority placement in preschool and must receive the required support and adaptations in school. Summarizing: the legislation and the policies in Sweden, and the welfare resources that are available should give support and make it possible to provide that the children with disabilities would have access to play at home, outdoor, in educational settings, and in various social situations with peers.

\subsection{Mapping of the users' needs}

\subsubsection{The studies included}

The documents employed in the mapping were published between 2002 and 2015. They were reports from national agencies (4), local authorities (2) non -governmental organization (1) advocacy disability association (1) $\mathrm{PhD}$ dissertation (1) universities (7 student thesis) from various programs: preschool teacher, landscape architect, occupational therapist, outdoor pedagogy and special educational needs.

The users involved in the reports were school children (60\% of the reports), young children ( $46 \%$ of the reports) infants and toddlers (20\% of the reports). In one report were included youths (defining youth as people of age 13-25).

Seven texts had a focus on a specific disability, while eight other refers to various disabilities. The disabilities that were mentioned were: reduced ability for mobility, vision, hearing and speech; others were deafblindness, cognitive disability, neuropsychiatric disorders (ADHD, autism), Down Syndrome, brain damage, cerebral palsy, allergies.

The exact total number of children involved is not always reported in the texts. Two studies based on surveys collected answers from about 90 thousand schoolchildren and youths. The studies based on interviews collected the views of more than 200 persons (children, parents and staff). Other documents made case studies in 39 municipalities, and in 5 preschools.

The methodologies employed for the data collection were interviews in $2 / 3$ of the cases; and surveys in 1/3. Other methods were: observations, collection of narratives, focus group interview, action research approach, field study, document analysis. 
The reports were evaluated based on the method of data collection, analysis etc. as having a high credibility (5), medium credibility (5) low credibility (1) missing evaluation (4). No ethical concerns were raised by the reviewers.

\subsubsection{Users' needs}

The needs reported by the users are many. The children say that all the children have the right to play and to have leisure time. To do that there is a need of making physical adaption to the playgrounds, so that they are accessible to children with disabilities. The playground should be adapted to the fact that children with disabilities may need support from adults in order to participate in certain activities. It should be possible for parents with disabilities and elderly grandparents to support young children in their play. In an overview, only $8 \%$ of the outdoor playgrounds were adapted so that children in wheelchair could participate. There is a need of a long-term planning of changes, of the development of guidelines, and of the use of the expertise from professional in making the adaptions. There is a need of more knowledge about the importance of play and a need of accessible places for children to play in. There is a need to take in consideration the child perspective when taking decisions. Children want to come to playgrounds every season, year around.

According to another report (Skogman, 2004) the play of children with disabilities needs to be supported by the existence of accessible and delimited settings with particular purposes, the support from an adult in play, for example enabling and initiating play with peers, and structured play activities.

The needs of the children with disabilities are more in general of having fun, develop autonomy, take initiative, develop higher self-esteem, and develop skills, feeling to belong to a community, having friends. "We are a lot of very tired parents that pull a very heavy last, trying to activate our children. We shall keep doing this of course, but we need help, - of a good kind - to help our children to be free from us" (mother, in Rinnan, 2007, p. 22). The children with disabilities need to participate in various leisure activities with other children (drama, theater, outdoor activities, scouting, and sports). The participation in leisure activities is highly beneficial to the children in several ways according to the parents: because of the activity itself (fun, enjoyment, happiness, skills, physical training, motor activity, self-esteem), but also because it facilitates relationships, interactions with other people, making friends. The engagement in activities is a need for everyone and the children with disabilities should have the right to choose among many choices: the offer of activities is often much more limited for them.

The children report that they need to experience autonomy and participation during leisure time, to experience personal growth and develop their identity. The users with disability report that they are passive during the leisure time, and that they do not participate in leisure activities as they would like to. Children with disabilities in an 
interview study report that they are alone or have only a few friends. There were some differences among the 20 children interviewed: the children with neuropsychiatric disability (NPD) did not participate in any activities and had no friends, while the other children participated in adapted leisure activities (Handisam, 2014).

Even in the large survey from the Agency of Public Health of Sweden (Statens Folkhälsoinstitut, 2014) the children with NPD reported lower physical activities and lower wellbeing at school. Children with medium and high impact disability spend less time with other children, they play more PC- and TV-games, and they have lower self-reported health. Even the parents of the children with NPD reported lower health. The families of children with medium and high impact disabilities reported lower living conditions.

Other studies emphasize the children's needs for movement; they should engage in daily outdoor activities, because they are beneficial for their wellbeing and their development. The children with disabilities need interactions with other children. They need to have authentic play activities, not training. The disability appears when there are limitations to participation in play activities.

An important condition to play is communication. If the child has difficulties in communicating, the caregivers may need support in developing their understanding so that they can play in a natural way and more freely with the child.

A large survey identified other problematic aspects. Children and youths with disability reported to a large extent than their non-disabled peers that they do not attend leisure activities because they feared that they would be treated badly. They had also lower level of activities, especially boys. They say that they have too much leisure time, that is, they had too little to do. Youth with disability reports three times more often that they have been bullied or marginalized during their leisure activities. The report concludes that there is a need of increasing the activity level and the participation in a variety of activities for children and youth with disability.

\subsubsection{Barriers}

The barriers were of difficult kind, as physical barriers, resource barriers, or psychological barriers.

Among the physical barriers there are thresholds, uneven surfaces, not adapted play equipment in the playground, and stairs, narrow spaces and bumpy roads, sandboxes that are not accessible, lack of pictorial, visual and tactile signals, fences that block the view when you sit in a wheelchair. An overflow of play materials and toys can sometimes make it difficult for some children to concentrate in one play activity. Too extensive and unspecified play areas may be barriers for children with disabilities.

The resource barriers are lack of economic resources, lack of information, lack of knowledge, limited competence and ability in the staff. Shortcomings in the welfare 
support system; teachers that do not plan activities for facilitating play with peers are barriers. The lack of economic resources of the family may hinder the child's participation to play activities that are expensive. Lower health and wellbeing, limited relations with other children may be barriers. "When the child has no friends it is a big problem for the family".

The psychological barriers are described as negative attitudes, for example when the staff thinks that children with disabilities would imply more work for them. Another example can be the fear of leisure-time leaders to accept in a group a child with disability, maybe due to a feeling of inadequacy. Many leisure-time leaders have no knowledge about how to support children that may be anxious in new situations. The adolescents may start new activities and then drop out because of difficulties as low self-esteem, lack of assistance, or previous negative experiences. The social interactions in educational setting may contribute to exclude children with disabilities, when their peers do not want to play with them. The parents and other adults may tend to overprotect them, impairing their autonomy. The adults may interfere with the play activity contributing to a withdrawn of the child from play. Individual characteristics of the child may be barriers to participation in specific play activities, as visual ability, balance, and sensitiveness to environmental stimuli. The child's may feel insecure for these reasons which can hinder his desire to engage in activities. Another barrier to play was, according to some mothers, the training that they have to do with their child. During the training the experienced a conflict between "to be" and "to act", which could hinder the upcoming of spontaneous playful situations for them.

\subsubsection{Facilitators}

Various facilitators were identified: changes and favorable conditions in the environment, staff development and attitudes, children's voice, collaboration between service providers and families.

The playground environment may be improved considering various aspects: equipment, land materials and vegetation and related to various activities as climbing, digging, playing with water etc. The preschool environments may be improved with language stimulating activities, by mean of adaptations and by mean of children's' participation in the design of the play environment, through giving importance of child' safety, and organizing small children groups. There are guidelines and legislation that give advice about providing inclusive services and buildings, which should be followed.

A facilitator is that the staff is trained on diversity and attitudes. The staff's positive attitudes are important in order to sustain children's participation in leisuretime activities. 
The policy adopted by the local authorities at the municipality level impacts the services that are offered to the children with disabilities: local principles and goals are expressed, clearer guidelines are formulated with practical checklists; accessibility coordinators are employed.

The development of long-sighted collaboration between authorities and services, local actors, and the community are facilitators. In bigger municipalities there might be overarching projects. The key factors for success identified at the local level were: common goals, support from municipal managers, events, and Child Rehabilitation services as key actor.

The leisure activities are successful when they are adapted to the children, not the other way around. The children feel much better when they have friends and when the children without disability are involved too. Will and fantasy are also identified as emotional facilitators. It is also good to let the child choose the activity, to introduce it in small steps and to introduce many activities early in life. A team around the child that has a starting point in the child's wishes and needs is good. Age-grouped activities are also preferable.

Information about which activities that are available should be easy to access for the parents. The staff may also invite the leisure time associations to school to inform about their activities.

Pictures may be valuable tools to facilitate the choice of activities. A collection of 145 pictures of leisure time activities has been created for this purpose by a local Health authority (Rinnan, 2007).

\subsubsection{Recommendations}

The specific recommendations of the studies reviewed ranged from the practical suggestions about playground materials, to the recommendation to follow the Article 31 of the Convention of the right of the child (1989). There are also other Swedish laws and inquiries that are to be followed: the Final report for the Child Safety (SOU 2003:127), the Planning and Building Act require that all the public places must be accessible, including playgrounds. The professional with competence on specific matters should be consulted.

There are recommendations to develop national indicators that are possible to disaggregate at municipal level about the type of activities and the disability (MUCF, 2014), to made regular national evaluations on the life conditions, and to give national support to the development of policies that can improve the wellbeing of children and youth with disabilities (Handisam, 2014). There are recommendations to the school to focus on the need of children with medium and high impact disability, and in particular NPD, and to the Welfare providers to support their families, follow-up their needs (Statens Folkhälsoinstitut, 2014) and also to give a leisure subvention to the family so that they can afford more activities (Handisam, 2014). 
Another recommendation is to incorporate children with disabilities in the planning, the evaluation and development of amusement parks and leisure time centers. The children with disabilities must also receive more information about their rights.

The municipal authorities are recommended to increase the participation of children and youth with disability in leisure activities, to secure the accessibility of arenas, and the participation of children to the community and the autonomy of the users. Training and education about play and disability is recommended for school heads, educators and leaders; other recommendations are to give support to the civil and ideal associations, mapping the children's needs through interviews and surveys. Evaluations of municipal activities and project are recommended, as well as targeted grants to the associations. It is important to enforce policies in the associations so that they welcome all the users (Rinnan 2007).

A common model of promotive, preventive and selective interventions for parents is recommended by Broberg et al. (2014).

\subsection{Discussion}

The results of the mapping seem indicate that there are some inconsistencies in the Swedish context, between the ambitious policies and the emerging shortcomings in the practices and experiences of children with disabilities. There are many agencies, authorities and associations involved and engaged in these matters, which are performing evaluations and giving suggestions. It seems that the topic of children's play and leisure times is taken seriously by many policy makers and stakeholders. There seems to be a certain degree of knowledge in the field among practitioners, but also a great need of professional development at several levels in educational settings, health care and welfare services.

A reflection is that the available literature and the mapping is representing more the needs of young children, schoolchildren and adolescents than the needs of infants and toddlers. There seems to be less information available on their needs in the Swedish context. This should be an area to develop in educational research.

There is also much more research and reports on the broader topic of leisure time activities, than on the topic of play, probably because the concept of leisure time is an official concept, that is regulated in the policy and in which it is stated that it should be made accessible to all the children and youth. Children and youth with disabilities have right to get support and assistance in order to participate to appropriate leisure activities, but what is done is in many cases not enough, and particularly for certain groups, considering the views of parents on these matters.

Groups that seem to need particular intervention and support are children with Autism Spectrum, ADHD and others similar disabilities, which are reporting 
loneliness, and lower levels of wellbeing and participation in play and leisure activities in several independent studies.

This review of existing reports, evaluations and research indicate the need of develop research on the topic of play for infants and toddlers, on the topic of preventive and early interventions to facilitate and support interaction and play and in particular social play for children with Autism Spectrum, ADHD, and other developmental disabilities, in various educational settings.

\section{References}

Barnombudsmannen (2015). Mina rättigheter [My rights]. Ombudsman for Children in Sweden. https://www.barnombudsmannen.se/

Berg, E. L., Nevelius, U. (2007). Delaktighet i lekaktivitet hos barn med funktionsnedsättning 4 arbetsterapeuters syn på hinder och förutsättningar. [Participation in play activities for children with disability: four occupational therapists' views of obstacles and possibilities] Thesis, Lund University, https://www.lu.se/lup/publication/1323962

Broberg, M., Herawati, N., Norlin, D., \& Starke, M. (2014). Riktat föräldrastöd RiFS-projektets slutrapport En aktionsforskningsansats för att kartlägga behov och förbättra stödet till föräldrar som har barn med funktionsnedsättning. [Directed support to parents. An action research study to map the needs and improve the support to parents who have children with disability] FoU i Väst Göteborgsregionens kommunalförbund: Göteborg.

Cronvall, S (2007). Livet ska kännas: en studie om lekfulla utemiljöer för fler barn i samhället.[Life has to be felt: a study on playful outdoor environments for more childen in our society]. Thesis, SLU, Institutionen för stad och land, Uppsala.

Diskrimineringsombudsmannen (2015). Equality Ombudsman. Retrieved at http://www.do.se/otherlanguages/english-engelska/

Education Act (2010:800) Sveriges Skollag. Retrieved at https://www.riksdagen.se/sv/DokumentLagar/Lagar/Svenskforfattningssamling/Skollag-2010800_sfs-2010-800/

Eriksson C. (2014). ALLA barns rätt till SKRUBBSÅR - barn med funktionshinder och deras tillgänglighet till lekplatser i Norrköpings kommun. [All children's right to scrapers: children with disability and their access to playgrounds in Norrköping] Thesis, Institutionen för kultur och kommunikation, Linköpings Universitet.

Eriksson, H., Hägg, C. (2014) Utomhuslekplatsers tillgänglighet för barn med funktionsnedsättning; En uppföljning. [Accessibility of outdoor playgrounds for children with disability: a follow up]. Thesis, Luleå tekniska universitet, Institutionen för hälsovetenskap,

Funktionsrätt (2019) The Swedish Disability Rights Federation: 39 organisations. https://funktionsratt.se/om-oss/in-english/

Habilitering (2015). Habilitering .[Rehabilitation and health: services for children with disability] Retrieved at http://habilitering.se/home

Handisam (2014) Barn äger. Handisams slutsatser och förslag utifrån studien "barn och unga med funktionsnedsättning - en beskrivning av deras vardag”. [Children own. Handisam conclusions and suggestions based on the study children and youth with disability, a description of their quotidian life]. Retrieved at http://www.mfd.se/stod-och-verktyg/publikationer/rapporter/ rapporter-2014/barn-ager/

Johansson S., Staus, A, (2014). Barn med Down Syndrom, Några pedagogers syn på hur man kan inkludera barn med Downs syndrom i förskoleverksamhet. [Children with Down Syndrom: 
teachers' view about their inclusion in preschool] Thesis, Umeå universitet, Institutionen för tillämpad utbildningsvetenskap.

Lekotek (2015). Karolinska Institutet. [Play consultants for children with disability and children with developmental delays] http://www.karolinska.se/for-patienter/alla-mottagningaroch-avdelningar-a-o/astrid-lindgrens-barnsjukhus/bm3-behallare/lekotek/

Karlsson, F. (2014). Betydelsen av fysisk aktivitet för barns koncentration i förskolan: En studie om betydelsen av fysisk aktivitet för barns koncentrationsförmåga vid samlingar i förskolan. [The impact of physical activity for children's attention in preschool]. Thesis, Karlstads universitet, Institutionen för pedagogiska studier.

Lika Unika (2015). Federationen mänskliga rättigheter för personer med funktionsnedsättning. [Human rights for persons with disability] http://www.likaunika.org/startsida.html

Lundström, E. (2007). Ett barn är oss fött: att bli förälder när barnet har en funktionsnedsättning: ett beskrivande och tolkande perspektiv. [A child is born in our family: to be parent when the child has a disability]. Diss. Stockholm: Stockholms universitet, 2007. Stockholm.

Malmberg, S.(2015) Lek utan hinder. Hur lekplatser kan anpassas för barn och vuxna med funktionsnedsättningar. [Play without obstacles: how playgrounds can be adapted to children and adults with disabilities] Thesis, Sveriges lantbruksuniversitet, SLU Uppsala, Landskapsarkitektprogrammet.

MUCF (2014). FOCUS 14 Unga fritid och organisering. [Youth, leisure time and organisation] Stockholm: MUCF

Myndigheten för Delaktighet (2015). The work of the Swedish Agency for Participation. http://www. mfd.se/other-languages/english/

Nacka Kommun (2015) Fritid för barn med funktionsnedsättning. [Leisure time for children with disability] https://www.nacka.se/uppleva--gora/kultur-och-fritid-for-funktionsnedsatta/

Rinnan, T. (2007). Mer är än bara lite kul - En skrift om hur vi kan utveckla fritiden för barn och unga med funktionsnedsättningar. [More than just a bit fun- a report on how we can develop leisure time for children and youth with disabilities] Sundbyberg: Handikappförbundens samarbetsorgan.

Rädda barnen (2002). Trappor, trösklar och tanklöshet [Stairs, thresholds and thoughtlessness] Barn och unga med funktionshinder om rätten till lek och fritid. [Children and youth with disabilities about the right to play and leisure time]. Stockholm: Save the children.

Skogman, E. (2004). Funktionshindrade barns lek och aktivitet: en studie av struktur och utförande i förskolan. [Disabled children's play and activity: a study on structure and performance in preschool] Diss. Stockholm: Univ., 2004. Stockholm.

Skolinspektionen (2015). Swedish Schools Inspectorate. http://www.skolinspektionen.se/en/ bout-Skolinspektionen/About-the-Swedish-Schools-Inspectorate/

Skolverket (2015). The Swedish National Agency of Education. http://www.skolverket.se/ om-skolverket/andra-sprak-och-lattlast/in-english

Social Services Act (2001: 453) Sveriges Socialtjänstlag https://www.riksdagen.se/sv/DokumentLagar/Lagar/Svenskforfattningssamling/Socialtjanstlag-2001453_sfs-2001-453/

Socialstyrelsen (2015). The National Board of Health and Welfare. Government agency. http://www. socialstyrelsen.se/english

SOU (2003:127). Governmental Inquiry: från barnolycksfall till barns rätt till säkerhet och utveckling. [From child accident to child right to safety and growth] Stockholm, Socialdepartmentet.

Specialpedagogiska Skolmyndigheten (2015). National Agency for Special Needs Education and Schools. Organisation och uppdrag [Organisation and mission] https://www.spsm.se/om-oss/ organisation-och-uppdrag/

Statens Folkhälsoinstitut (2012). Hälsa och välfärd hos unga med funktionsnedsättning. [Health and welfare for young persons with disability] Östersund: Statens folkhälsoinstitut.

Stiftelsen Funka (2015). http://www.stiftelsenfunka.se/Om-Stiftelsen/ [Function Foundation] 
Support and Service Act for persons with disability (1993:387). LSS Lag om Stöd och Service för vissa med funktionsnedsättning. https://www.riksdagen.se/sv/Dokument-Lagar/Lagar/ Svenskforfattningssamling/Lag-1993387-om-stod-och-ser_sfs-1993-387/

UR (2009) Leka livet. Delaktighetens Dilemma [Play for life. The Dilemma of Participation] Sveriges Utbildningsradio. https://urskola.se/Produkter?q=delaktighetens+dilemma\&show_access=on United Nations. (1989). Convention of the Rights of the Child (Swedish text). http://www. raddabarnen.se/om-oss/barnkonventionen/barnkonventionen-lang-version/

United Nations (2006). Conventions of the Rights of persons with disabilities (SÖ 2008: 26). http:// www.un.org/disabilities/documents/convention/crpd_swedish.pdf 


\section{Play for children with disabilities: some reflections on the results on the users' needs and on the role of technologies}

\subsection{Short summary of the Section $n .2$}

This chapter concludes the results of the report on users' needs from LUDI Working Group 4. The effort in WG4 was on investigating the users' needs as a necessary base for the development methods, tools and frameworks for play for children with disabilities.

The main aim of this report was to investigate if children with disabilities have access to and participate in the broad range of play activities. The aim was also to investigate their needs according to parents and members of disabilities associations in different societal contexts. To collect the users' answers several questionnaires were developed and distributed in more than thirty countries. The previous chapters in section 1 present the surveys and the analysis of answers from parents and members of disability associations. The section 2 presents 3 case studies at the national level (Finland, Lithuania and Sweden) of users' needs based on literature reviews of reports and research, which give also indication of the needs that are emerging in various contexts, depending on specific policies and provisions.

From the results of the surveys, we can state that children with disabilities would like to play with other children, but they rather risk to be lonely; teachers are not competent enough to support and create good setting for playing especially in mainstream schools. Many children with disabilities want to play freely with friends and their family members, but they have often to deal with barriers and shortcomings. Some parents feel that they have to prioritize training. The needs may be different for children with different disabilities and some children are reported to be involved in various play activities. There are however large needs of adaptations in many activities. Most of the playgrounds are still not accessible for children with special needs.

\subsection{New technologies}

As the importance of play for children was grounded in the Garvey's thought (1990, p. 4), the play was classified within LUDI along two dimensions: cognitive and social dimensions. 
The available technological tools and devices, when usable and accessible, may support the development of children's skills when they practice any type of play.

Play is one of the most important activities in childhood, at the same time, play is one of the most important devices for child to learn.

In early childhood, children use to play to construct social relations for the common play experience. While playing, and growing during playing, children develop their language skills and other motor and social skills.

This development process is sensitive to the used play tools and technical devices.

Nowadays - in our digital age - children during the play activities might get into contact with IT tools at a very early stage. Teachers, educators, kindergarten teachers and IT developers have recognized this, and all over the world a lot of hardware and software products were developed for children. In this section the authors would like to give a short review about the state of the art related to this aspect.

Pretend and role playing games are very popular kind of computer games. The relationship between pretend play, social competences and involvement in schoolbased activities in children aged 5-7 years was investigated by Uren and Stagnitti in 2008 (Uren et al., 2008). They found a significant relationship between elaborate pretend play and object substitution scores, involvement scores and peer play interaction scores. The conclusion was that social competence and involvement skills are related to a child's ability to engage in pretend play.

The Internet and video games changed the way in which children play. The younger children love to dress up their favourite characters from tales, the older children prefer role-playing games. One of these very popular games is "Dressing up" type games, and uses some augmented reality tools (Microsoft, 2016).

Children's play focus changes around the age of 10-12 years. From traditional desktop games their focus turns to mobile platforms and games. The Commonsensemedia.org site collected the most popular games for this age group (Commonsensemedia, 2016). In this collection about fifty games can be found. Some of them are typical entertainment games (e.g. Adventures of Poco Eco and Lost Sound game, which gives a meditative musical journey through a lush neon wonderland). The Kuddle is a photo-sharing app and gives a good intro to the social media.

The Marble Math with marble mazes proposes math practice for fun, Dragon Box Element is an innovative geometry app that integrates learning with play. The DIY App is a creative community app for children, kids learn, share and build skills on excellent social app. The Box Island introduces the logic of computer science with a cute coding adventures. Questimate is a dynamic estimation game and lets children design their own questions. DK The Human Body App's gorgeous reference shows the wonders of human anatomy.

The Slice it! is a tough but really funny geometry puzzle game for brainy players. Playing with Duolingo app gives opportunity to learn languages for free with plentiful, fun, free lessons. 
Children over 14 may play with a lot of robust desktop games. The most popular console games are designed to PlayStation, Xbox console with Kinect sensor and Nintendo Wii. With respect to these products, the following question arises: when is it good for children to start playing video games? This question is a controversial subject and researchers start to explore the effects of screened entertainment media on young children, but they did not explore the relation between the starting time of playing with videogames between any other factors. A lot of studies published in the last decade found that children under the age of three should not be exposed to any form of screen entertainment (TheGuardian.com, 2014), because there have also been links to the later development of ADHD. After the age of three the videogames can help children with numeracy and literacy. For older children there are plenty of games with creative and educational value.

The most obvious example is the building simulator, Minecraft. Minecraft is able to teach everything while playing from architecture to physics, geology, and electronics. The developer company of the Minecraft is TeacherGaming (Teachergaming, 2016). They released a special edition from Minecraft, the MinecraftEdu, designed for classroom use. MinecraftEdu allows teachers to set up and manage several kinds of teaching and learning projects.

The other popular videogame is SimCity that can teach strategic thinking as well as providing information on history, geography and urban planning.

There are also excellent sims like Orbiter that teach children the basics about the aeronautics. Most of videogames can help with hand-eye coordination, develop fine motoric skills, logical thinking, and teamwork for young.

Another project deals with the problem of developing serious games for children with mild and moderate learning difficulties. Called, Intelligent Serious Games for Social and Cognitive Competence" (ISG4C.eu, 2016). By using the suite of serious games for desktop and mobile usage, students with learning difficulties will increase their skills and competences in achieving goals, managing their behaviour in a social context, anticipating the consequences of their behaviour for self and others, generating creative solutions, building a positive sense of self-efficacy, managing their time and resource to prepare for the school activities, improve cooperation with peers and teachers/trainers, coping with difficulties and managing social interactions. An important goal of the curriculum is to enable persons with learning difficulties to learn and understand how to improve their social and cognitive competences and to develop an appreciation of the value and practice of the lifelong learning.

\subsection{Developing games based on users' needs}

In this section the topic of digital games and the design of user interface in digital games from the viewpoint of special needs users is developed. In spite of the fact that $10 \%$ of the population worldwide has some disabilities, most software engineering 
companies do not develop yet products for special users, probably because they do not recognize the potential in a market that is considered limited.

This section provides a list of minimal requirements that every software engineer, computer scientist and WEB designer should take into account if they develop a new software or a new WEB site with gamification elements (Sik-Lanyi, 2008).

Visual Impaired and Partially Sighted Persons

It is important to keep on the developer's mind that the visual impairment and partially sighted people have no perfect vision. The visus of perfect vision is 1 . A partially sighted person's visus is between 0.1 and 0.3 .

- Ensure that all information can be accessed via text or sound, such that blind users can use screen readers or Braille display to access the information;

- Give pre-recorded audio as an alternative mean;

- Allow users to navigate the site by using keyboard (the mouse is hardly used by blind users);

- Minimize the users' memory load because blind users can only hear one word at a time and need memory to integrate parts of the heard information (Hung, 2001).

- For partially Sighted Persons

- Ensure the text size is large enough otherwise low vision users usually need screen magnifier to enlarge the text.

- Give audio option to notify low vision users about new information.

- Minimize the users' memory load because the effective screen size is very small while using screen magnifier.

- For users with low vision pictures must be drawn with thick contour lines. The user can be given the option to modify the contour line thickness of the objects. The user must be able to vary the colour of the objects and background and the speed of motion and to stop the animation (Sik Lányi, 2005).

\subsubsection{Colour Deficient (colour blind) persons}

Colour blindness is mostly neglected; even most of the people do not consider this as a serious problem. It is quite common to see combinations of background and foreground colours that make pages virtually unreadable for colour blind users. Background, text, and graphics colours should be carefully chosen to allow for persons with colour blindness. Designing for colour blind people is complicated. It's not a matter of green/red or yellow/blue combinations.

The most important issue in designing for colour blind users is not to rely on colour alone to convey information and not to use colour as a primary means to impart information (Karagol-Ayan, 2001).

If we have no possibility to test our software by the help of colour blind people, we have to see it in greyscale setting at least to check whether all the information is visible or not. 


\section{Deaf and hearing impaired persons}

Persons with impaired hearing may have a limited vocabulary. This is one of the problems with hearing impaired persons. Therefore new information and instructions have to use simple language alongside cartoon-like presentation. They still require sounds to accompany the graphics. This also applies to anyone with any cognitive impairment.

- Give visual information (text and/or picture) that is redundant with audible information;

- Allow for the users to configure frequency and volume of audible cues.

- Do not design interactions to depend upon the assumption that a user will hear audio information.

For deaf and hard of hearing persons to have access to multimedia applications, ways need to be developed to support the presentation of complex sounds and closed captioning for speech (Sik Lányi, 2006).

\section{Physically Disabled Persons}

The biggest problem for persons with impaired fine motor ability is using the input devices.

- Do not design the navigation and input only using it by mouse, because the users might have poor motor ability;

- Do not design the navigation, input and commands using it by voice input devices because of the control problem of face muscles;

- Do not develop the navigation using multiple keys simultaneously.

The multimedia software must be accessible via the keyboard, therefore it has to have an easy use and good keyboard navigation system. Thus the task is to find the optimal navigation method for the mobility impaired user. If the user does not have a special input device, navigation can be facilitated with a moving rectangle the speed of which is adjustable or to use voice controlled navigation or command system (Sik Lányi, 2006).

\section{Intellectual disability}

There is a wide variation of cognitive impairments that could be categorized as Memory, Perception, Problem-solving, and Conceptualizing disabilities. Memory disabilities include difficulty obtaining, recognizing, and retrieving information from short-term storage, as well as long-term and remote memory.

It is necessary to design multimedia software or WEB pages in ways that minimize the skills and abilities required to navigate them. Auditory output might seem confusing these users, or be difficult for them to understand. The designers need to define terms that may not be known to the cognitive disabled persons.

- Minimize the cognitive load while navigating in the software 
- Use graphics for navigation whenever possible

- Avoid animated graphics and the use of overlay large file sizes. Use animations and dynamic display with care.

To sum up design principles (ISO 92411-11, 1998; Sik-Lanyi, 2012)

- Ensure presentation at appropriate speed

- Allow users to go back

- Allow User Control

- Make any text plain text

- Never convey information by colour alone

- Ensure sufficient contrast

- Help users navigate

- Make clear Maintain organization

- Use unique and informative text descriptions for any hyperlinks

- Use accessibility features

- Design simply in simple layouts

- Use fallbacks

- Make systems consistent and error free

- Aim for compatibility with assistive technologies

- Allow keyboard access

- Do not include elements that are known to cause seizures

\subsection{Conclusion}

To sum up, children with disabilities must have access to play as other children do, but the results of this report show that they may lack the possibilities to participate in play. Thanks to new technologies and extra effort to support play for children the developers may be able to create new software for these children to help them close up to other children. The support of friends, family and trainers is however inevitable.

\section{References}

Hung, E. (2001). Universal usability in practice, Blind and Low Vision Users. Retrieved at: http:// www.otal.umd.edu/uupractice/vision/

ISG4 Competence (2016). Intelligent Serious Games for Social and Cognitive Competence (ERASMUS+ 2015-1-TR01-KA201-022247) http://www.isg4competence.eu/

ISO 9241-11 (1998). Ergonomic requirements for office work with visual display terminals (VDT)s Part 11 Guidance on usability. Retrieved at https://www.iso.org/standard/16883.html.

Karagol-Ayan, B. (2001). Universal usability in practice, Color vision confusion. Retrieved at http:// www.otal.umd.edu/uupractice/color/ 
Uren, N., Stagnitti, K. (2009). Pretend play, social competence and involvement in children age 5-7 years. The concurrent validity of the Child-Initiated Pretend Play Assessment. Australian Occupational Therapy Journal, 56(1), 33-40.

Sik Lányi, C., Mátrai, R., Molnár, G., \& Lányi, Zs. (2005). User Interface Design Question of Developing Multimedia Games and Education Programs for Visual Impairment Children. Special Issue of Elektrotechnik \& Informationstechnik (e\&i), 12: 488-494.

Sik Lányi, C. (2006). Multimedia Medical Informatics System in Healthcare. In: Ichalkaranje, A., et al. (Eds.), Intelligent Paradigms for Assistive and Preventive Healthcare. Springer-Verlag, pp. 39-91.

Sik Lányi, C. (2008). Multimedia Software Interface Design for Special Needs Users. In: Encyclopedia of Information Science and Technology, 2nd Edition, IGI Global, 2008.

Sik Lanyi C., Brown D., Standen P, Lewis J., \& Butkute V. (2012). Results of user interface evaluation of serious games for students with intellectual disability. Acta Polytechnica Hungarica, 9(1): 225-245, Retrieved at http://www.uni-obuda.hu/journal/Issue33.htm 


\section{Contributors}

Mara Allodi Westling, $\mathrm{PhD}$, is Professor of Special Education at Stockholm University, department of Special Education, Coordinator of Research School in Special education. She has a professional background as teacher and special educator in inclusive educational settings and received the PhD degree in 2002 at Stockholm University. She teaches and supervises students in programs on inclusion and on special educational needs and provisions. She has published research on the social climate of learning environments; children's' views; well-being and health; values and motivational theories; early and special needs interventions on communication, play and social relations in educational settings. She is currently developing in collaboration with a multidisciplinary research team a project with a family support intervention for very preterm children. She has worked with systematic research reviews by appointment of the Swedish Royal Academy of Science and of the governmental Inquiry on equal gender opportunities and with an evaluation of the education of newly arrived immigrant students by appointment of the Swedish National Agency of Education. She is appointed as chairman of the Council of the Swedish Institute of Educational Research, and appointed as member of the governmental 2015 year's Swedish School Committee.

Eglè Celiešienè has defended her doctoral dissertation in the field of modeling intercultural communication and educational innovations (2011). She has improved her qualification in different world-famous universities in Switzerland, France, the USA (Washington, Indiana), Canada (Toronto), etc. E.Celiesiene is a member of the global network "Society for New Communications Research", and takes an active part in international networks "SocialWork\&Society' Academy" and "CIVITAS". She has been conducting teaching courses according to the innovative methodology "project PILIETIS” for more than ten years in Lithuania (accredited lecturer).

Pedro Encarnação is an Adjunct Assistant Professor at Católica Lisbon School of Business and Economics, Universidade Católica Portuguesa (UCP), Portugal. He is a Research Affiliate of the Glenrose Rehabilitation Hospital, Edmonton, Canada. He has received the 'Licenciatura' degree in 1994, the M.Sc. degree in 1998, and the Ph.D. degree in 2002, all in Electrical and Computers Engineering from the Instituto Superior Técnico, Lisbon, Portugal. From 2000 to 2013 we was with the Faculty of Engineering of the UCP. He served as Associate Dean of the Faculty of Engineering between 2002 and 2008 and as the coordinator of the subject area of Mathematics between 2001 and 2013. In 2008/09 he was a Visiting Professor (Research) at the Faculty of Rehabilitation Medicine, University of Alberta, and at the Glenrose Rehabilitation Hospital, both in Edmonton, Canada. He worked with the Dynamical Systems and Ocean Robotics Lab at the Institute for Systems and Robotics, Lisbon, on 
the problems of nonlinear control with applications to autonomous ocean vehicles. His current research interests include Rehabilitation Engineering, namely the use of robotic systems in the rehabilitation of persons with disabilities, and nonlinear control of autonomous vehicles."

Donatella Fantozzi is Researcher at the University of Pisa, teaches General Didactics and Specific Learning Disorders at the Course of Degree Primary Education Sciences. Research and study themes: Specific Learning Disorders and scholastic difficulties in general; inclusive teaching design; job placement of people with disabilities; disability and the project of life. Among her last publications: Scuola e lavoro tra formazione e orientamento delle persone con disabilità intellettiva, in Nuova Secondaria Ricerca, Studium Edizioni-Editrice La Scuola, Brescia, n 7, marzo 2019, anno XXXVI- pp. 62-67; Ludolinguistica e apprendimento della letto-scrittura, in PedagogiaPiùDidattica, Vol. 4 - n. 2 - ottobre 2018, Erickson, Trento 2018, pp. 42-48; DSA e fruibilità dei libri di testo nella scuola primaria, ETS, Pisa 2016; Il soggetto disabile nei contesti lavorativi. La funzione del tutor, in R.Biagioli, Tutor and mentoring in education, ETS Pisa 2015, pp.255-266; Il docente specializzato: competenza, tutela, condivisione, Italian Journal of Special Education for Inclusion anno II, n. 2, 2014, Pensa Multimedia Editore Srl, pp. 81-95.

Maria Gladh is trained as a social pedagogue/social worker (bachelor and master degree) and she is PhD-student at Stockholm University, Department of Special Education since 8th of August 2016. Since 2011 she is working as an advisor for compulsory school for learning disabilities within a municipal school board in the north of Stockholm. Earlier she has mainly been working in preschools, special schools and health- and social care. Her research as a PhD-student will take place within research group Special education and young children which has focus on young children's welfare, learning and development, and the need for developing a proactive inclusive learning environment for all children. The main interest regarding research is to link the theoretical understanding of a child's cognitive development as determined by an interaction between social relations, environmental contexts and biological conditions, with the actions taken and policies formulated within the broader field of education.

Giedrè Kvieskienè is the initiator of positive sociology, which incorporates the components of education, culture and values, has published more than 250 scientific articles and two monographs (the third one is already submitted for publication). In the past 15 years G. Kvieskienè has been on study trips to US universities, other schools of higher education and scientific conferences. She is a member of management board of international networks, such as the network of social work and state welfare "Social Work \& Society' Academy" and global network of civil education "CIVITAS International”, represents Lithuania as an expert in European network fighting with 
poverty, and conducts long-standing theoretical and practice-oriented research, the results of which are presented in public lectures, scientific reports and publications.

Johanna Lundqvist is a researcher and Senior Lecturer in Special education at Mälardalen University, Sweden. She has a PhD degree in Special Education from Stockholm University. Her research interests are support provisions, inclusion and transitions in early school years. She is presently involved in a research project about children's learning journeys from preschool to school. She has worked as a teacher and as a special educator in schools and in a resource team.

Elisabeth Lundström is senior lecturer in special education with a focus on rehabilitation (early intervention). Her academic background includes preschool teacher, special education from Stockholm Educational College and a Ph.D. in Special Education from Stockholm University. Elisabeth Lundström has twenty yearlong clinical experience as a special education teacher in rehabilitation activities of which ten in an activity for parents with infants with disabilities (Spädbarnsverksamheten Tittut). Her research concerns mainly the experience of becoming a parent when the child has a disability, but even play and early interaction.

Lise Roll-Pettersson is professor of Special Education at Stockholm University. Her academic background includes a bachelor's degree in pre-school teaching and special education from Lund University and a Ph.D. in education from Stockholm University. She has published and presented research concerning children with intellectual disabilities and children with autism in different contexts. Recent research has focused mainly on applied behavior analysis, aspects influencing implementation of evidenced based interventions and early intervention, play, parental perspectives and higher education content regarding these issues.

Maria Saridaki, PhD - National and Kapodistrian University of Athens, Greece msaridaki@media.uoa.gr. Maria studies play, games and storytelling in their different applications within and beyond the digital world. She is a Research \& Teaching Associate at the Laboratory of New Technologies of the National and Kapodistrian University of Athens, where she works on new, playful environments and studies the experience of users with and without disability. Maria has a $\mathrm{PhD}$ in playful interactions from University of Athens and her research interest lies on Games, Playfulness \& New Transmedia Environments with a special interest on inclusive participatory design and community building through playfulness \& storytelling.

Eva Siljehag is senior lecture of Special Education at Stockholm University. Her academic background includes a bachelor's degree in preschool teaching and a master degree in special education from Stockholm Institute of Education and a Ph.D. in education from Stockholm University. She teaches and supervises students in 
special educator training. Her research focuses on democratic knowledge processes in education and their social conditions. Of particular interest is research aimed at including preschool environments and young children in special education context including play and their learning opportunities with peers.

Cecilia Sik-Lanyi University of Pannonia, Egyetem str. 10., 8200 Veszprem, Hungary. e-mail: lanyialmos.uni-pannon.hu. Cecilia Sik-Lanyi studied Mathematics and Computer Science (M.S.) - József Attila University (1984), and Teacher of Mathematics - Berzsenyi Daniel Teacher Training College in 1988. She obtained the degree of Dr. Univ. at the University of Veszprém, Hungary in Physical-chemistry (1993) and of PhD at the University of Veszprem, Hungary in Computer Science (2000). She has worked as a software engineer and as an associate professor for program languages at the University of Pannonia. Currently she is teaching: Virtual Reality and its application, user interface design, computer graphics for informatics engineering students. $\mathrm{PhD}$ and Masters' supervision has an emphasis on Virtual Reality for the rehabilitation of children with disabilities and patients with mental health issues. She got the "Master teacher" award of the Hungarian Ministry of Education in 2001 and the AAATEdiamond-award" of the Association for the Advancement of Assistive Technology in Europe in 2015. She has published more than 300 refereed articles and conference papers, and worked as guest editor for many renowned journals and books. Her research area is Virtual Reality, Human Computer Interaction, Design for All.

Eira Suhonen PhD., University lecturer, Special teacher, University of Helsinki, Faculty of Behavioral Sciences, Department of Teacher Education, Special Education Section; e-mail: eira.suhonen@helsinki.fi She is a university lecturer at the University of Helsinki. Her main research interest is in early childhood special education. She has focused in her research on play, early intervention and children with special educational needs.

Veronika Szucs. University of Pannonia, Egyetem str. 10., 8200 Veszprem, Hungary e-mail: szucs@.uni-pannon.hu Veronika Szucs studied Computer Science University of Pannonia (B.S. 2010, M.S. 2013). She is working on the obtaining her Ph.D degree in Information Technologies. She has worked as a senior system and software developer. She is an assistant lecturer, doctoral candidate at the University of Pannonia, at the Faculty of Information Technologies, department of Electrical Engineering and Information Systems. Currently she is teaching: Virtual Reality and its application, Basics in Information technologies for informatics engineering students. PhD and Masters' supervision has an emphasis on Virtual Reality for the rehabilitation of children with disabilities and patients with mental health issues. She got the "Government fellowship" award of the Hungarian Ministry of Education in 2012. She has published more than 30 refereed articles and conference papers, and worked as a co-author for four book chapters related to the rehabilitation, virtual 
reality applications. Her research area is Virtual Reality, Applied Multimedia, HCI devices, 3D game engines, Mobile applications.

Mariatta Takala is Professor of Special Education. She works in Finland at the University of Oulu. Her research interests are inclusion, comparative special education, hearing-impairment and communication challenges. E-mail: Marjatta. takala@oulu.fi

Elina Sylvia Viljamaa is Doctor of Philosophy (Education) and works as University lecturer at the University of Oulu (Finland) - Faculty of Education and Special education elina.viljamaa@oulu.fi

The fields of interests are: childhood studies, play, children with special needs, children's multimodality, narrativity, play. Approaches employed are narrative research, phenomenology, posthumanism.

She participates in a Nordic network focusing on values and value education.

Rano Zakirova Engstrand is a doctoral student at the Department of Special Education, Stockholm University since January 2015. She holds a post-graduate diploma in Special Education from Stockholm University. She has a considerable teaching experience at different levels both nationally and internationally in such subjects as special education, inclusive education, civic education, didactics and pedagogy of teaching communicative English. Her current research interests include broad issues pertaining to education of children with autism spectrum disorders in inclusive classrooms; teachers' professional development and teacher education, parental perspectives, and implementation science.

Tamara Zappaterra (Ph.D.) was Associate Professor of "Teaching and Special Education” at University of Florence, where she was Dean's Delegate for students with disabilities, President of Master Degree Course "School leadership and Clinical Pedagogy" and Member of the Doctorate Board in "Educational Sciences and Psychology". She was also Member of Center for Study and Research for Disability Issues (CESPD) of University of Florence; Scientific Committee Member of Representative Board (on behalf of Italy) of European Agency for Special needs and Inclusive Education (CE). In 2019, she moved to the University of Ferrara. Her scientific activity is directed in disabilities educational studies. 